\title{
A EXPRESSÃO DO GLUT4 NO TECIDO ADIPOSO DE CAMUNDONGOS VARIA DE ACORDO COM A SENSIBILIDADE À INSULINA DURANTE O DESENVOLVIMENTO DA OBESIDADE
}

Dissertação apresentada ao Programa de PósGraduação em Fisiologia Humana do Instituto de Ciências Biomédicas da Universidade de São Paulo, para obtenção do título de Mestre em Ciências 


\section{A EXPRESSÃO DO GLUT4 NO TECIDO ADIPOSO DE CAMUNDONGOS VARIA DE ACORDO COM A SENSIBILIDADE À INSULINA DURANTE O DESENVOLVIMENTO DA OBESIDADE}

Dissertação apresentada ao Programa de PósGraduação em Fisiologia Humana do Instituto de Ciências Biomédicas da Universidade de São Paulo, para obtenção do título de Mestre em Ciências

Área de Concentração: Fisiologia Humana

Orientador: Prof. Dr. Ubiratan Fabres Machado

Versão Corrigida. A versão original eletrônica encontra-se disponível tanto na Biblioteca do ICB quanto na Biblioteca Digital de Teses e Dissertações da UPS (BDTD). 
DADOS DE CATALOGAÇÃO NA PUBLICAÇÃO (CIP)

Serviço de Biblioteca e Informação Biomédica do

Instituto de Ciências Biomédicas da Universidade de São Paulo

reprodução não autorizada pelo autor

Belpiede, Luciana Tocci.

A expressão do GLUT4 no tecido adiposo de camundongos varia de acordo com a sensibilidade à insulina durante o desenvolvimento da obesidade / Luciana Tocci Belpiede. -- São Paulo, 2015.

Orientador: Prof. Dr. Ubiratan Fabres Machado.

Dissertação (Mestrado) - Universidade de São Paulo. Instituto de Ciências Biomédicas. Departamento de Fisiologia e Biofísica. Área de concentração: Fisiologia Humana. Linha de pesquisa: Expressão de GLUT4, resistência insulínica e inflamação durante o desenvolvimento da obesidade.

Versão do título para o inglês: GLUT4 expression in mouse adipose tissue changes in parallel to the insulin sensitivity during obesity development.

1. Obesidade 2. Resistência insulínica 3. Inflamação 4. GLUT4 5. Tecido adiposo 6. MSG I. Machado, Prof. Dr. Ubiratan Fabres II. Universidade de São Paulo. Instituto de Ciências Biomédicas.

Programa de Pós-Graduação em Fisiologia Humana III. Título. 
Candidato(a): $\quad$ Luciana Tocci Belpiede.

Título da Dissertação: $\quad$ A expressão do GLUT4 no tecido adiposo de camundongos varia de acordo com a sensibilidade à insulina durante 0 desenvolvimento da obesidade.

Orientador(a): $\quad$ Prof. Dr. Ubiratan Fabres Machado.

A Comissão Julgadora dos trabalhos de Defesa da Dissertação de Mestrado, em sessão pública realizada a ......... . considerou
( ) Aprovado(a)
( ) Reprovado(a)

Examinador(a): Assinatura:

Nome:

Instituição:

Examinador(a): Assinatura:

Nome:

Instituição:

Presidente: Assinatura:

Nome:

Instituição: 


\section{Certificado}

Certificamos que o protocolo registrado sob $n^{\circ} \mathbf{8 7}$ nas fls. $\mathbf{0 8}$ do livro $\mathbf{0 3}$ para uso de animais em experimentação, sob a responsabilidade do Prof(a) Dr(a) Ubiratan Fabres Machado Coordenador (a) da Linha de pesquisa "Regulação do gene Slc2a4 em tecido adiposo ao longo do desenvolvimento da obesidade" do qual participam o(s) aluno(s) Luciana Tocci Belpiede, Aline David Silva, está de acordo com os Princípios Éticos de Experimentação Animal adotado pela Sociedade Brasileira de Ciência de Animais de Laboratório (SBCAL) e foi aprovado pela COMISSÃO DE ÉTICA NO USO DE ANIMAIS (CEUA) em 03.09.2013, com validade de 4 anos.

Săo Paulo, 03 de setembro de 2013.

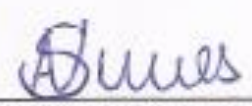

Prof. Dr. ANDERSON DE SÁ NUNES Vice-Coordenador-CEUA-ICB/USP

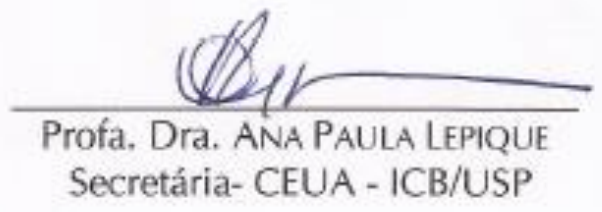
Secretária- CEUA - ICB/USP 
Dedico este trabalho ao meu fiel companheiro Rafael Leandro que tanto me apoiou $e$ incentivou na realização deste sonho e aos meus queridos pais Mauro e Fátima 


\section{AGRADECIMENTOS}

É inacreditável como algumas pessoas ficam permanentemente marcadas em nossas vidas, seja por participar de forma positiva ou negativa. Graças a Deus tenho peças fundamentais que participaram ou participam de grandes acontecimentos em minha vida e aqui deixarei alguns agradecimentos a estes parceiros:

Começo pelos meus pais Mauro Belpiede e Fátima Estevan, que me proporcionaram a vida. Agradeço muito pela educação que me deram e por tudo que fizeram para que eu fosse o ser humano que sou; por investirem em meus estudos e batalharem junto comigo para que eu chegasse onde estou;

Agradeço, também, meu marido querido que tanto amo, por ter me ajudado sempre sem deixar que eu desanimasse ou me abalasse ao encontrar qualquer obstáculo em meu caminho e ainda, por aguentar minhas crises de angústia na expectativa de dar tudo certo;

Ao meu orientador Ubiratan Machado que me concedeu esta grande oportunidade e às maravilhosas funcionárias do laboratório Maristela Okamoto e Helayne Freitas que sempre tiveram disponíveis para me auxiliar com muita parceria e paciência no desenvolvimento deste projeto.

Meus parceiros de mestrado e amigos incondicionais que sempre caminharam comigo e nunca me deixaram sozinha em qualquer circunstância. Amo aqueles que me amam e me querem bem, por isso vocês: Bruna Lins, Daniel Blanc e Sinésio Junior têm meu amor, minha amizade verdadeira e minha imensa e eterna gratidão por todos os momentos que me proporcionaram. À minha querida Patrícia Nunes que foi fundamental para me motivar através de sua fé imensurável;

Minha querida amiga Aline David que me auxiliou muito ao longo do desenvolvimento do mestrado e que me apresentou uma pessoa muito querida, a pentelha, Janayna Dias que sempre me consolou e me acalmou me oferecendo seu ombro amigo;

Agradeço muito ao Zé Maria e Paloma da secretaria que, com muita eficiência, administram os assuntos relacionados à pós-graduação, além da querida Leila Affini, Tarcísio e Patrícia que sempre estiveram disponíveis quando precisei;

À todos os professores do departamento de Fisiologia e Biofísica do ICB-I que sempre me receberam de forma muito acolhedora quando precisei e que são muito importantes como exemplos de profissionais; e aos colegas de pós-graduação que, assim como eu, batalharam e batalham muito pelas suas conquistas; 
Aos funcionários lindos do biotério, da limpeza e do apoio didático que realizam um trabalho impecável nas dependências do departamento e aos funcionários de outros departamentos que sempre se disponibilizaram quando precisei;

Aos funcionários da biblioteca do ICB-1, em especial Teresa Cristina Soutto e Mônica Amaral, que me auxiliaram muito na formatação do trabalho com muita dedicação e paciência;

Aos componentes de minha banca de qualificação de mestrado que me auxiliaram muito na evolução desta dissertação: Rosana Mori, William Festuccia e Eliane Akamine;

Aos queridos Sandra Moreira e Gil Santos, com quem convivi bastante tempo e que me acolheram com muito carinho em sua casa;

Ao apoio financeiro da CAPES;

À Deus que SEMPRE me acolhe com muito carinho e que NUNCA me deixa sem qualquer explicação; a pessoa mais perfeita que já existiu neste universo e que nunca falha. 
"Então, disse o Senhor a Moisés: Por que clamas a mim? Dize aos filhos de Israel que marchem. E tu, levanta a tua vara, e estende a tua mão sobre o mar, e fende-o, para que os filhos de Israel passem pelo meio do mar em seco." (Êxodo 14: 15-16) 


\section{RESUMO}

BELPIEDE, L. T. A expressão do GLUT4 no tecido adiposo de camundongos varia de acordo com a sensibilidade à insulina durante o desenvolvimento da obesidade. 2015 . $72 \mathrm{f}$. Dissertação (Mestrado em Fisiologia Humana) - Instituto de Ciências Biomédicas, Universidade de São Paulo, São Paulo, 2015.

A resistência insulínica acompanha-se de redução na expressão do transportador de glicose GLUT4 (codificado pelo gene SLC2A4) no tecido adiposo. O aumento da massa adiposa está relacionado com produção acentuada de citocinas inflamatórias, tais como o TNFA (fator de necrose tumoral A), que por ativar a via do NFKB (fator nuclear kappa B) regula negativamente o gene SLC2A4. Assim, este estudo tem como objetivo analisar a evolução da regulação de expressão do Slc2a4/GLUT4, em tecido adiposo perigonadal de camundongos CD1, durante a progressão do desenvolvimento da obesidade induzida por glutamato monossódico (MSG), e exacerbada por dieta hiperlipídica. Animais neonatos foram divididos em grupo controle (C), tratados com salina e grupo obeso (MSG) tratados com MSG. Após o desmame, animais C foram alimentados com dieta normolipídica (DN) e MSG foram alimentados tanto com DN quanto com dieta hiperlipídica (DH) por 4, 8, 12 e 16 semanas. Os resultados mostraram que animais MSG desenvolveram obesidade progressivamente, o que foi exacerbado pela dieta $\mathrm{DH}$. Essa evolução levou à resistência insulínica, hiperinsulinemia e hiperglicemia, sempre mais acentuadas nos animais MSG-DH. Ainda, a resistência à insulina foi acompanhada por redução na expressão de Slc2a4/GLUT4 no tecido adiposo com aumento da expressão de Tnfa, o que deve estar relacionado. Interessantemente, no início do desenvolvimento da obesidade (4 semanas), animais MSG- DN revelaram aumento da sensibilidade à insulina, sem alteração de glicemia ou insulinemia, mas com aumento no conteúdo de GLUT4; efeitos esses que já não foram observados nos animais MSG-DH. Concluindo, a obesidade MSG evoluiu de maneira bifásica: precocemente, aumentou o conteúdo de GLUT4 e a sensibilidade insulínica; posteriormente decaiu o GLUT4 e surgiu uma resistência insulínica levando ao diabetes tipo 2 (DM2). A ingestão de dieta hiperlipídica foi capaz de antecipar e/ou exacerbar a ocorrência dos eventos que levaram ao DM.

Palavras-chaves: Obesidade. Resistência insulínica. Inflamação. GLUT4. Tecido adiposo. MSG. 


\begin{abstract}
BELPIEDE, L. T. GLUT 4 expression in mouse adipose tissue changes in parallel to the insulin sensitivity during obesity development. 2015. 72 p. Masters thesis (Human Physiology) - Instituto de Ciências Biomédicas, Universidade de São Paulo, São Paulo, 2015.

Insulin resistance is accompanied by reduction in the glucose transporter GLUT4 expression (codified by the $S L C 2 A 4$ gene) in adipose tissue. Increased fat mass induces high production of inflammatory citokines, including TNF (tumor necrosis factor A), which is an activator of NFKB (nuclear factor kappa B), a powerful repressor of SLC2A4 gene. The present study investigates de regulation of Slc2a4/GLUT4 expression in epididymal adipose tissue of mice, during the evolution of obesity, exacerbated or not by hyperlipidic diet. Neonatal male mice were treated with saline (control, C) or monosodium glutamate (MSG) to develop obesity. After weaning, $\mathrm{C}$ animals received normolipidic diet (C-ND) and obese animals received normolipidic (MSG-ND) or hyperlipidic (MSG-HD) diets for 4, 8, 12 and 16 weeks. MSG animals rapidly developed a progressive obese pattern, and that was exacerbated by HD. This evolution led to insulin resistance, hyperinsulinemia and hyperglycemia, which was accompanied by reduction in adipose tissue Slc2a4/GLUT4 expression, and increased Tnfa mRNA expression. However, precociously (4 weeks), MSG-ND mice revealed increased insulin sensitivity and GLUT4 expression, with unchanged insulinemia and glycemia; however, that was not observed in MSGHD. Concluding, MSG-induced obesity present a biphasic evolution: earlier (4 weeks), adipose tissue GLUT4 content increases, and that should participate on the increased insulin sensitivity; later on, GLUT4 decreases and insulin resistance settles, leading to type 2 diabetes (T2D). Besides, hyperlipidic diet intake anticipates and/or exacerbates the evolution for T2D.
\end{abstract}

Keywords: Obesity. Insulin resistance. Inflammation. GLUT4. Adipose tissue. MSG. 


\section{LISTA DE ILUSTRAÇÕES}

Figura 1 - Diferenciação de adipócitos .....................................................................19

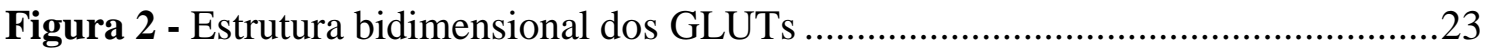

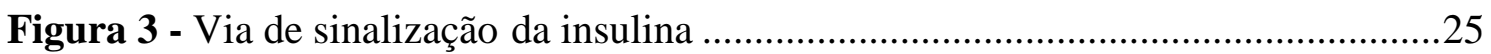

Figura 4 - Cascata de ativação do NFKB a partir do TNFA ….....................................27

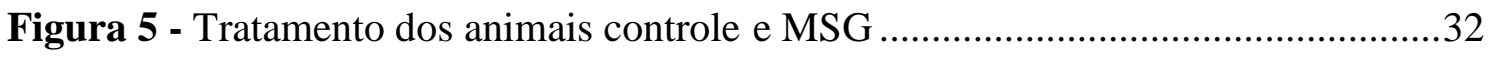

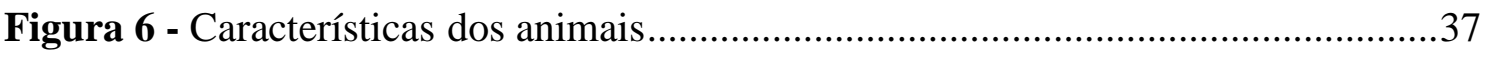

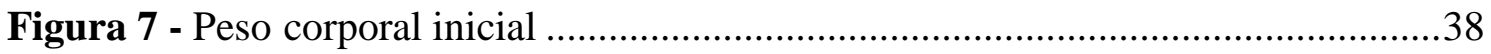

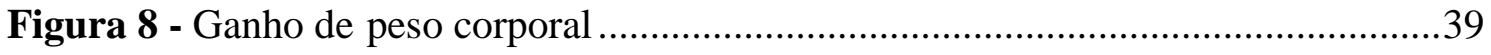

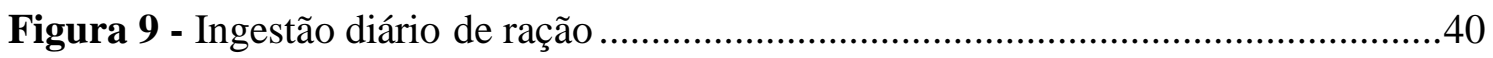

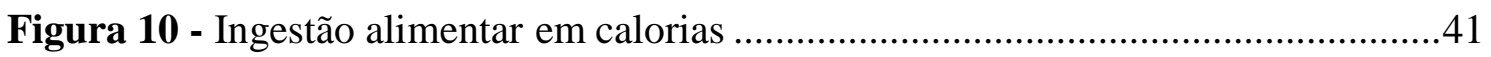

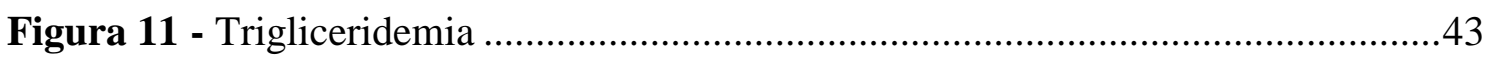

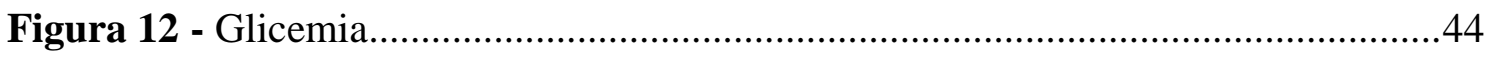

Figura 13 - Colesterol plasmático total .................................................................45

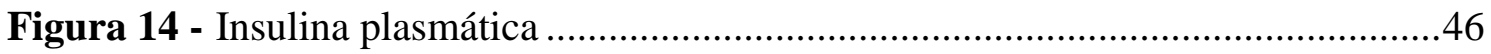

Figura 15 - Teste de tolerância à insulina intraperitoneal ...........................................47

Figura 16 - Conteúdo de GLUT4 em tecido adiposo perigonadal ................................48

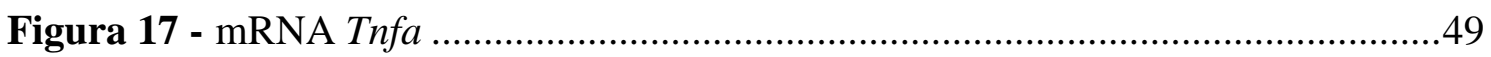

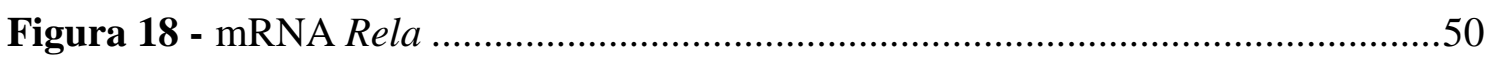

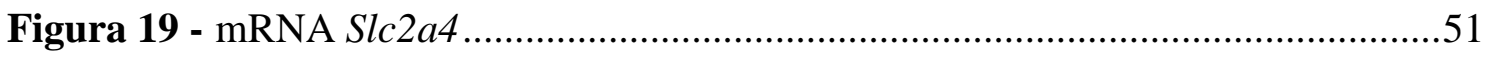




\section{LISTA DE TABELAS}

Tabela 1 - Composição nutricional da DN e DH e sua equivalência calórica.................31

Tabela 2 - Características dos ensaios de qPCR (Taqman) utilizados...........................35

Tabela 3 - Avaliação da obesidade ............................................................................42 


\section{LISTA DE ABREVIATURAS E SIGLAS}

\begin{tabular}{|c|c|}
\hline AGEs & do inglês, advanced glycation end products \\
\hline $\mathrm{Akt} / \mathrm{PKB}$ & do inglês, protein kinase $B$ \\
\hline BAT & do inglês, brown adipose tissue \\
\hline $\mathrm{C}$ & controle \\
\hline cDNA & do inglês, complementary DNA \\
\hline CEUA & comissão de ética no uso de animais \\
\hline $\mathrm{Ct}$ & do inglês, cycle threshold \\
\hline DM2 & diabetes mellitus do tipo 2 \\
\hline DN & dieta normolipídica \\
\hline DH & dieta hiperlipídica \\
\hline ECL & do ingles, enhanced chemiluminescence \\
\hline EDTA & ácido etilenodiaminotetracético \\
\hline ELISA & do inglês, enzyme linked immunosorbent assay \\
\hline EPM & erro padrão da média \\
\hline EROs & espécies reativas de oxigênio \\
\hline $\mathrm{GH}$ & do inglês, growth hormone \\
\hline GLUT & do inglês, glucose transporter \\
\hline $\mathrm{HCD}$ & do inglês, high carbohydrate diet \\
\hline $\mathrm{HCl}$ & cloreto de hidrogênio \\
\hline HFD & do inglês, high fat diet \\
\hline IL & interleucina \\
\hline ITT & do inglês, insulin tolerance test \\
\hline IR & do inglês, insulin receptor \\
\hline IRS & do inglês, insulin receptor substrate \\
\hline kcal & quilocaloria \\
\hline kITT & constante de decaimento da glicose \\
\hline mRNA & do inglês, messenger $R N A$ \\
\hline mTor & do inglês, mammaliam target of rapamycin \\
\hline MSG & do inglês, monosodium glutamate \\
\hline $\mathrm{NaCl}$ & cloreto de sódio \\
\hline NFKB & do inglês, nuclear factor kappa $B$ \\
\hline PCR & do inglês, polymerase chain reaction \\
\hline PDK1 & do inglês, phosphoinositide-dependent kinase 1 \\
\hline PI3K & fosfatidilinositol-3-quinase \\
\hline PIP2 & Fosfatidilinositol-4,5-bifosfato \\
\hline PIP3 & fosfatidilinositol-3,4,5-trifosfato \\
\hline qPCR & do inglês, quantitative PCR \\
\hline $\mathrm{RX}$ & raio $\mathrm{X}$ \\
\hline SDS-PAGE & do inglês, sodium duodecyl sulphate polyacrylamide gel eletrophoresis \\
\hline SGLT & do inglês, sodium glucose cotransporters \\
\hline SLC & do inglês, solute carries \\
\hline
\end{tabular}


sWAT

TNF

UA

vWAT

WAT do inglês, subcutaneous white adipose tissue

do inglês, tumor necrosis factor

unidades arbitrárias

do inglês, visceral white adipose tissue

do inglês, white adipose tissue 


\section{SUMÁRIO}

1 INTRODUÇÃO

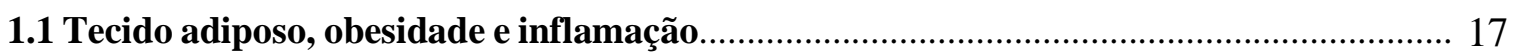

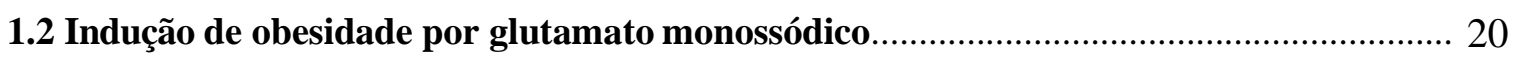

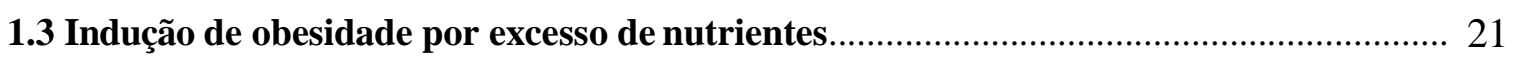

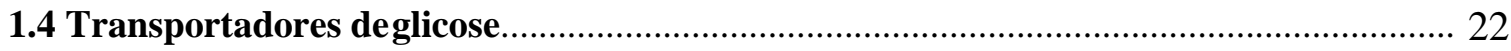

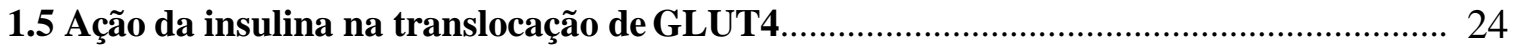

1.6 Mediadores inflamatórios na obesidade e resistência insulínica...................................... 26

2 JUSTIFICATIVA

3 OBJETIVOS

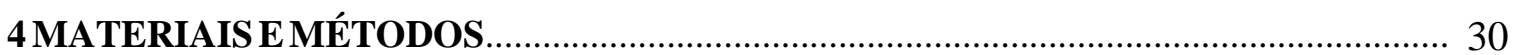

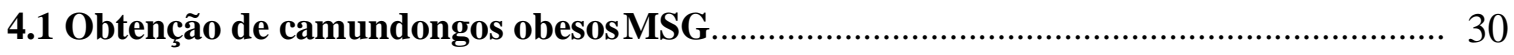

4.2 Tratamento com dieta e obtenção de parâmetros morfométricos.................................... 30

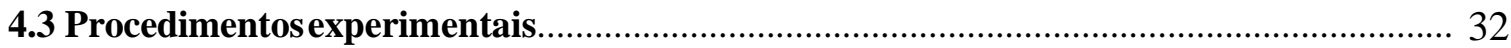

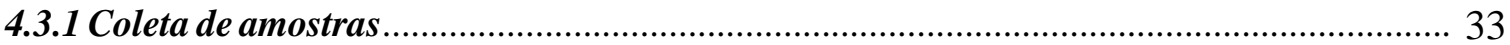

4.3.2 Teste de tolerância à insulinaintraperitoneal............................................................... 33

4.3.3 Determinação da concentração de substâncias em amostra de sangue e plasma ............. 33

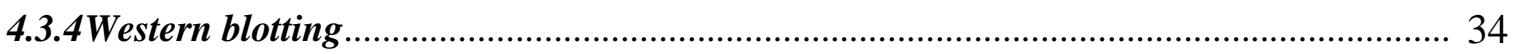

4.3.5 Transcrição reversa e reação em cadeia da polimerase em tempo real............................ 34

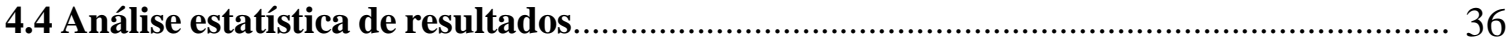

5 RESULTADOS

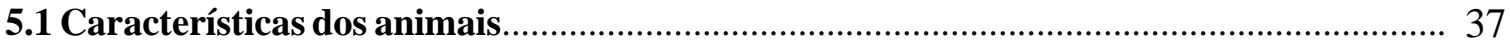

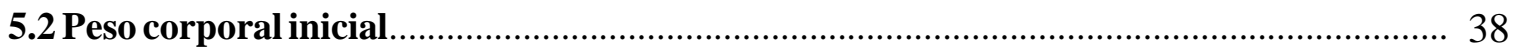

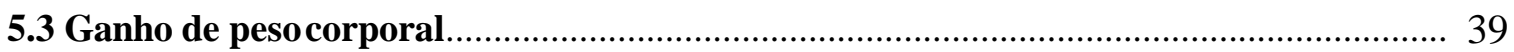

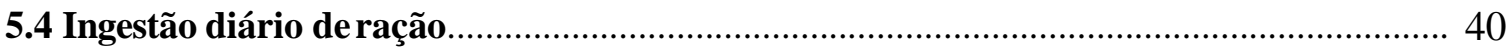

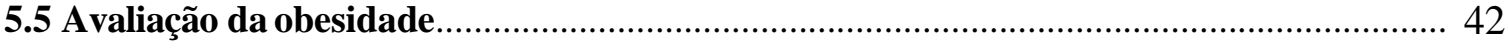

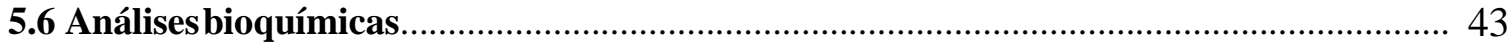

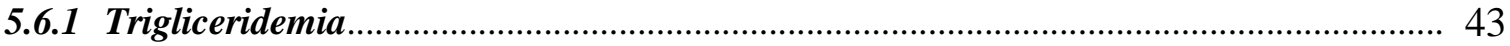

5.6.2 Glicemia

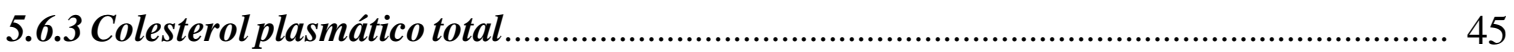

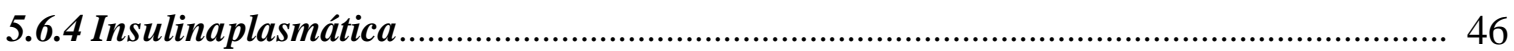

5.7 Teste de tolerância à insulina intraperitoneal............................................................ 47 
5.8 Conteúdo de GLUT4 em tecido adiposo periepididimal. 48

5.9 Expressão de mRNA em tecido adiposo perigonadal. 49

5.9.1 mRNATnfa 49

5.9.2 mRNARela 50

5.9.3 mRNASlc2a4. 51

6 DISCUSSÃO. 52

7 CONCLUSÃO. 57

REFERÊNCIAS 58 APÊNDICES

APÊNDICE A - Peso corporal final 67

APÊNDICE B - Consumo de dieta relativo ao peso corporal. 68

APÊNDICE C - Conteúdo de GLUT4 por grama de tecido adiposo perigonadal. 69

APÊNDICE D - Conteúdo de GLUT4 por tecido adiposo perigonadal total.. 70

APÊNDICE E - Expressão de mRNA Gapdh.. 71

APÊNDICE F - Correlação entre tecido adiposo perigonadal e mRNA Tnfa 


\section{INTRODUÇÃO}

A obesidade é um relevante problema de saúde pública que tem crescido de forma rápida e progressiva nas últimas décadas. Seus principais causadores são a ingestão excessiva de calorias e a falta de exercícios físicos, existindo também a influência de fatores genéticos (TAI; WONG; WEN, 2015).

De acordo com a Organização Mundial de Saúde (WORLD HEATH ORGANIZATION, 2015), em 2014, na população mundial adulta com mais de 18 anos de idade 39\% apresentava sobrepeso e $13 \%$ obesidade. Assim, são cerca de 2 bilhões de adultos que estão acima do peso, no mundo e, deste total, 0,5 bilhões são obesos.

A literatura científica tem investigado cada vez mais o tecido adiposo, que relacionado com a ocorrência de inflamação, representa um importante fator de risco para o desenvolvimento de resistência insulínica e diabetes mellitus tipo 2 (DM2) (HOTAMISLIGIL; SHARGILL; SPIEGELMAN, 1993). Entretanto, não estão claros os mecanismos precursores destes eventos, que, aparentemente, envolvem não apenas o excesso de tecido adiposo branco, mas também sua distribuição corporal (SORENSEN et al., 2015).

Assim, existindo uma elevada incidência de obesidade, a qual se relaciona ao desenvolvimento de outros distúrbios, consequentemente teremos um aumento de todas as comorbidades da obesidade comprometendo a saúde da população mundial.

\subsection{Tecido adiposo, obesidade e inflamação}

A obesidade é uma síndrome que pode ser definida como uma condição de depósito anormal ou excessivo de gordura no organismo (CHAN; WOO, 2010), resultado do desbalanço entre a ingestão de calorias e o dispêndio energético (HOTAMISLIGIL; SHARGILL; SPIEGELMAN, 1993). O desenvolvimento desta síndrome está associado ao aumento do tecido adiposo, cujas características, tanto morfológica quanto funcional são distintas nos diferentes territórios em que se apresenta.

Em 1994, com a descoberta da leptina, o tecido adiposo passou a ser visto como um órgão endócrino (ZHANG et al., 1994), que desempenha importante papel na homeostase energética (PARK; KIM; BAE, 2014). Esse fato expandiu o estudo de moléculas secretadas por células que atuam de maneira autócrina, parácrina ou mesmo endócrina, as quais são conhecidas como citocinas e denominadas de acordo com o tecido que as produz, no caso do tecido adiposo adipocitocinas ou adipocinas (LIMA; CURI, 2012). 
Existem dois principais tipos de tecido adiposo: marrom (brown adipose tissueBAT) e branco (white adipose tissue- WAT) (PARK; KIM; BAE, 2014). O BAT é bem definido em recém-nascidos e tem como principal característica a participação no mecanismo de controle da temperatura corporal (MÖSSENBÖCK et al., 2014), pelo aumento do consumo de energia, através da termogênese, oxidando um substrato e dissipando a energia gerada sob a forma de calor (MÖSSENBÖCK et al., 2014; PARK; KIM; BAE, 2014). Sua presença em humanos adultos não é tão bem definida, porém, recentemente, vêm sendo investigadas discretas áreas de BAT em humanos, relacionando-as ao controle glicêmico e à sensibilidade insulínica (MÖSSENBÖCK et al., 2014).

Classicamente, o WAT é conhecido como um dinâmico reservatório de energia (ALHASANI; JOOST, 2005; MÖSSENBÖCK et al., 2014), capaz de realizar este estoque sob a forma de triglicerídeos (PARK; KIM; BAE, 2014), além de participar da função imune e sustentação dos tecidos (TRAN; KAHN, 2010). É composto por diversos tipos celulares, os quais interagem através da secreção de adipocinas (BAPTISTA; SILVA; BOROJEVIC, 2015; ROSENWALD; WOLFRUM, 2014). De modo geral, indivíduos obesos apresentam aumento da massa de tecido adiposo branco, o que pode levar a diversas desordens metabólicas (TRAN; KAHN, 2010).

O WAT está distribuído por todo o corpo, existindo dois principais depósitos, tanto em humanos, quanto em outras espécies: tecido adiposo visceral (visceral white adipose tissue- vWAT), o qual está presente ao redor de órgãos abdominais, e o tecido adiposo subcutâneo (subcutaneous white adipose tissue- sWAT), que está localizado abaixo da pele. Existem ainda sub-classificações do vWAT: tecido adiposo mesentérico, retroperitoneal, perigonadal e omental. O sWAT está principalmente presente ao redor de quadris, coxas e nádegas (PARK; KIM; BAE, 2014).

O tecido adiposo como um todo (BAT e WAT) é constituído tanto por componentes celulares, quanto por componentes não celulares, sendo o volume dos primeiros representado principalmente pelos adipócitos. Ainda podem ser encontradas fibras colágenas, fibras reticulares, células nervosas, células do estroma vascular, nódulos linfáticos, células imunes (leucócitos e macrófagos), fibroblastos e pré-adipócitos (células adiposas indiferenciadas) (FONSECA-ALANIZ et al., 2006; HOTAMISLIGIL; SHARGILL; SPIEGELMAN, 1993; MARTINEZ-SANTIBAÑEZ; CHO; LUMENG, 2014).

Adipócitos maduros brancos são compostos por grandes gotas de gordura (às vezes única), esféricas, envoltas por finas bordas que acondicionam o citoplasma e o núcleo (MARTINEZ-SANTIBAÑEZ; CHO; LUMENG, 2014; ROSENWALD; WOLFRUM, 2014). 
Por outro lado, células mais jovens possuem diversas gotas menores de gordura, o que se descreve como multilocular (MARTINEZ-SANTIBAÑEZ; CHO; LUMENG, 2014). Estas células são derivadas de células-tronco pluripotentes, e o processo de diferenciação em adipócitos (adipogênese- Figura 1) resulta da interação de diversos fatores transcricionais, sendo alguns destes fatores sensíveis a nutrientes, metabólitos e hormônios. Assim, mudanças alimentares podem alterar não apenas o processo de lipogênese (estoque lipídico), mas também a adipogênese (diferenciação/desenvolvimento de adipócitos) e a função do WAT (AL-HASANI; JOOST, 2005).
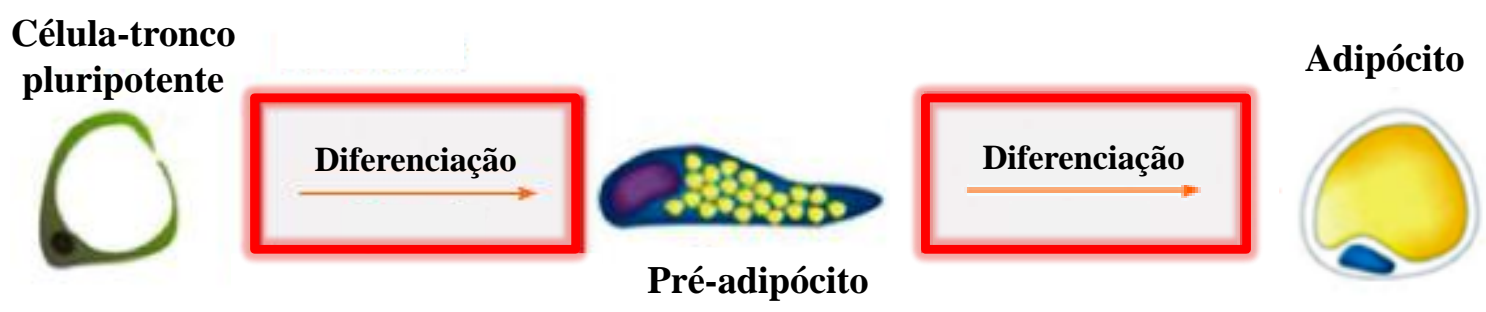

Figura 1 - Diferenciação de adipócitos - A figura acima representa um esquema de diferenciação da célula-tronco pluripotente até adipócito maduro branco, o que caracteriza o processo de adipogênese. Nota-se que o pré-adipócito possui diversas gotas menores de gordura em seu citoplasma e quando se diferencia estas gotículas se coalescem, formando gotas maiores e, muitas vezes, única. Adaptado de Baptista; Silva; Borojevic, 2015.

Conforme já mencionado o WAT é o principal reservatório energético do organismo, visto que seus adipócitos possuem todas as enzimas e substratos necessários para a síntese de triglicerídeos, o que os confere a capacidade de armazenamento lipídico. Esta síntese ocorre a partir de ácidos graxos e glicerol, e é denominada de lipogênese, conforme mencionado anteriormente. No entanto, a lipogênese ocorre apenas, quando há maior oferta de nutrientes e, em situações de déficit, este estoque é mobilizado a partir do processo inverso, a lipólise (AHIMA; FLIER, 2000; FONSECA-ALANIZ et al., 2006; KRONENBERG et al., 2010; ROSENWALD; WOLFRUM, 2014). Quando há um balanço positivo entre a oferta de energia e o gasto calórico desenvolve-se a obesidade (GREGOR; HOTAMISLIGIL, 2011; JÉQUIER; TAPPY, 1997; YIN et al., 2013), que envolve um componente inflamatório, caracterizado por aumento na liberação de citocinas (BAPTISTA; SILVA; BOROJEVIC, 2015).

Ainda, a obesidade também envolve o desenvolvimento de depósitos lipídicos ectópicos, o que pode determinar a coexistência de diversas outras doenças crônicas (PARK; 
KIM; BAE, 2014; WHITE et al., 2013). Esta síndrome é o principal fator de risco para o desenvolvimento de DM2, que ocorre pela presença de resistência insulínica e secreção reduzida de insulina (AL-HASANI; JOOST, 2005).

Como já antecipado, as pesquisas sobre obesidade vêm ampliando a atenção ao desenvolvimento do processo inflamatório subclínico (CURUVINEL et al., 2010; MARTINEZ-SANTIBAÑEZ; CHO; LUMENG, 2014). Esse processo não é semelhante à inflamação local classicamente caracterizada por vermelhidão, inchaço, calor e dor, com alta atividade metabólica local, e que representa uma resposta do organismo visando reparar o local em que houve injúria ou infecção. Esta diferença ocorre desde as causas da inflamação até as características metabólicas do processo que, no caso da obesidade, apresenta um padrão crônico e redução da taxa metabólica (GREGOR; HOTAMISLIGIL, 2010). Segundo Hotamisligil e colaboradores (1995), na obesidade, a secreção de citocinas pró-inflamatórias pelos adipócitos brancos soma-se a secreção proveniente de macrófagos infiltrados no tecido. Observa-se indução na expressão de fator de necrose tumoral (tumor necrosis factor alphaTNFA) (HOTAMISLIGIL; SHARGILL; SPIEGELMAN, 1993), interleucina-1 (IL- 1) (KOIVISTO; PELKONEN; CANTELL, 1989; NELSON; WALSHI; SHEEHAN, 1994) e interleucina-6 (IL-6) (PICKUP et al., 1997; YUDIKIN et al., 1999) em tecido adiposo branco de animais obesos.

\subsection{Indução de obesidade por glutamato monossódico}

Para avaliar a obesidade em animais existem diversos modelos experimentais. No presente estudo utilizou-se um modelo de obesidade hipotalâmica, desenvolvido por meio do tratamento neonatal com glutamato monossódico (monosodium glutamate - MSG), e exacerbado pela utilização de dieta hiperlipídica, cujas características serão discutidas mais adiante.

O glutamato, ou ácido glutâmico, é um aminoácido neurotransmissor excitatório, de ação predominante no sistema nervoso central. Em altas doses, torna-se tóxico, por aumentar, de forma persistente, a condutância na membrana a íons, levando a perda do equilíbrio iônico nos neurônios, em especial do cálcio. Para tentar restabelecer o fluxo iônico e osmótico, ocorre exaustão de estoques energéticos e consequente morte celular (KIZER; NEMEROFF; YOUNGBLOOD, 1978). Além disso, o aumento intracelular de cálcio também pode provocar morte celular por estimular uma série de enzimas que facilitam este processo, tais como, lipases, proteases, ATPases e DNAses (BESANCON et al., 2008; COYLE et al., 1981). O 
MSG é o sal sódico do ácido glutâmico, que em solução tampão (como o plasma) dissocia-se liberando o glutamato.

Ratos e camundongos recém-nascidos não apresentam a barreira hemato-encefálica desenvolvida, e, por isso, são sensíveis à ação neurotóxica do MSG. No período neonatal, a administração do MSG em doses adequadas lesa diversas estruturas na região circunventricular, principalmente o núcleo arqueado do hipotálamo (KIZER; NEMEROFF; YOUNGBLOOD, 1978). O hipotálamo possui grande importância na homeostase energética (HOCHBERG; HOCHBERG, 2010), e a administração de MSG em animais neonatos causa obesidade na idade adulta, além de redução na tolerância à glicose, resistência insulínica e DM2 (MACHADO; SHIMIZU; SAITO, 1993; MACHADO; SHIMIZU; SAITO, 1994; MACHO et al., 2000; NAGATA et al., 2006).

A lesão hipotalâmica causa queda na concentração plasmática de GH (growth hormone) (KOVACS et al., 2000; MAITER et al., 1991) e aumento na de corticosterona (HIMMS-HAGEN, 1989; MAGARIÑOS et al., 1988), o que junto com redução na atividade termogênica do tecido adiposo marrom (YOSHIOKA; YOSHIDA; KONDO, 1991), leva ao desenvolvimento da obesidade. Ainda, demonstrou-se em camundongos obesos por tratamento com MSG uma importante redução na expressão de transportadores de glicose do tipo 4 (GLUT4), o que desempenha importante papel no desenvolvimento da resistência insulínica e do DM2 nesse modelo (MACHADO; SHIMIZU; SAITO, 1993; MACHADO; SHIMIZU; SAITO, 1994; PAPA, SERAPHIM; MACHADO, 1997).

\subsection{Indução de obesidade por excesso de nutrientes}

Tanto o desenvolvimento da obesidade como da resposta inflamatória podem estar relacionados ao excesso de nutrientes (GREGOR; HOTAMISLIGIL, 2011). Para indução de obesidade em modelos animais, muitos autores utilizam dietas ricas em lipídeos (high fat dietHFD) ou em carboidratos (high carbohydrate diet- HCD). No entanto, não existe um padrão para o conteúdo destes nutrientes, nem mesmo um limite pré-estabelecido, o que acaba sendo um dos grandes problemas neste modelo de obesidade, que pode estimular/induzir resultados contraditórios (MONTGOMERY et al., 2013).

De modo geral, investigações realizadas com animais alimentados com HFD ou HCD avaliam doenças ou alterações relacionadas a este consumo, tais como perfil plasmático e hepático de lipídeos, susceptibilidade à aterosclerose, desenvolvimento de cálculos biliares, desenvolvimento da obesidade, metabolismo mitocondrial, inflamação e estresse oxidativo 
(BRESLIN et al., 2010; MONTGOMERY et al., 2013; PAIGEN, 1995), entre outras. No presente estudo utilizamos a HFD para exacerbar a obesidade induzida por MSG.

Estudos com camundongos CD1, tanto machos (BRESLIN et al., 2010) quanto fêmeas (GAO; MA; LIU, 2015) alimentados com HFD demonstram a ação do excesso deste nutriente na indução de ganho de peso corporal. Este ganho parece ser maior em machos quando comparado às fêmeas, submetidas às mesmas condições, o que indica a relação entre aspectos fisiológicos específicos de cada gênero (GAO; MA; LIU, 2015).

A HFD parece induzir progressivamente uma variedade de desordens metabólicas, incluindo maior adiposidade (hipertrofia de adipócitos e depósitos ectópicos de gordura), resistência insulínica, hiperinsulinemia e hipertrofia de ilhotas pancreáticas, sinais estes que foram associados à expressão de genes relacionados à inflamação crônica e à presença de esteatose hepática. Por meio de análises histológicas de WAT pode-se indicar a HFD como um potente estimulador da hipertrofia de adipócitos, o que confirma sua eficácia no desenvolvimento da obesidade (GAO; MA; LIU, 2015).

\subsection{Transportadores de glicose}

A glicose é a principal fonte de energia de organismos eucariontes, exercendo papel central no metabolismo e homeostasia celular. Pode ser adquirida pela dieta, a partir da hidrólise de dissacarídeos ou polissacarídeos ou ser formada a partir de outros substratos no fígado e rim (WOOD; TRAYHURN, 2003). É uma molécula polar e insolúvel na bicamada lipídica da membrana plasmática e, portanto, necessita de proteínas carreadoras associadas à membrana para ser transportada (SCHEEPERS; JOOST; SCHURMANN, 2004).

Em células epiteliais, tais como as do intestino delgado e do túbulo renal, o transporte de glicose é realizado através de proteínas transportadoras dependentes de sódio (sodium glucose cotransporters- SGLTs) em membrana apical (MACHADO, 1998). Para o transporte de glicose acoplado ao sódio, os SGLTs, pertencentes à família de genes SLC5A, realizam a captação deste monossacarídeo da membrana apical para o meio intracelular, contra o gradiente de concentração da glicose, mas a favor do gradiente eletroquímico do sódio, havendo, portanto, um transporte simultâneo de moléculas de glicose e íons sódio (WRIGHT et al., 2004). Concentrada na célula epitelial, a glicose se difunde a favor de seu gradiente de concentração para o interstício, através de proteínas transportadoras de glicose por difusão facilitada conhecidas como GLUTs (glucose transporters), codificadas por genes da família SLC2A (SCHEEPERS; JOOST; SCHURMANN, 2004). Os GLUTs também se 
expressam em todos os demais tipos celulares do organismo, garantindo o aporte celular de glicose. Tanto os SGLTs quanto os GLUTs pertencem a uma mesma superfamília de genes carreadores de soluto, identificada como SLC (solute carriers) (MACHADO; SHAAN; SERAFIM, 2006; SCHEEPERS; JOOST; SCHURMANN, 2004).

Os GLUTs são codificados por uma família de genes $S L C 2 A$ que inclui 13 genes e quatro pseudogenes (JOOST et al., 2002). Realizam transporte bidirecional da glicose e de outras hexoses (conforme a isoforma), sempre a favor do gradiente de concentração do substrato (MACHADO; SHAAN; SERAFIM, 2006; SCHEEPERS; JOOST; SCHURMANN, 2004). Estes carreadores possuem 12 segmentos transmembrânicos (S1 a S12) com sequências de aminoácidos bastante conservadas nas diferentes isoformas (JOOST; THORENS, 2001). Os segmentos S1 a S12 mantêm-se ligados por alças de conexão, e as terminações $\mathrm{NH}_{2}$ e $\mathrm{COOH}$ localizam-se no meio intracelular (SCHEEPERS; JOOST; SCHURMANN, 2004), conforme ilustrado a seguir (Figura 2):

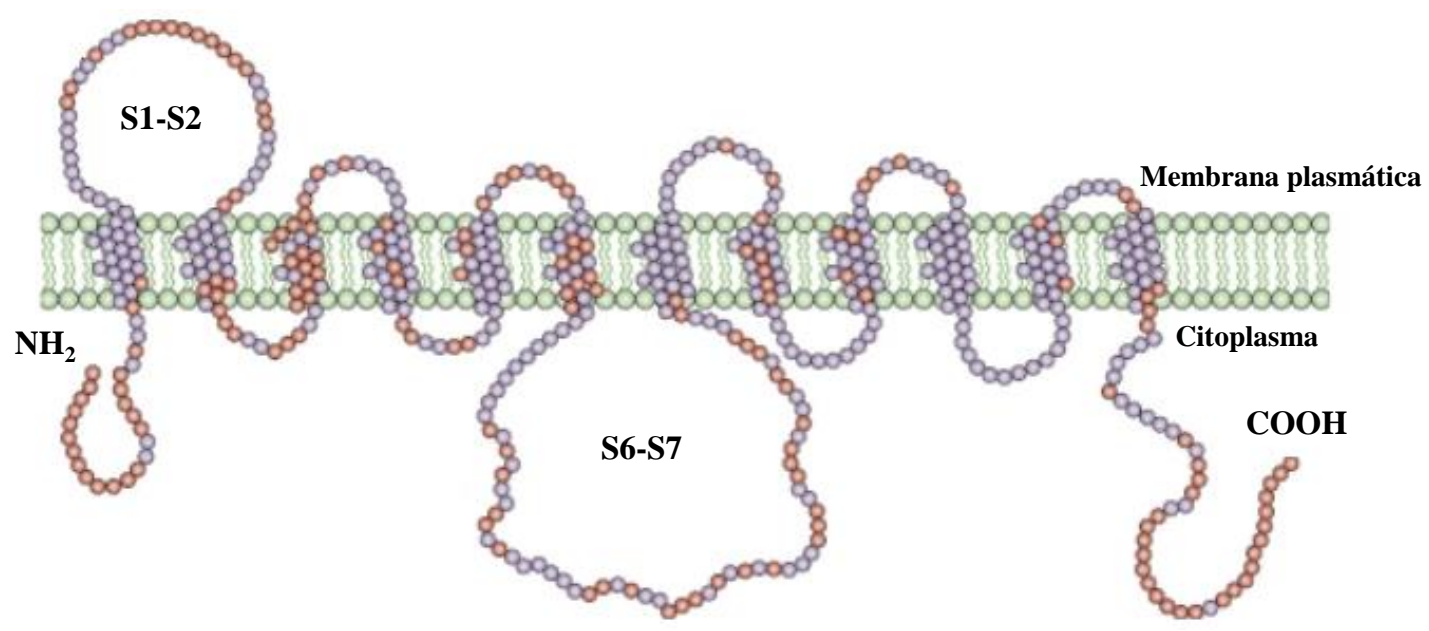

Figura 2 - Estrutura bidimensional dos GLUTs - Os círculos de coloração azul na figura acima representam aminoácidos conservados nas diferentes isoformas de GLUT. Adaptado de Bryant; Govers; James, 2002.

Os GLUTs possuem expressão tecido e célula-específica, e muitas vezes ocorre a expressão de mais de uma isoforma no mesmo tipo celular. Possuem diferentes características funcionais, além de distintas propriedades cinéticas e variável afinidade pelos substratos (MACHADO; SHAAN; SERAFIM, 2006; WOOD; TRAYHURN, 2003). 


\subsection{Ação da insulina na translocação de GLUT4}

Cushman e Wardzala, na década de 80, propuseram a translocação de proteínas transportadoras de glicose, para a membrana plasmática em resposta à insulina, caracterizando o mecanismo de captação de glicose dependente de insulina. Este transportador foi posteriormente identificado como a isoforma quatro de transportador de glicose por difusão facilitada - o GLUT4 (FUKUMOTO et al., 1989).

O GLUT4, codificado pelo gene $S L C 2 A 4$, é altamente expresso nos tecidos adiposos branco e marrom e nos músculos cardíaco e esquelético. Em reposta ao estímulo insulínico (CARVALHEIRA; ZECCHIN; SAAD, 2002; SALTIEL; KANH, 2001; THORENS; CHARRON; LODISH, 1990; TOZZO; GNUDI; KAHN, 1997) ocorre a translocação de vesículas citoplasmáticas, contendo GLUT4, para a membrana plasmática, aumentando a densidade do transportador, e, consequentemente, a captação de glicose (BRADY; PESSIN; SALTIEL, 1999; KOISTINEN; ZIERATH, 2002; MACHADO; SHIMIZU; SAITO, 1994). Contrariamente, quando decaem os níveis insulínicos, há internalização deste transportador, reduzindo novamente o influxo de glicose (REA; JAMES, 1997). No músculo, a contração muscular per se também é capaz de induzir a translocação do GLUT4, por mecanismos independentes dos ativados pela insulina.

O receptor da insulina (insulin receptor- IR) é uma glicoproteína constituída por duas subunidades $\alpha$ e duas $\beta$, unidas por ligações dissulfeto. As subunidades $\alpha$ são localizadas no extracelular e possuem sítio de ligação da insulina. As subunidades $\beta$ cruzam a membrana, contêm atividade tirosina cinase intrínseca (na porção citosólica), e assim são responsáveis pela transmissão do sinal insulínico à célula (BJÖRNHOLM; ZIERATH, 2005; KAHN, 1985; KASUGA; KARLSSON; KAHN, 1982). O IR fosforilado permitirá tanto a ligação quanto a fosforilação de resíduos de tirosina de vários substratos proteicos intracelulares, como IRS, Shc e Cbl (CARVALHEIRA; ZECCHIN; SAAD, 2002). A partir da fosforilação do IRS, passam a existir sítios de reconhecimento para moléculas que contenham domínios específicos $\mathrm{SH}$, como a subunidade regulatória da fosfatidilinositol-3-cinase (PI3K), o que ativa esta enzima (BIDDINGER; KAHN, 2006; CARVALHEIRA; ZECCHIN; SAAD, 2002; HABER et al., 2001; KANZAKI, 2006) e a mobiliza para a membrana plasmática (OLSON, 2012). A mobilização da PI3K favorece sua ação em substratos lipídicos, em particular, o fosfatidilinositol-4,5-bifosfato (PIP2) que, então, será fosforilado originando o PIP3 (CHANG; CHIANG; SALTIEL, 2004; KANZAKI, 2006; OLSON, 2012). O PIP3 pode recrutar proteínas como a Akt/PKB (protein kinase $B$ ), pela interação com domínios 
específicos (domínio PH). Para que a Akt seja ativada e possa exercer seus efeitos biológicos, esta cinase depende de dois eventos de fosforilação: um deles deve ocorrer no resíduo treonina 308 e outro no resíduo serina 473. A fosforilação em treonina 308 é mediada pela cinase dependente de fosfoinositídeos 1 (PDK1), por meio de sua interação com PIP3, na membrana plasmática; já a fosforilação em serina 473 parece ser realizada pelo complexo mTORC2 (OLSON, 2012; TOKER; MARMIROLI, 2014). A mTOR (mammaliam target of rapamycin) é uma proteína com atividade serina/treonina cinase que pertence à mesma família da PI3K e que funciona como subunidade catalítica de dois diferentes complexos protéicos conhecidos por mTORC1 e mTORC2, os quais atuam em substratos específicos promovendo efeitos distintos (TOKER; MARMIROLI, 2014).

Uma vez que a Akt tenha sido fosforilada, tanto em treonina quanto em serina, vários efeitos podem ocorrer na célula adiposa e muscular, destacando-se a translocação de vesículas ricas em GLUT4, e, assim, aumentando a captação de glicose pela célula (Figura 3) (CHANG; CHIANG; SALTIEL, 2004; KANZAKI, 2006; OLSON, 2012).

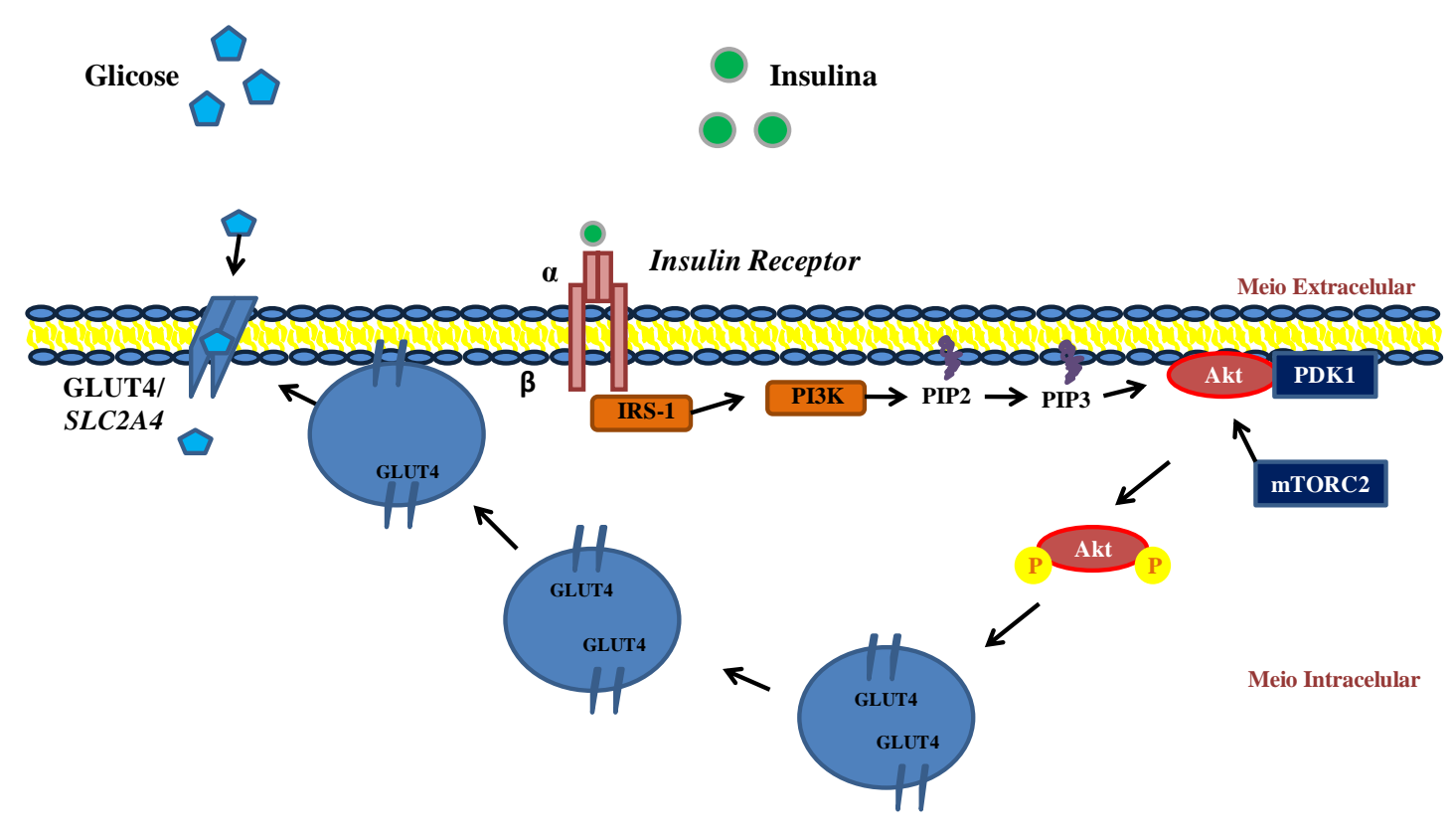

Figura 3 - Via de sinalização intracelular da insulina - Na figura acima é possível observar que a interação entre o hormônio e seu receptor, desencadeia uma série de fosforilações intracelulares que culminam em ativar a Akt, através da fosforilação, a qual estimula a translocação de GLUT4 para a membrana plasmática.

Caso estas vias não funcionem de forma adequada, instala-se uma situação de resistência insulínica que é definida como uma resposta biológica menor do que a esperada para determinada dose de insulina (HOTAMISLIGIL; SHARGILL; SPIEGELMAN, 1993). 
Entretanto, em situações de resistência à insulina durante longo prazo, o que mais se evidencia é uma redução na expressão do GLUT4 (CORRÊA-GIANELLA; MACHADO, 2013). Nesse sentido, já foi demonstrado, em camundongos knockout para GLUT4 (ABEL et al., 2001), que a redução na expressão gênica deste transportador reduz o conteúdo de proteína na membrana celular, induzindo resistência insulínica, independentemente de alterações na via de sinalização do hormônio (BERGER et al., 1989; MACHADO; SHIMIZU; SAITO, 1993).

\subsection{Mediadores inflamatórios na obesidade e resistência insulínica}

Como já foi dito anteriormente, a obesidade envolve um quadro crônico de inflamação, com produção anormal de citocinas pró-inflamatórias (CESCHI et al., 2007). Segundo Gregor e Hotamisligil (2011), adipócitos tratados com TNFA apresentam redução na sinalização da insulina e, consequentemente, redução na captação de glicose. Assim, esta citocina passou a ser conhecida como um importante agente indutor de resistência à insulina.

A ação do TNFA no tecido adiposo se dá de forma autócrina ou parácrina (CHIELLINI et al., 2002; COPPACK, 2001) e decorre da interação com seu receptor específico de membrana, o que, entre outros efeitos, induz a ativação do fator nuclear кappa B (nuclear factor карра B - NFKB). A família NFKB é composta por RELA (p65), NFKB1 (p50/p105), NFKB2 (p52/p100), C-REL e RELB, sendo as subunidades p65 e p50, na forma de homo- ou hetero-dímeros, preponderantes na homeostasia de adipócitos brancos (FURUYA et al., 2013; LI; VERMA, 2002; PERKINS, 2007).

Os NFKBs, no estado inativo, localizam-se no citoplasma associados a uma proteína inibitória (IKB). A fosforilação de IKB ocorre através da IKB cinase (IKK) a qual é composta pelas subunidades IKK[1]- $\alpha$, IKK[2]- $\beta$ e IKK[3]- $\gamma$ e estimula a dissociação de IKB e NFKB, sendo o dímero de NFKB liberado para translocação ao núcleo, onde se ligará a regiões específicas do DNA (KB site) de genes alvos (GREGOR; HOTAMISLIGIL, 2011; FURUYA et al., 2013). A Figura 4 resume a via de ativação do NFKB a partir do TNFA. 


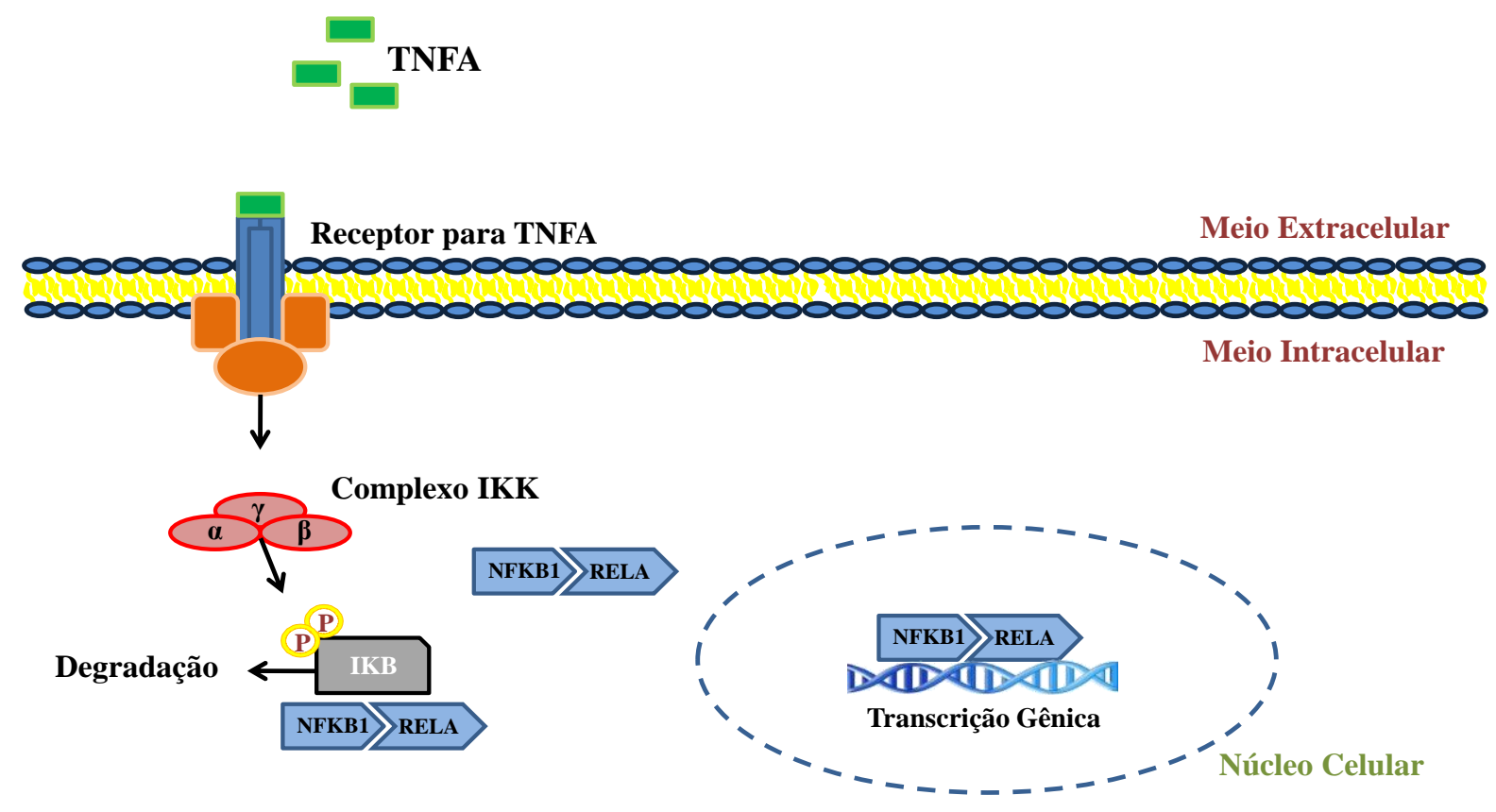

Figura 4 - Cascata de ativação do NFKB a partir do TNFA - Pode-se observar nesta figura que a interação do TNFA com seu receptor de membrana ativa o complexo IKK, o qual fosforila e degrada o IKB, liberando o heterodímero para translocação nuclear e, consequentemente, ação em sequências específicas do DNA para transcrição gênica.

$\mathrm{Na}$ obesidade, além dos fatores pró-inflamatórios, existem outros possíveis fatores que ativem esta via, como as espécies reativas de oxigênio (EROs) e produtos finais de glicação avançada (advanced glycation end products - AGEs) (KRETZ-REMY et al., 1996; LI, 2006). Já foi demonstrado que o NFKB está ativado no tecido adiposo de camundongos obesos (ob/ob) alimentados com dieta hiperlipídica (CAI et al., 2005), e obesos por tratamento com MSG (FURUYA et al., 2010). Adicionalmente, destaca-se que recentemente nosso grupo demonstrou que o gene $S L C 2 A 4$ é regulado negativamente pelo NFKB, tanto em adipócitos (3T3-L1) (FURUYA et al., 2013) como em células musculares L6 (FURUYA et al., 2013), determinando então o mecanismo preponderante na redução da captação de glicose induzida por insulina, nas situações de resistência e/ou DM2, como ocorre na obesidade avançada.

Considerando o descrito acima, o conhecimento da regulação da expressão do gene $S L C 2 A 4$ no tecido adiposo durante a evolução obesidade $\rightarrow$ resistência insulínica $\rightarrow$ DM2 poderá balizar caminhos promissores na prevenção e/ou tratamento da resistência insulínica/DM2. 


\section{JUSTIFICATIVA}

A obesidade e o diabetes mellitus são responsáveis por diversas doenças associadas, e muitos dos mecanismos moleculares envolvidos na etiopatogenia e na fisiopatologia precisam ser esclarecidos. Sabe-se que, na obesidade, a densidade do GLUT4 pode reduzir quando há um quadro de resistência à insulina, no entanto, não se conhece detalhadamente os mecanismos moleculares que levam a essa regulação do gene $S L C 2 A 4$. Nossa hipótese é que durante a evolução da obesidade o estímulo pró-inflamatório se instale, ativando NFKB, e que este possa induzir a regulação negativa do gene $S L C 2 A 4$.

No entanto, nenhum estudo avaliou temporalmente as variações na expressão dos genes para $N F K B$ (no caso deste projeto a subunidade RELA) e TNFA em tecido adiposo de animais obesos e resistentes à insulina, relacionando com a expressão de SLC2A4/GLUT4. Assim, pretendemos investigar a partir de qual momento ocorre esta redução de Slc2a4/GLUT4, e se o consumo de dieta hiperlipídica é capaz de modular essa evolução, agindo como um coadjuvante à obesidade para indução de inflamação e desenvolvimento da resistência à insulina.

Acreditamos que a determinação de mecanismos moleculares relacionados à obesidade e DM2 contribuirá na criação de estratégias para prevenção e/ou tratamento da resistência insulínica e do DM2. 


\section{OBJETIVOS}

\subsection{Geral}

O objetivo do presente estudo foi analisar a evolução da regulação de expressão do Slc2a4/GLUT4, em tecido adiposo perigonadal de camundongos CD1, durante a progressão do desenvolvimento da obesidade induzida por MSG, e exacerbada com dieta hiperlipídica.

\subsection{Específicos}

Avaliou-se temporalmente a expressão de Slc2a4/GLUT4, ganho de peso corporal, medidas de adiposidade, índices plasmáticos de colesterol e insulina, além da glicemia e trigliceridemia de animais obesos, tratados com MSG, alimentados ou não com dieta hiperlipídica, durante 4, 8, 12 e 16 semanas. A fim de relacionar estes parâmetros com o desenvolvimento da resposta inflamatória também foi investigada a expressão de Tnfa e Rela. 


\section{MATERIAIS E MÉTODOS}

\subsection{Obtenção de camundongos obesos MSG}

Camundongos CD1 (machos e fêmeas) foram acondicionados no biotério de Experimentação do Departamento de Fisiologia e Biofísica do Instituto de Ciências Biomédicas da Universidade de São Paulo, nas seguintes condições: a) ciclo de 12/12 horas de claro/escuro, luzes acesas às $7 \mathrm{~h}$; b) temperatura ambiente $23 \pm 2{ }^{\circ} \mathrm{C}$; e c) oferta plena de água e ração para roedores (Nuvilab, Colombo, PR, Brasil). Após período de adaptação os animais foram colocados para acasalamento.

Depois do acasalamento, as fêmeas prenhes ficaram em gaiolas individuais do $18^{\circ}$ dia de gestação até o desmame das respectivas ninhadas (os filhotes foram desmamados no $21^{\circ}$ dia após o nascimento). Logo após o nascimento, os filhotes receberam injeção subcutânea de $2 \mathrm{mg} / \mathrm{g}$ peso corpóreo de glutamato monossódico6 (Sigma- Aldrich Chemicals, Steinhein, Germany), (grupo obeso - MSG) ou $\mathrm{NaCl}$ 0,9\% (grupo controle - C) durante 5 dias consecutivos; e, no sétimo dia, uma injeção de 4 mg/g peso corpóreo (PAPA et al., 2002). Após o desmame, os animais foram mantidos nas mesmas condições ambientais, sendo selecionados apenas os animais machos para o estudo. O protocolo experimental de obtenção e tratamento dos animais foi aprovado pela Comissão de Ética no Uso de Animais (CEUA) e está registrado sob o número 87, nas folhas 08 do livro 03 para uso de animais em experimentação sob a responsabilidade do Professor Doutor Ubiratan Fabres Machado.

\subsection{Tratamento com dieta e obtenção de parâmetros morfométricos}

Após o desmame, os animais controle continuaram se alimentando com dieta normolipídica (DN) (Pragsoluções Biociências, Jaú-SP, Brasil) e os animais MSG foram divididos em dois grupos: dieta normolipídica (DN) ou hiperlipídica (DH) (Pragsoluções Biociências, Jaú-SP, Brasil). As composições de ambas as dietas estão apresentadas no quadro abaixo (Tabela 1). Assim, tivemos três grupos experimentais: a) Controle - dieta normolipídica; b) MSG - dieta normolipídica e c) MSG - dieta hiperlipídica. 
Tabela 1- Composição nutricional da DN e DH e sua equivalência calórica

\begin{tabular}{|c|c|c|c|c|}
\hline Ingredientes & $\begin{array}{c}\text { Dieta } \\
\text { normolipídica } \\
(\mathrm{g}) \\
\end{array}$ & $\begin{array}{c}\text { Dieta } \\
\text { normolipídica } \\
\text { (kcal) } \\
\end{array}$ & $\begin{array}{c}\text { Dieta } \\
\text { hiperlipídica } \\
(\mathrm{g}) \\
\end{array}$ & $\begin{array}{c}\text { Dieta } \\
\text { hiperlipídica } \\
\text { (kcal) }\end{array}$ \\
\hline$\underline{\text { Caseina }}$ & 202 & 808 & 200 & 800 \\
\hline$\underline{\text { Sacarose }}$ & 100 & 400 & 100 & 400 \\
\hline Amido de milho & 397 & 1588 & 115.5 & 462 \\
\hline$\underline{\text { Maltodextrina }}$ & 130.5 & 522 & 132 & 528 \\
\hline$\underline{\text { Banha de porco }}$ & -- & -- & 312 & 2880 \\
\hline Óleo de soja & 70 & 630 & 40 & 360 \\
\hline Celulose & 50 & 0 & 50 & 0 \\
\hline Mix mineral & 35 & 0 & 35 & 0 \\
\hline Mix vitamina & 10 & 40 & 10 & 40 \\
\hline$\underline{\text { L-Cistina }}$ & 3 & 12 & 3 & 12 \\
\hline$\underline{\text { Colina }}$ & 2.5 & 0 & 2.5 & 0 \\
\hline Total & 1000 & 4000 & 1000 & 5482 \\
\hline
\end{tabular}

Para avaliar o consumo calórico dos animais, considerou-se, então, a equivalência de 4 kcal para cada $1 \mathrm{~g}$ consumido de dieta normolipídica e 5,482 kcal para cada $1 \mathrm{~g}$ consumido de dieta hiperlipídica.

As avaliações experimentais foram realizadas após 4, 8, 12 e 16 semanas de tratamento com as dietas. 
Segue abaixo um esquema (Figura 5) que ilustra o tratamento dos animais:

TRATAMENTO (SEMANAS)

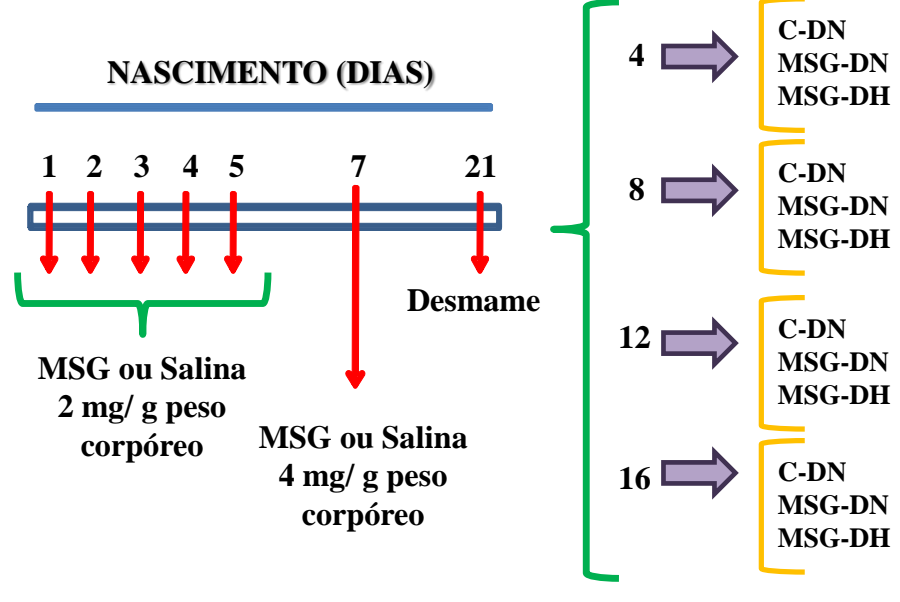

LEGENDA:

DN: Dieta Normolipídica

DH: Dieta Hiperlipídica

C: Animais tratados com Salina (Controle)

MSG: Animais tratados com MSG (Obesos)

Figura 5 - Tratamento dos animais controle e MSG - Este esquema ilustra o tratamento desde o período de nascimento até o desmame e introdução da dieta.

Os animais foram semanalmente pesados e o consumo diário de ração (da gaiola) também foi avaliado. Os valores obtidos dessa ingestão foram divididos pelo número de animais de cada gaiola.

Para avaliar o grau de obesidade, foi utilizado o índice de Lee calculado pela raiz cúbica do peso corporal do animal (g), dividido pelo comprimento naso-anal (cm), e multiplicado por 100 [peso corporal $(\mathrm{g})^{1 / 3} /$ comprimento naso-anal (cm)] x 100 (PAPA et al., 2002).

\subsection{Procedimentos experimentais}

Antes da realização de eutanásia, os animais foram anestesiados com injeção intraperitoneal de tiopental sódico (50 mg/kg peso corporal) e, apenas após a abolição dos reflexos corneanos e retirada da pata ao estímulo da dor, foram iniciados os procedimentos. A anestesia dos animais foi realizada após privação alimentar de quatro horas. Uma vez anestesiados, o comprimento naso-anal foi medido, para cálculo do índice de Lee. 


\subsubsection{Coleta de amostras}

Amostras de tecido adiposo perigonadal foram retiradas e imediatamente congeladas em nitrogênio líquido, para posterior análise de proteínas (coxim direito) e mRNA (coxim esquerdo). Foi, então, realizada punção cardíaca para coleta de sangue em tubos heparinizados, mantidos à $4{ }^{\circ} \mathrm{C}$ até centrifugação (1000 x g, 10 minutos). O plasma foi separado e imediatamente armazenado à $-20{ }^{\circ} \mathrm{C}$ para posterior dosagem de níveis plasmáticos de colesterol total e insulina.

\subsubsection{Teste de tolerância à insulina intraperitoneal}

Para o teste de tolerância à insulina, os animais também foram submetidos à privação alimentar de quatro horas. As amostras de sangue foram coletadas a partir de secção causal nos tempos 0 (basal), 5, 10, 15, 20, 30, 40 e 60 minutos após a sobrecarga intraperitoneal de insulina regular (Humulin: Lilly, São Paulo- Brasil), 0,75 U/kg de peso corporal. A concentração de glicose sanguínea foi determinada com o auxílio de um glicosímetro (ACCUCHEK ${ }^{\circledR}$ Active- Roche, Mannheim, Alemanha), e a constante de decaimento da glicose (kITT) foi calculada a partir da regressão linear do logaritmo neperiano dos valores glicêmicos obtidos de 0 a 60 minutos no teste (YAMAUCHI et al., 2011).

\subsubsection{Determinação da concentração de substâncias em amostras de sangue e plasma}

Anteriormente à eutanásia, foram mensuradas a glicemia (por glicosímetro- ACCUCHEK ${ }^{\circledR}$ Active-Roche, Mannheim, Alemanha) e a trigliceridemia (por triglicerímetroAccuntrend ${ }^{\circledR}$ GCT- Roche, Mannheim, Alemanha), a partir de sangue obtido por secção caudal. A concentração de colesterol plasmática foi avaliada por método enzimáticocolorimétrico com o kit de Colesterol Liquiform (Labtest, Lagoa Santa, MG, Brasil). Ainda, a concentração de insulina plasmática foi avaliada por meio do método colorimétrico ELISA (enzyme linked immunosorbent assay- Millipore, Missouri, USA). 


\subsubsection{Western blotting}

Amostras de tecido adiposo perigonadal foram homogeneizadas utilizando-se Polytron PT 3100 KINEMATICA ® (BRINKMAN), em tampão de homogeneização (Tris 10 mM; EDTA 1,0 mM; Sacarose $250 \mathrm{mM}$ ) na proporção de 1:4 (peso:volume), e centrifugadas a $1.000 \mathrm{x} \mathrm{g}$, à $4{ }^{\circ} \mathrm{C}$, por 15 minutos. $\mathrm{O}$ intranadante foi recuperado e uma alíquota foi armazenada à $-20{ }^{\circ} \mathrm{C}$, como extrato total livre de gordura. A concentração de proteínas totais das amostras foi determinada pelo emprego de reagente de Bradford (Bio-Rad Laboratories, Hercules, CA, USA).

As proteínas foram separadas por SDS-PAGE (sodium duodecyl sulphate polyacrylamide gel electrophoresis), utilizando-se o método desenvolvido por Laemmli e modificado por Garfin (1990) que envolve um sistema descontínuo de dois géis contíguos para o empacotamento (stacking gel) e separação (resolving gel) das proteínas. A eletroforese foi realizada em tampão Tris-HCl 25 mM, Glicina 190 mM, SDS 0,1\%, EDTA 2 mM, pH 8,3, sob voltagem constante para o empacotamento $(75 \mathrm{mV})$ e corrente constante para a separação (60 mA).

A transferência eletroforética das proteínas do gel para uma membrana de nitrocelulose Hybond-ECL (Amersham, Buckinghahmshire, UK) foi realizada sob corrente constante de $40 \mathrm{~mA}$, durante 16 horas, à $4^{\circ} \mathrm{C}$, em tampão Tris- $\mathrm{HCl}$ 12,5 mM, Glicina $95 \mathrm{mM}$, metanol 20\%, $\mathrm{pH} 8,3$. As membranas de nitrocelulose foram incubadas com anticorpo antiGLUT4 (rabbit anti-GLUT4 polyclonal antibody, Milipore, Darmstadt, Alemanha), a revelação foi feita por quimioluminescência, com imediatamente exposição a filme de $\mathrm{RX}$ (Hyperfilm - Amersham, Buckinghamshire, UK) durante 1 a 15 minutos.

A intensidade dos blots foi avaliada por densitometria óptica (Software Image Quant TL, GE Healthcare Bio-Sciences, Uppsala, SW), e o resultado numérico foi expresso em unidades arbitárias (UA). A média do grupo controle em cada membrana foi considerada como 100 e cada valor individual foi normalizado em relação à essa média. Os conteúdos de GLUT4, calculados com base nestes valores, foram expressos em unidades arbitrárias por micrograma de proteína $(\mathrm{UA} / \mu \mathrm{g})$.

\subsubsection{Transcrição reversa e reação em cadeia da polimerase em tempo real (qRT-PCR)}

Fragmentos de cerca de $0,1 \mathrm{~g}$ de tecido foram congelados em nitrogênio líquido para posterior extração do RNA total através da técnica do Trizol (GIBCO, Gaithersburg, USA), 
conforme instruções do fabricante. Um $\mu \mathrm{L}$ da amostra de RNA total foi retirado para leitura em Nanodrop $^{\text {TM }} 2000$ UV-Vis Spectrophotometers (Thermo Fisher Scientific, Canadá, USA) e avaliação da concentração de ácido nucléico e da pureza da amostra.

A reação de transcrição reversa para a síntese de DNA complementar (cDNA), foi realizada a partir da adição de $0,5 \mu \mathrm{L}$ Random primers $(0,5 \mu \mathrm{g} / \mu \mathrm{L})$ (Invitrogen Life Technologies, USA), $1 \mu \mathrm{L}$ de ImProm-II ${ }^{\mathrm{TM}}$ Reverse Transcriptase (Promega, USA), $1 \mu \mathrm{L}$ nucleotídeos dNTPmix (0,5 mM) (Invitrogen Life Technologies, USA), 2,4 $\mu \mathrm{L} \mathrm{MgCl}_{2}(25$ $\mathrm{mM}$ ) (Promega, USA), $4 \mathrm{uL}$ de Improm-II 5X ${ }^{\mathrm{TM}}$ reaction buffer $(1 \mathrm{x})$ (Promega, USA) e água livre de nuclease (nuclease free water - Life Technologies, USA) para volume final de $5 \mu \mathrm{L}$, à $1 \mu \mathrm{g}$ de RNA total da amostra.

Após transcrição reversa, os cDNAs sintetizados foram utilizados para realização da PCR em tempo real utilizando-se o sistema Taqman (Invitrogen Life Technologies, USA). As sondas inventoriadas e a designação do kit são apresentados na Tabela 2.

Tabela 2 - Características dos ensaios de qPCR (Taqman) utilizados

\begin{tabular}{c|c|c|c}
\hline Genes & Identificação do ensaio & Tamanho do fragmento & Sonda Taqman \\
\hline Slc2a4 & NM_0092042 & 79 & Mm01245502_m1 \\
\hline Gapdh & NM_008084.2 & 107 & Mm999999915_g1 \\
\hline Tnfa & NM_013693.3 & 61 & Mm00443260_g1 \\
\hline Rela & NM_009045.4 & 67 & Mm00501346_m1 \\
\hline
\end{tabular}

A quantidade de cDNA para cada gene foi otimizada a partir de curva-padrão que permite avaliar a linearidade e a eficiência da amplificação. Para essa finalidade, foram utilizadas as diluições $(1 ; 0,5 ; 0,25 ; 0,125$ e 0,0625$)$ de cDNA de amostras usadas apenas para teste nos ensaios de PCR em tempo real. As diluições de cDNA e os respectivos valores de $\mathrm{Ct}$ foram colocados em gráfico que permite verificar a relação entre essas duas variáveis $(\mathrm{Ct} \mathrm{x}$ $\log$ da diluição de cDNA).

Os sinais de fluorescência emitidos pelos fluoróforos foram detectados pelos equipamentos Rotor Gene 3000 (Corbett Research, Mortlake, 2137 NSW, Austrália). Os dados foram analisados pelos seus respectivos softwares. Em ambos, a partir do sinal de fluorescência detectado, fase exponencial de amplificação, foi gerado um valor numérico que é denominado cycle threshold $\left(\mathrm{C}_{\mathrm{t}}\right)$ (WONG; MEDRANO, 2005). Para cada amostra de 
cDNA, o Ct de cada gene alvo foi registrado e comparado com o $\mathrm{Ct}$ do controle endógeno sendo:

Os valores de $\mathrm{Ct}$ obtidos nesses ensaios foram utilizados para calcular a expressão relativa de mRNA de cada gene alvo em relação à do controle endógeno. Essa relação é denominada Delta $\mathrm{Ct}(\Delta \mathrm{Ct})$ :

$$
\Delta \mathrm{Ct}=\left(\mathrm{Ct}_{\text {gene alvo }}-\mathrm{Ct}_{\text {controle endógeno }}\right)
$$

Com objetivo de avaliar a variação de expressão entre os grupos foi utilizado o parâmetro Delta Delta $\mathrm{Ct}(\Delta \Delta \mathrm{Ct})$ que é calculado utilizando o Delta $\mathrm{Ct}$ da média dos controles, através da seguinte fórmula:

$$
\Delta \Delta \mathrm{Ct}=\left(\Delta \mathrm{Ct}_{\mathrm{amostra}}-\Delta \mathrm{Ct}_{\text {controle }}\right)
$$

Os dados de $\Delta \Delta \mathrm{Ct}$ foram transformados em escala logarítmica $\left(2^{-\Delta \Delta \mathrm{Ct}}\right)$ para comparar dados entre os grupos. A expressão foi interpretada pelo aumento ou diminuição após o tratamento.

\subsection{Análise estatística dos resultados}

Todos os valores foram expressos como média + EPM. Os dados foram submetidos à análise estatística por ANOVA (análise de variância) de uma via, seguida por teste StudentNewman-Keuls, após aprovação no teste de Bartlett, ou então seguida pelo teste de Bonferroni. Ainda, foram realizadas algumas análises de correlação de Pearson e teste " $\mathrm{t}$ " de Student. Valores de $P<0,05$ foram considerados significantes. 


\section{RESULTADOS}

\subsection{Características dos animais}

Na Figura 6 são ilustradas fotos dos camundongos C-DN, MSG-DN e MSG-DH nos diferentes períodos de tratamento. É possível observar a obesidade dos animais MSG desde a primeira avaliação.
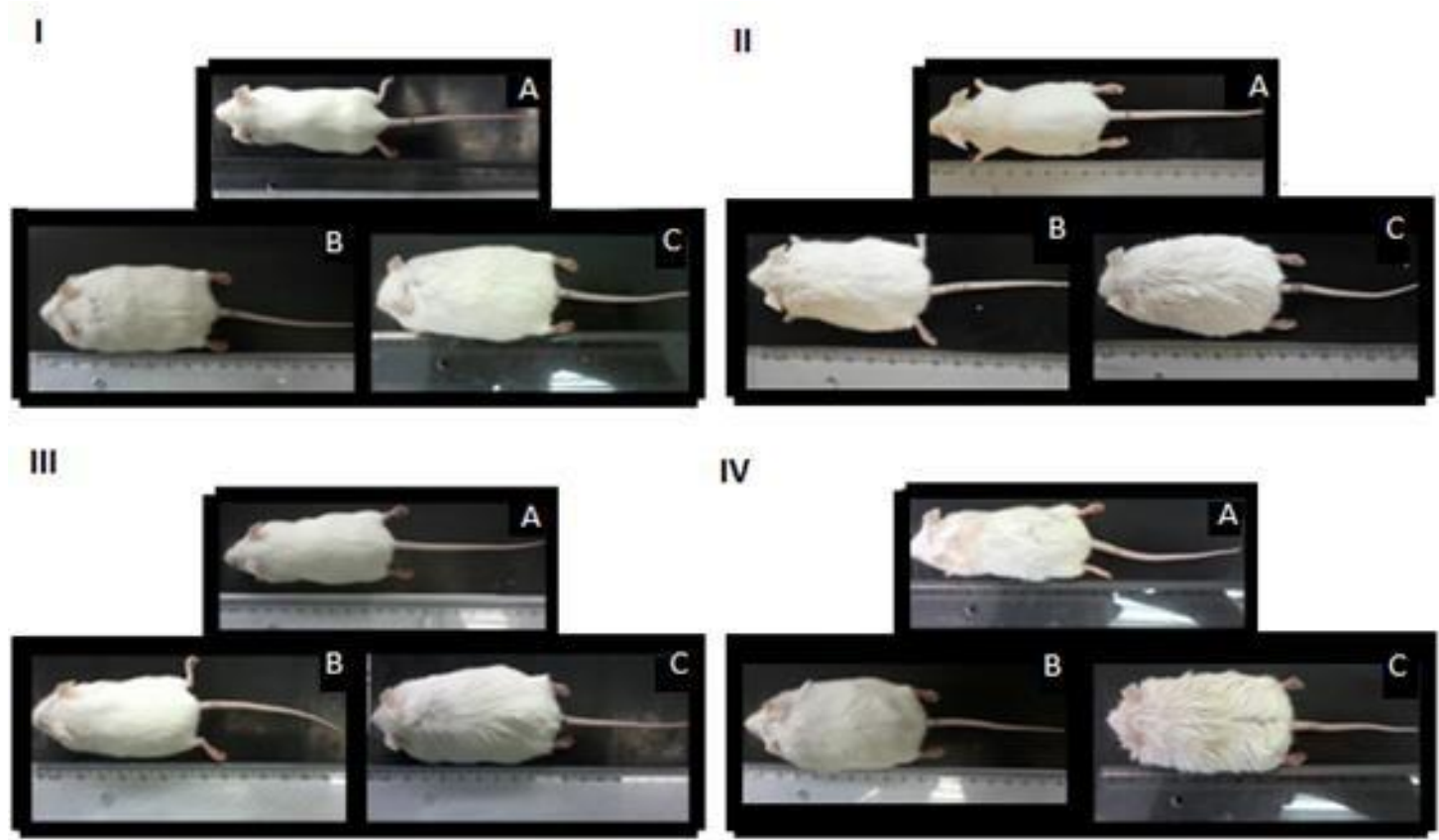

IV

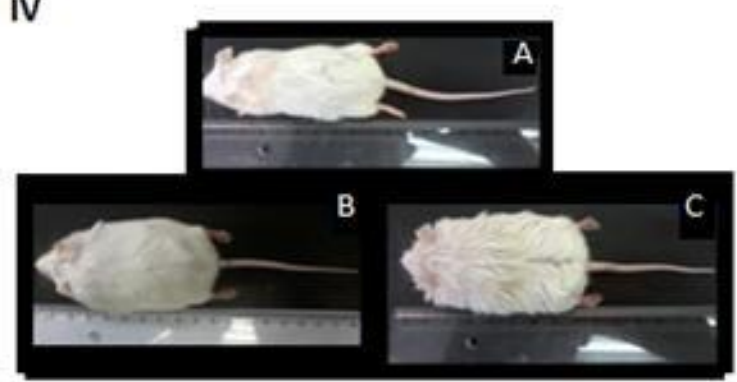

Figura 6 - A figura acima mostra a vista dorsal de camundongos do grupo controle alimentados com dieta normolipídica (C-DN) e camundongos do grupo obeso alimentados com dieta normolipídica (MSG-DN) ou hiperlipídica (MSG-DH), após 4 (I), 8 (II), 12 (III) ou 16 (IV) semanas de tratamento. Camundongos C-DN (A), MSG-DN (B) e MSG-DH (C). 


\subsection{Peso corporal inicial}

A Figura 7 demonstra a massa corporal dos animais logo após o desmame e, portanto, com quatro semanas de idade. Pode-se notar que os animais MSG (DN e DH) possuem um peso corporal significantemente menor, se comparados aos animais controle $(\mathrm{DN})(P<0,001)$.

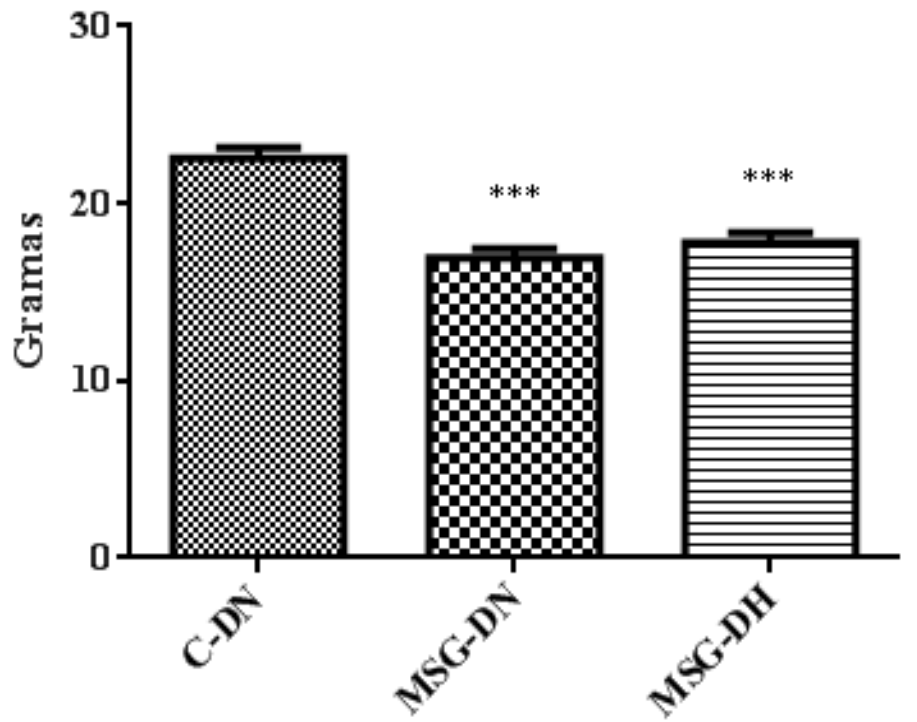

Figura 7 - Massa corporal no desmame dos animais designados para os diferentes grupos experimentais: controle alimentado com dieta normolipídica (C-DN) e obeso alimentado com dieta normolipídica (MSG-DN) ou hiperlipídica (MSG-DH). Valores são médias \pm EPM, ANOVA de uma via seguida de Student-Newman-Keuls; n= 22 a 24 animais. ${ }^{* * *} P<0,001$ vs C-DN. 


\subsection{Ganho de peso corporal}

A Figura 8 ilustra o delta de ganho de peso corporal dos animais ao final dos períodos de tratamento. Desde a quarta semana, os animais MSG-DH apresentaram maior ganho de peso, quando comparados aos grupos C-DN e MSG-DN $(P<0,001)$. O grupo MSG-DN mostrou maior ganho de peso somente ao final de 12 e 16 semanas, quando comparado ao grupo C-DN $(P<0,001)$.

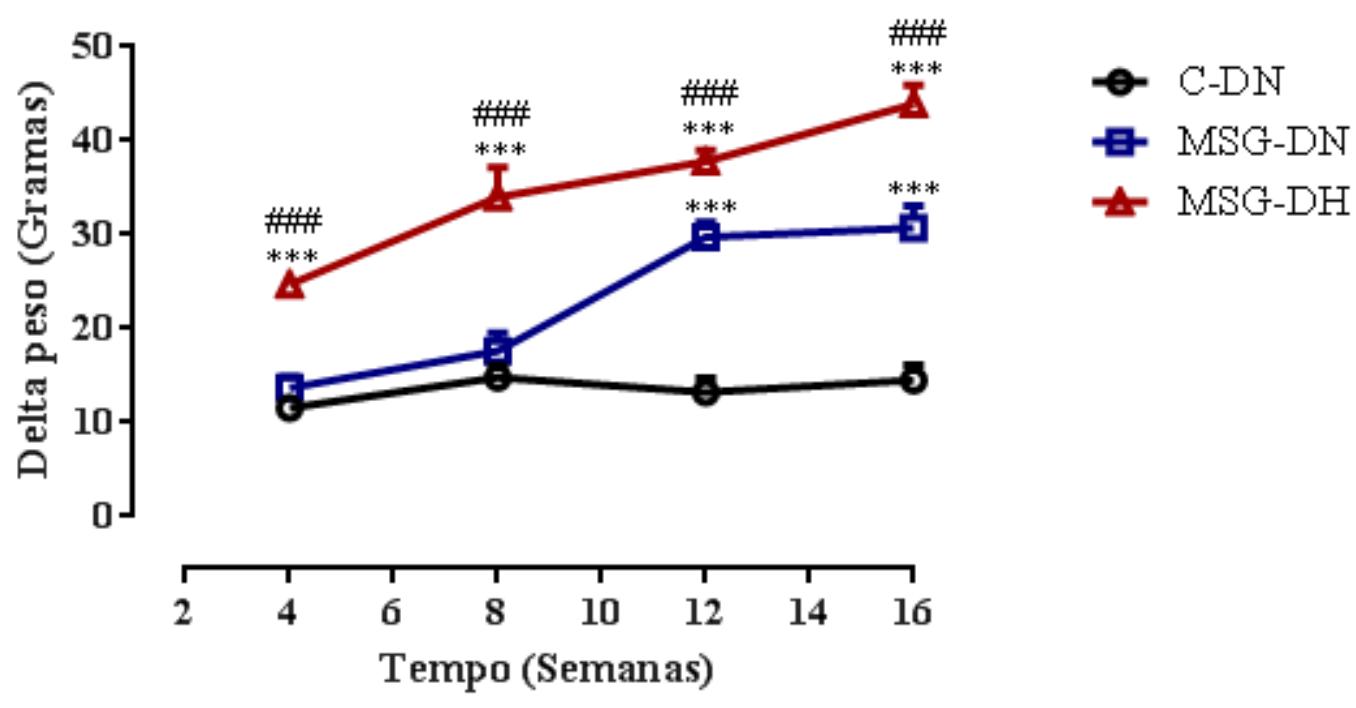

Figura 8 - Delta de ganho de peso dos camundongos controle (C-DN), e obesos alimentados com dieta normolipídica (MSG-DN) ou hiperlipídica (MSG-DH) ao final de 4, 8, 12 e 16 semanas. Valores são médias \pm EPM, ANOVA de duas vias seguida de Bonferroni; $\mathrm{n}=5$ a 15 animais. ${ }^{* * * *} P<0,001$ vs CDN e ${ }^{\# \# \# ~} P<0,001$ vs MSG-DN. 


\subsection{Ingestão diária de ração}

A Figura 9 mostra a ingestão de ração em gramas. Pode-se observar que o consumo de ração foi apenas transitoriamente menor $(P<0,05)$ no grupo MSG-DN (8 semanas) quando comparado ao grupo C-DN. Por outro lado, o grupo MSG-DH ingeriu sempre menor quantidade de ração (em comparação a C-DN e MSG-DN), o que se exacerba com o tempo.
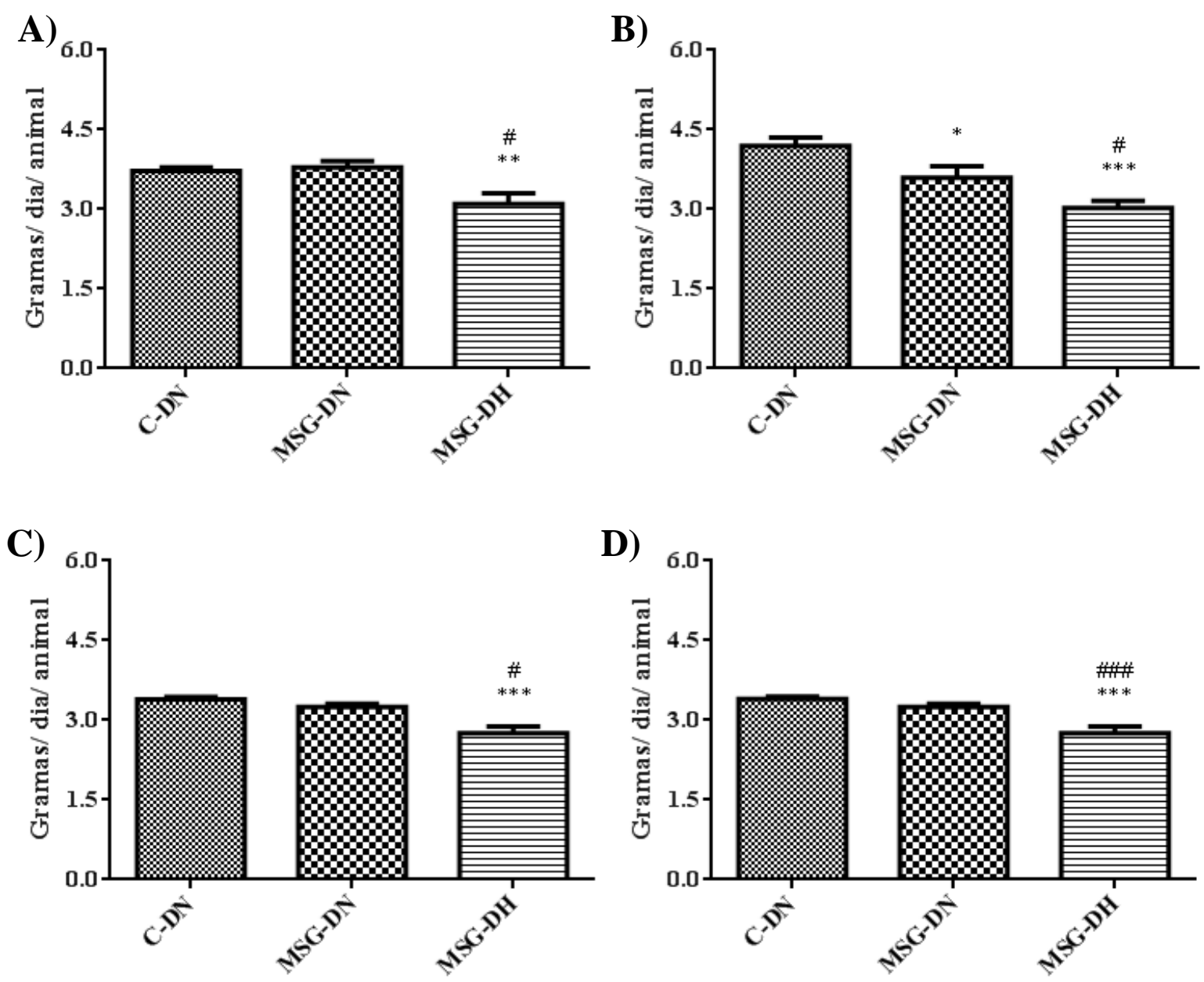

Figura 9 - Consumo diário de ração dos camundongos controle (C-DN) e obesos alimentados com dieta normolipídica (MSG-DN) ou hiperlipídica (MSG-DH) durante 4 (A), 8 (B), 12 (C) e 16 (D) semanas. Valores são médias \pm EPM, ANOVA de uma via seguida de Student-Newman-Keuls; $\mathrm{n}=5$ a 9 animais. ${ }^{*} P<0,05,{ }^{* *} P<0,01 \mathrm{e}^{* * * *} P<0,001$ vs C-DN; ${ }^{\#} P<0,05$ e ${ }^{\# \# \#} P<0,001$ vs MSG-DN. 
A Figura 10 mostra a ingestão alimentar em calorias. Observa-se que a menor ingestão de ração (em gramas) pelo grupo MSG-DN na oitava semana refletiu-se em menor ingestão calórica. A partir de 12 semanas, o grupo MSG-DH passa a ingerir maior quantidade de calorias, o que se exacerba em 16 semanas.
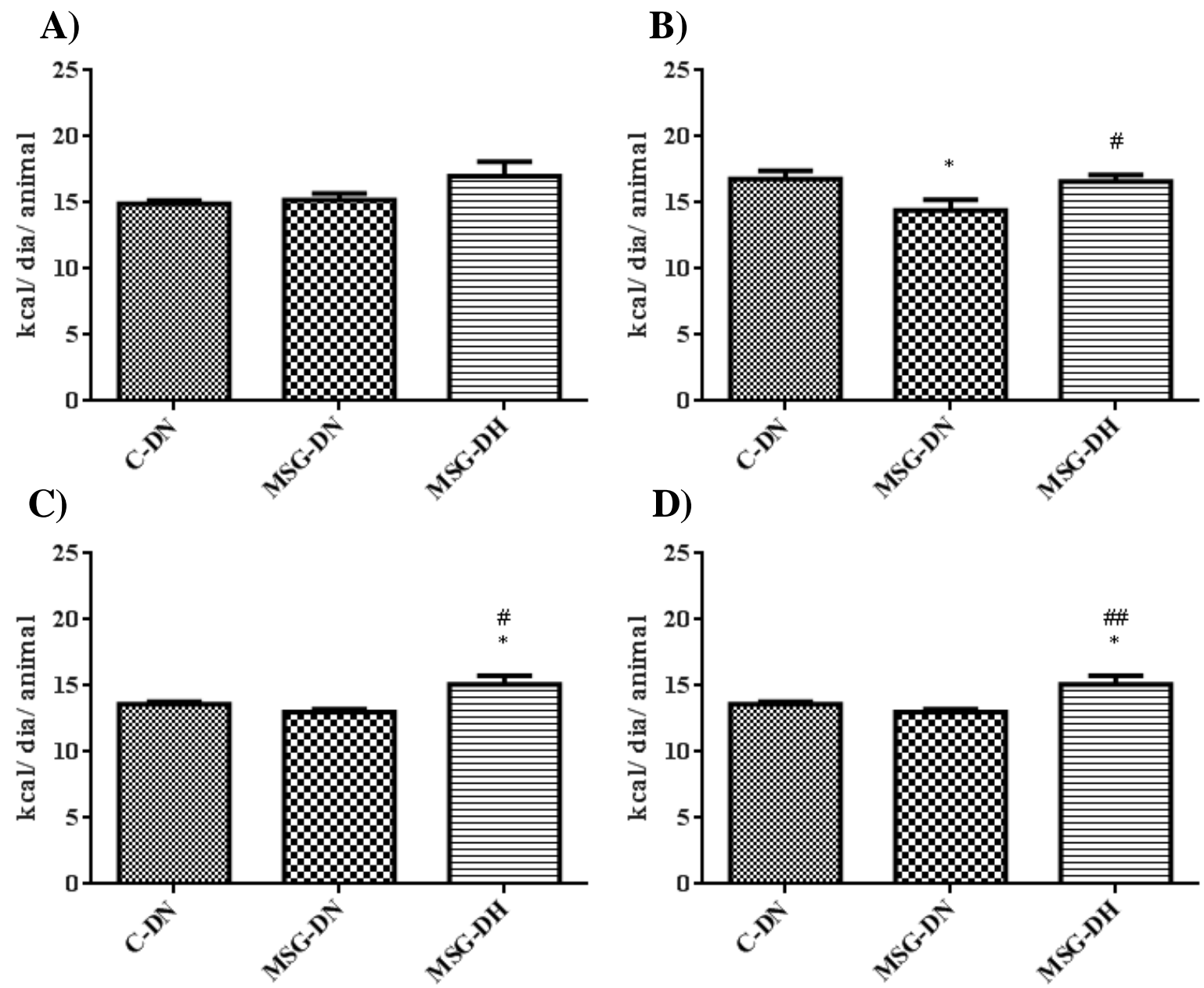

Figura 10 - Ingestão alimentar em calorias dos camundongos controle (C-DN) e obesos alimentados com dieta normolipídica (MSG-DN) ou hiperlipídica (MSG-DH), durante 4 (A), 8 (B), 12 (C) e 16 (D) semanas. Valores são médias \pm EPM, ANOVA de uma via seguida de Student-Newman-Keuls; n= 5 a 9 animais. ${ }^{*} P<0,05$ vs $C-D N ;{ }^{\#} P<0,05$ e ${ }^{\# \#} P<0,01$ vs MSG-DN. 


\subsection{Avaliação da obesidade}

A Tabela 3 mostra que o índice de Lee e o peso total do tecido adiposo perigonadal é significantemente maior $(P<0,001)$ nos animais MSG, quando comparados aos C-DN, desde a quarta semana. Além disso, após 16 semanas de tratamento, os animais MSG-DH apresentaram elevação em ambos os parâmetros $(P<0,01)$ quando comparados aos animais do grupo MSG-DN.

Tabela 3 - Avaliação morfométrica da obesidade.

\begin{tabular}{|c|c|c|c|c|}
\hline Períodos & Parâmetro & C-DN & MSG-DN & MSG-DH \\
\hline \multirow{2}{*}{4 semanas } & Índice de Lee $\left(\mathrm{g} / \mathrm{cm}^{3}\right)$ & $\begin{array}{c}31,00 \pm 0,20 \\
n=11\end{array}$ & $\begin{array}{c}34,70 \pm 0,60^{* * *} \\
n=6\end{array}$ & $\begin{array}{c}36,00 \pm 0,80^{* * *} \\
\mathrm{n}=7\end{array}$ \\
\hline & $\begin{array}{l}\text { Peso do adiposo } \\
\text { [perigonadal (g)] }\end{array}$ & $\begin{array}{c}0,69 \pm 0,07 \\
n=7\end{array}$ & $\begin{array}{c}1,79 \pm 0,31^{* *} \\
\mathrm{n}=9\end{array}$ & $\begin{array}{c}2,73 \pm 0,19^{* * * \# \#} \\
\mathrm{n}=5\end{array}$ \\
\hline \multirow{2}{*}{8 semanas } & Índice de Lee $\left(\mathrm{g} / \mathrm{cm}^{3}\right)$ & $\begin{array}{c}31,60+0,30 \\
n=12\end{array}$ & $\begin{array}{c}35,80 \pm 0,64^{* * *} \\
n=12\end{array}$ & $\begin{array}{c}37,40 \pm 0,68^{* * * \#} \\
\mathrm{n}=10\end{array}$ \\
\hline & $\begin{array}{l}\text { Peso do adiposo } \\
\text { [perigonadal }(\mathrm{g})]\end{array}$ & $\begin{array}{c}0,67 \pm 0,09 \\
n=7\end{array}$ & $\begin{array}{c}1,64 \pm 0,07^{* * *} \\
n=6\end{array}$ & $\begin{array}{c}2,00 \pm 0,12^{* * * \#} \\
\mathrm{n}=7\end{array}$ \\
\hline \multirow{2}{*}{12 semanas } & Índice de Lee $\left(\mathrm{g} / \mathrm{cm}^{3}\right)$ & $\begin{array}{c}29,70 \pm 2,10 \\
n=10\end{array}$ & $\begin{array}{c}37,10 \pm 0,60^{* * *} \\
n=14\end{array}$ & $\begin{array}{c}37,00 \pm 0,67^{* * *} \\
\mathrm{n}=15\end{array}$ \\
\hline & $\begin{array}{l}\text { Peso do adiposo } \\
\text { [perigonadal }(\mathrm{g})]\end{array}$ & $\begin{array}{c}1,05 \pm 0,11 \\
\mathrm{n}=9\end{array}$ & $\begin{array}{c}2,27 \pm 0,04^{* * *} \\
n=10\end{array}$ & $\begin{array}{c}2,70 \pm 0,28^{* * *} \\
n=12\end{array}$ \\
\hline \multirow{2}{*}{16 semanas } & Índice de Lee $\left(\mathrm{g} / \mathrm{cm}^{3}\right)$ & $\begin{array}{c}32,80 \pm 0,29 \\
n=4\end{array}$ & $\begin{array}{c}36,50 \pm 0,64^{* * *} \\
n=5\end{array}$ & $\begin{array}{c}39,00 \pm 0,49^{\text {***\#\# }} \\
\mathrm{n}=8\end{array}$ \\
\hline & $\begin{array}{l}\text { Peso do adiposo } \\
\text { [perigonadal (g)] }\end{array}$ & $\begin{array}{c}1,49 \pm 0,09 \\
n=10\end{array}$ & $\begin{array}{c}2,09 \pm 0,11^{* * *} \\
\mathrm{n}=12\end{array}$ & $\begin{array}{c}2,70 \pm 0,15^{* * * \# \#} \\
\mathrm{n}=7\end{array}$ \\
\hline
\end{tabular}

Camundongos controle alimentados com dieta normolipídica (C-DN) e obesos alimentados com dieta normolipídica (MSG-DN) ou dieta hiperlipídica (MSG-DH) foram avaliados após os períodos de tratamento indicados. Valores são médias \pm EPM, ANOVA de uma via seguida de Student-NewmanKeuls. ${ }^{* *} P<0,01$ e ${ }^{* * * *} P<0,001$ vs C-DN; ${ }^{\#} P<0,05$ e ${ }^{\# \#} P<0,01$ vs MSG-DN. 


\subsection{Análises bioquímicas}

\subsubsection{Trigliceridemia}

A Figura 11 demonstra a concentração sanguínea de triglicerídeos em amostra colhida após privação alimentar de quatro horas, entre 11 e 13 horas do dia. É possível notar que nem o tratamento com MSG, nem a dieta hiperlipídica alteraram este parâmetro.

A)

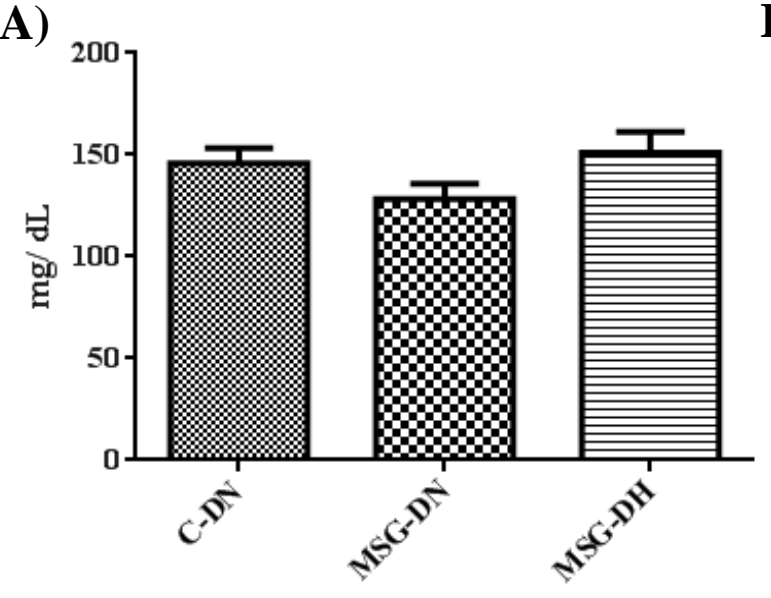

C)

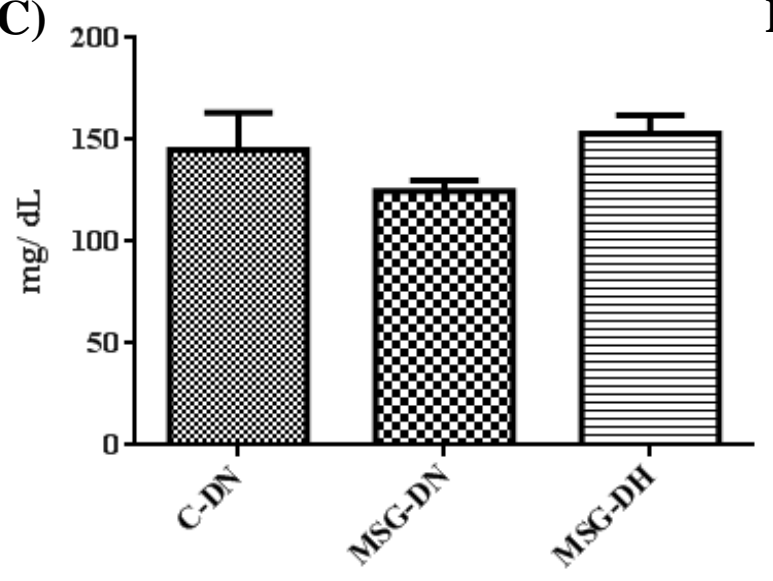

B)

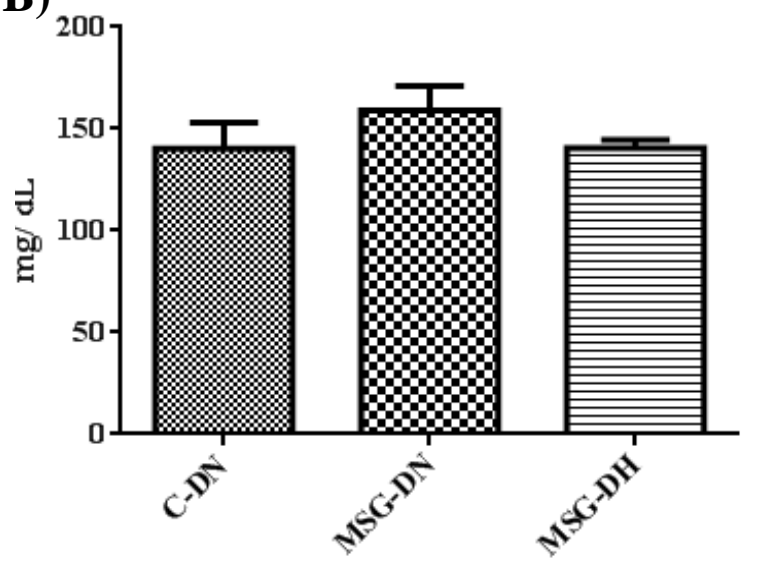

D)

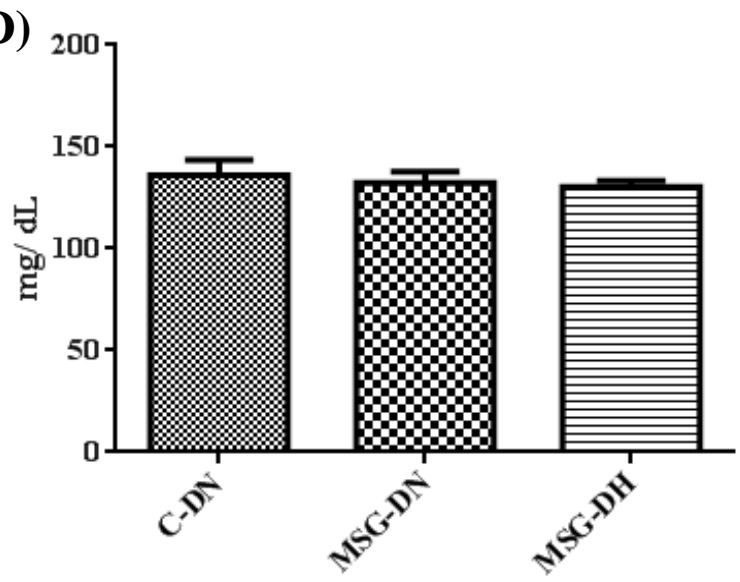

Figura 11 - Triglicerídeos sanguíneos em camundongos controle e obesos alimentados com dieta normolipídica (C-DN) ou hiperlipídica (MSG-DH), durante 4 (A), 8 (B), 12 (C) e 16 (D) semanas. Valores são médias \pm EPM, ANOVA de uma via seguida de Student-Newman-Keuls; n= 4 a 14 animais. 


\subsubsection{Glicemia}

A Figura 12 mostra a glicemia em amostra sanguínea colhida após privação alimentar de quatro horas, entre 11 e 13 horas do dia da eutanásia. Após 12 e 16 semanas, o grupo MSG-DH apresentou maior concentração de glicose sanguínea quando comparado aos demais grupos $(P<0,05$ a $P<0,01$ conforme o grupo e o período).
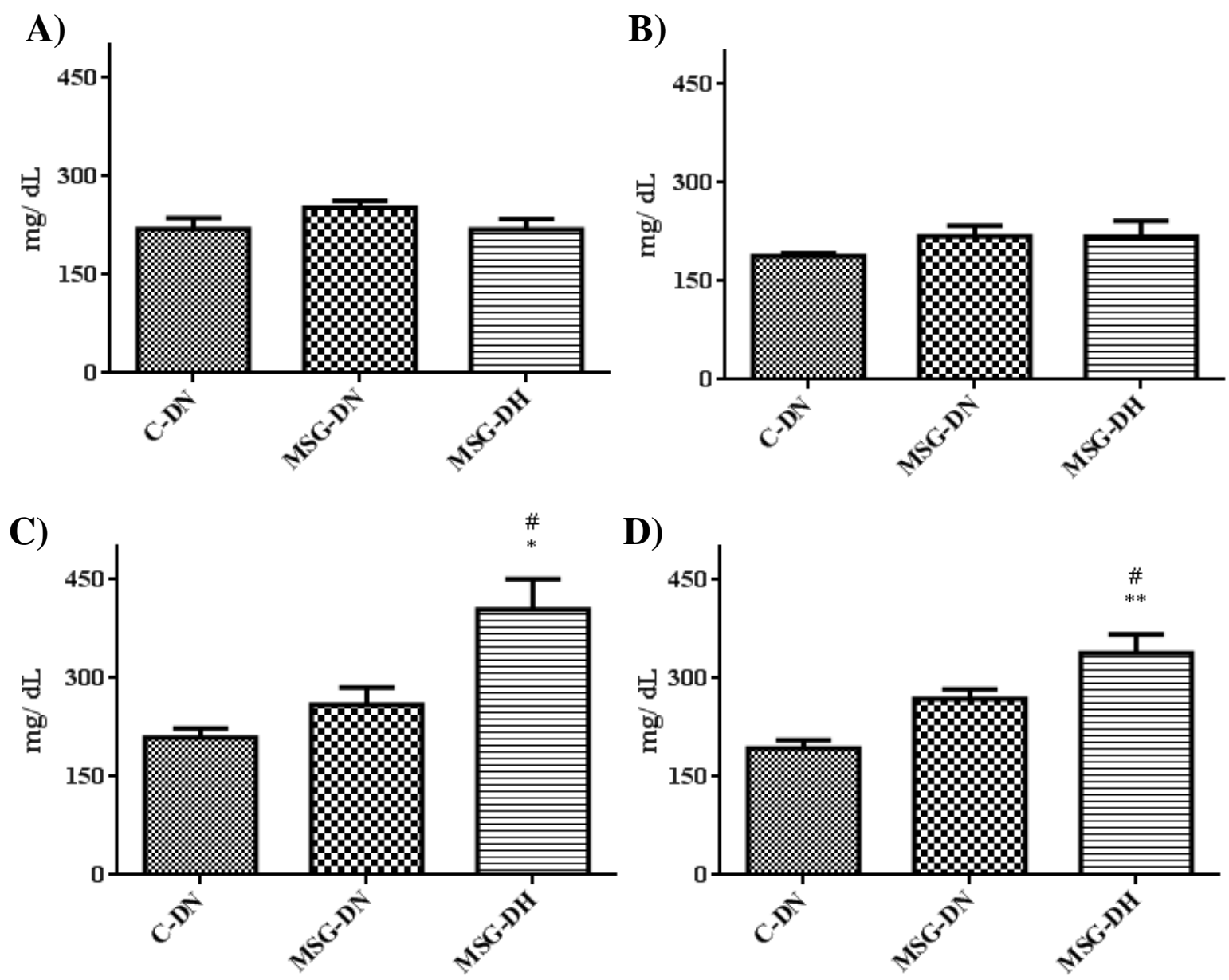

Figura 12 - Glicemia de camundongos controle (C-DN) e obesos alimentados com dieta normolipídica (MSG-DN) ou hiperlipídica (MSG-DH), durante 4 (A), 8 (B), 12 (C) e 16 (D) semanas. Valores são médias \pm EPM, ANOVA de uma via seguida de Student-Newman-Keuls; $\mathrm{n}=4$ a 15 animais. ${ }^{*} P<0,05$ e ${ }^{* *} P<0,01$ vs $C-D N$; ${ }^{\#} P<0,05$ vs MSG-DN. 


\subsubsection{Colesterol plasmático total}

A Figura 13 demonstra os níveis plasmáticos de colesterol total, em amostras coletadas entre 11 e 13 horas do dia, após privação alimentar de quatro horas. Nota-se que a partir da quarta semana de tratamento os animais MSG-DH apresentaram níveis elevados de colesterol, o que foi se exacerbando com o tempo. Curiosamente, os animais MSG-DN mostraram um aumento transitório deste parâmetro (apenas em 4 semanas), quando comparados aos animais C-DN $(P<0,05)$.
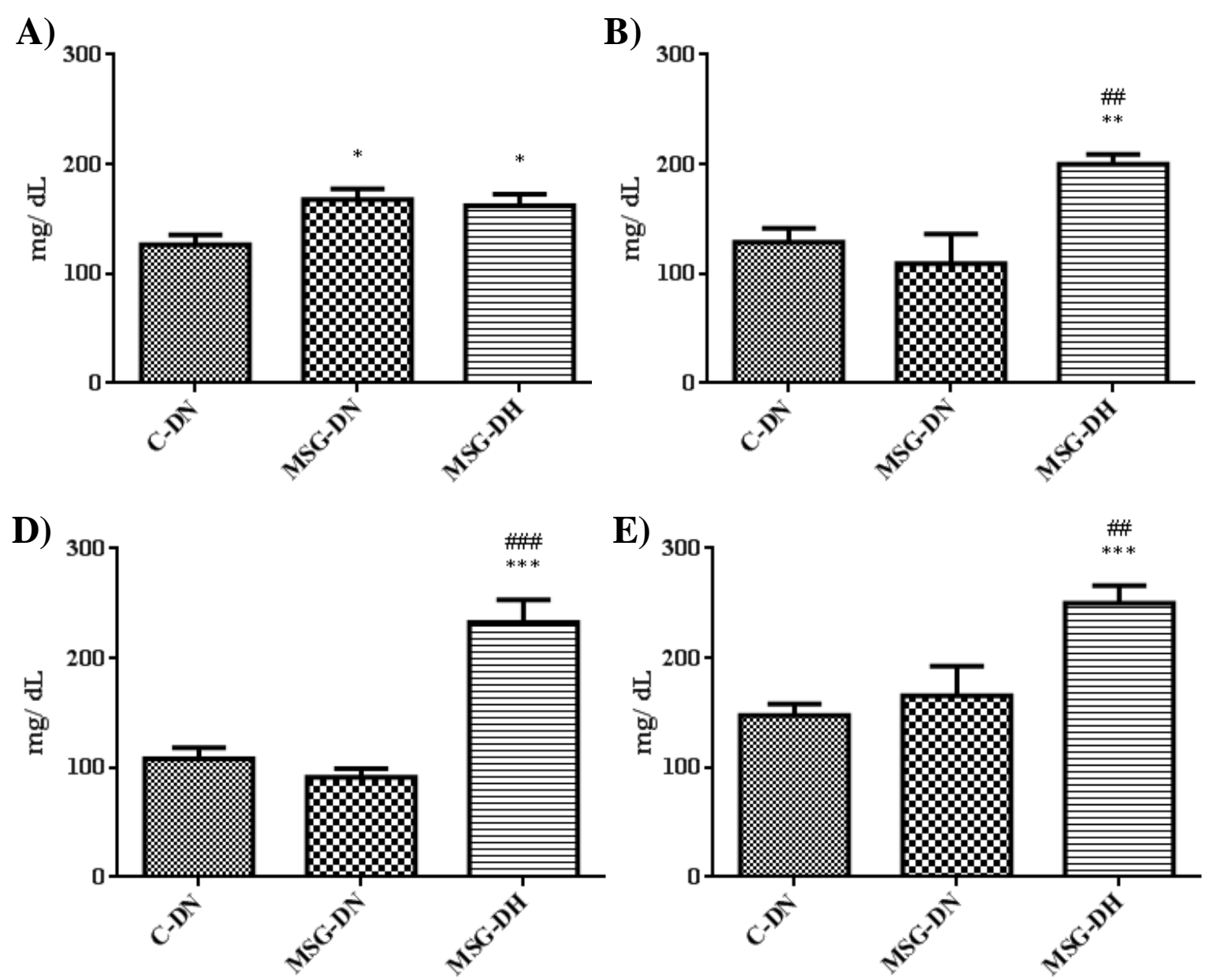

Figura 13 - Colesterol plasmático total de camundongos controle (C-DN) e obesos alimentados com dieta normolipídica (MSG-DN) ou hiperlipídica (MSG-DH), durante 4 (A), 8 (B), 12 (C) e 16 (D) semanas. Valores são médias \pm EPM, ANOVA de uma via seguida de teste Student-Newman-Keuls; n= 4 a 8 animais. ${ }^{*} P<0,05,{ }^{* *} P<0,01$ e ${ }^{* * * *} P<0,001$ vs C-DN; ${ }^{\# \#} P<0,01$ e ${ }^{\# \# \#} P<0,001$ vs MSG-DN. 


\subsubsection{Insulina plasmática}

Na Figura 14 estão os dados de insulina em amostras plasmáticas coletadas entre 11 e 13 horas do dia, após privação alimentar de quatro horas, em animais tratados por 4 e 16 semanas. Pode-se notar que no período mais curto de tratamento (4 semanas), não houve alteração significante nos níveis insulinêmicos entre os animais dos diferentes grupos avaliados. Contrariamente, em 16 semanas, a insulina plasmática se mostrou elevada nos animais obesos, independentemente da dieta consumida $(P<0,05)$, quando comparados aos animais do grupo C-DN.
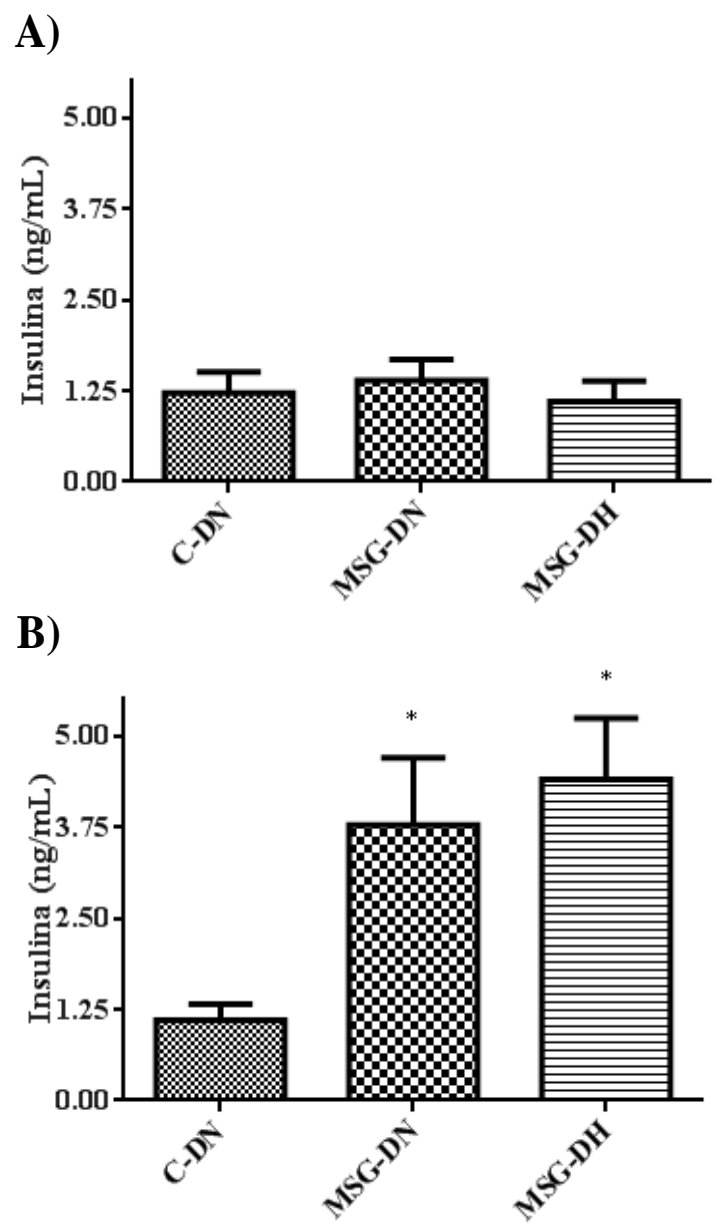

Figura 14 - Insulina plasmática de camundongos controle (C-DN) e obesos alimentados com dieta normolipídica (MSG-DN) ou hiperlipídica (MSG-DH), durante 4 (A) e 16 (B) semanas. Valores são médias \pm EPM, ANOVA de uma via seguida de Student-Newman-Keuls; $\mathrm{n}=3$ a 8 animais. ${ }^{*} P<0,05$ vs C-DN. 


\subsection{Teste de tolerância à insulina intraperitoneal(ITT)}

A constante de decaimento da glicose (kITT), obtida no ITT, é mostrada na Figura 15. Para esse experimento, os animais também foram submetidos a quatro horas de privação alimentar. Observa-se que, a partir de 8 semanas, os animais MSG, independentemente da dieta consumida, apresentaram kITT menor que o observado em C-DN $(P<0,01$ a $P<0,001$, conforme o grupo e o período), indicando a presença da resistência à insulina. Diferentemente, após 4 semanas de tratamento, o kITT foi maior em animais MSG-DN $(P<0,05$ vs C-DN), indicando um estado transitório de maior sensibilidade à insulina, o que não foi observado nos animais MSG-DH ( $P<0,05$ vs MSG-DN).

A)

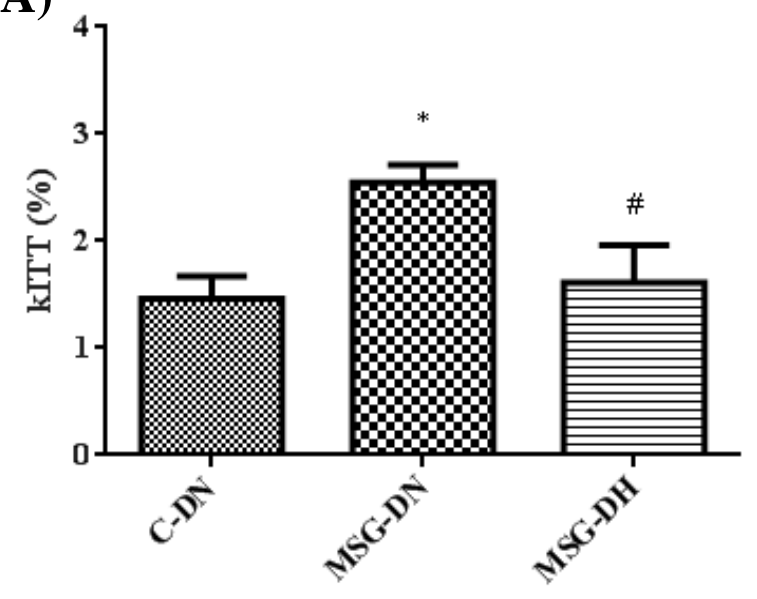

D)

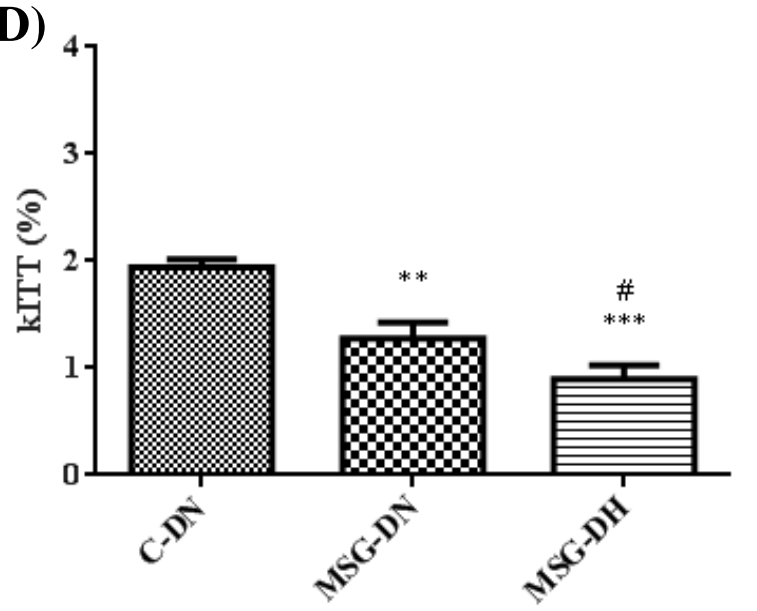

B)

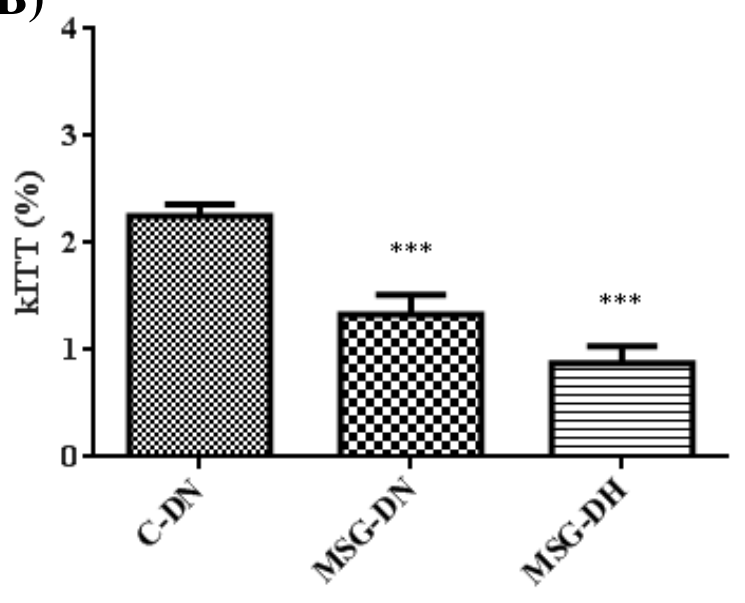

E)

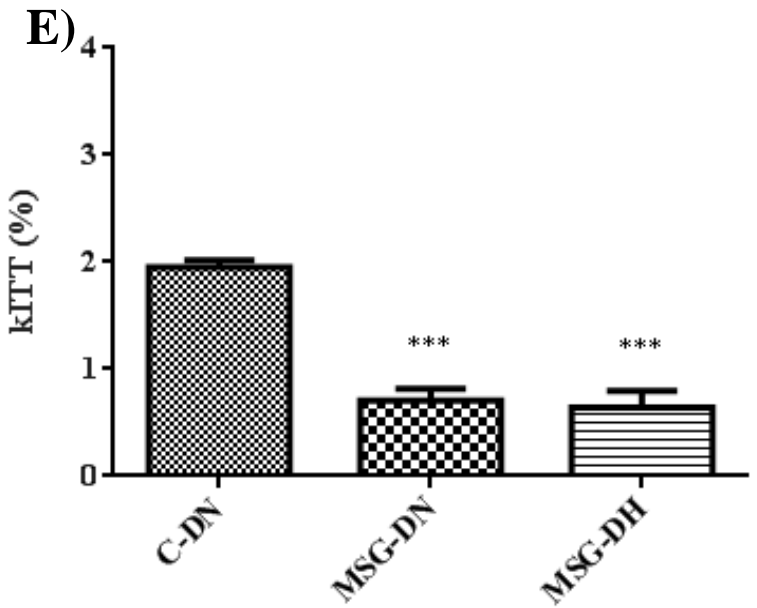

Figura 15 - Constante de decaimento da glicose (kITT) obtida a partir de teste de tolerância à insulina intraperitoneal em animais controles (C-DN) e obesos alimentados com dieta normolipídica (MSGDN) ou hiperlipídica (MSG-DH), durante os períodos de 4 (A), 8 (B), 12 (C) e 16 (D) semanas de tratamento. Valores são médias \pm EPM, ANOVA de uma via seguida de Student-Newman-Keuls; $\mathrm{n}=$ 4 a 9 animais. ${ }^{*} P<0,05,{ }^{* *} P<0,01 \mathrm{e}^{* * *} P<0,001$ vs C-DN; ${ }^{\#} P<0,05$ vs MSG-DN. 


\subsection{Conteúdo de GLUT4 em tecido adiposo perigonadal}

O conteúdo de GLUT4, em tecido adiposo perigonadal, é mostrado na Figura 16. Nota-se que, a partir de 8 semanas de tratamento, a quantidade de GLUT4 foi fortemente reduzida $(P<0,001)$ nos animais MSG, independentemente da dieta consumida. Contrariamente, na quarta semana, animais MSG-DN apresentaram aumento de 20\% $(P<0,01)$ na quantidade de GLUT4, quando comparados a animais C-DN. Entretanto, neste período, a ingestão de dieta hiperlipídica já havia reduzido o conteúdo de GLUT4 $(P<0,001$ vs C-DN e MSG-DN).
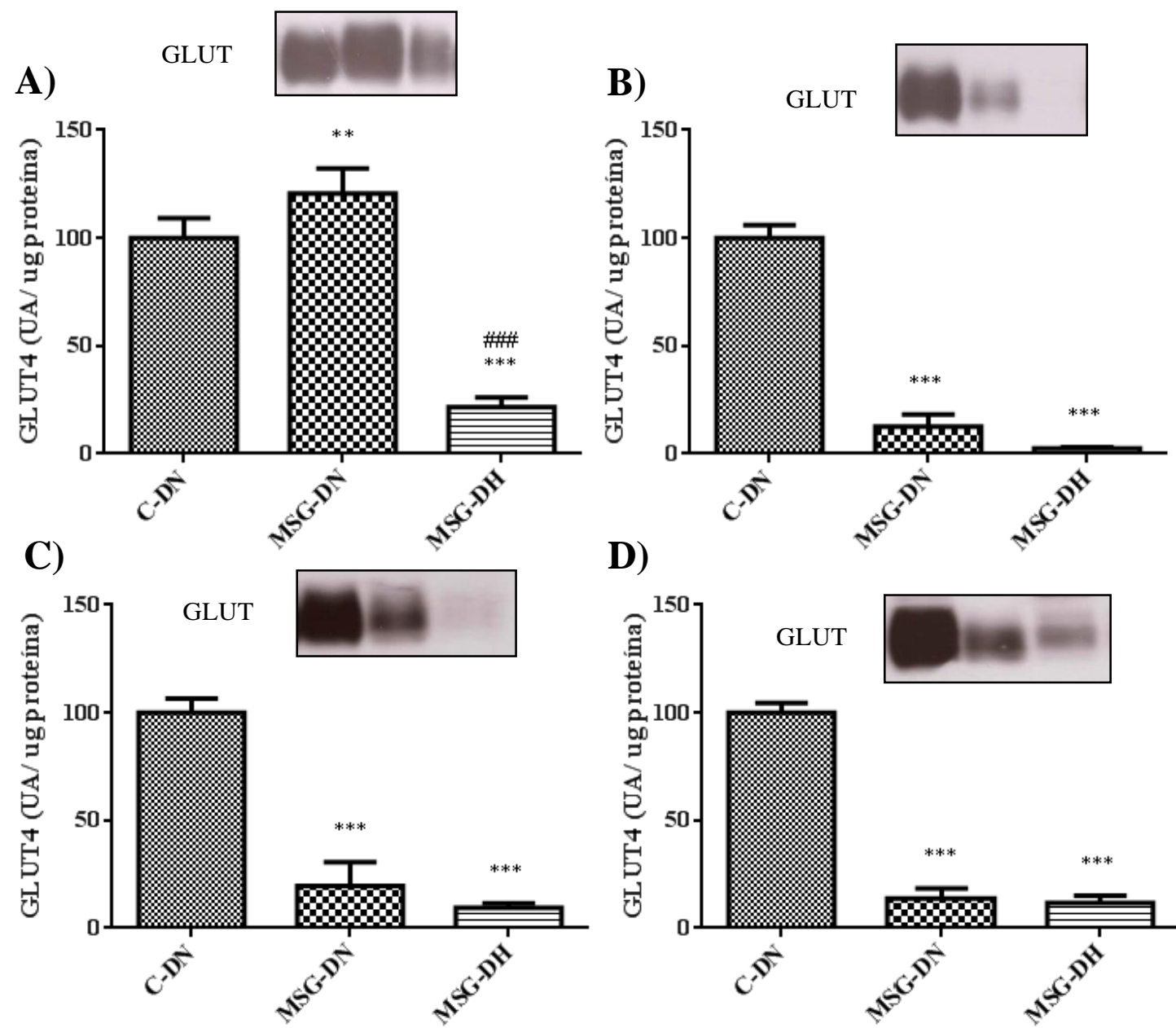

D)

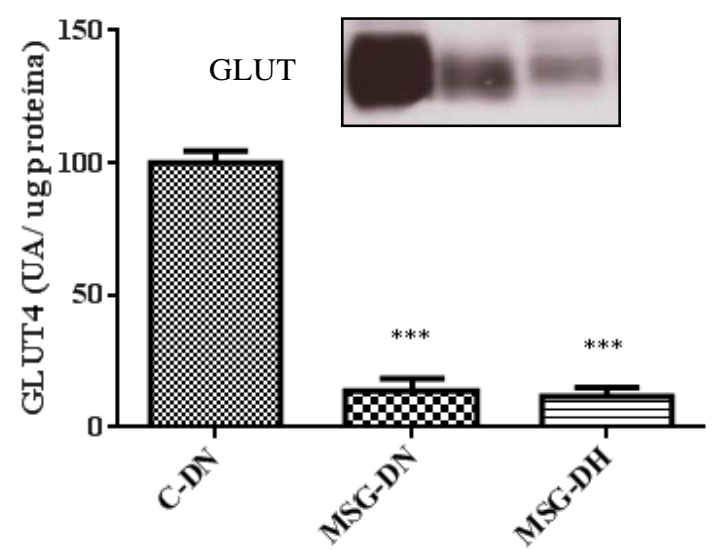

Figura 16 - Conteúdo de GLUT4 em tecido adiposo perigonadal de animais controles (C-DN) e obesos alimentados com dieta normolipídica (MSG-DN) ou hiperlipídica (MSG-DH), durante os períodos de 4 (A), 8 (B), 12 (C) e 16 (D) semanas de tratamento. Valores são médias \pm EPM, ANOVA de uma via seguida de Student-Newman-Keuls; $\mathrm{n}=4$ a 6 animais. ${ }^{* *} P<0,01$ e ${ }^{* * * *} P<0,001$ vs C-DN; ${ }^{\# \# \#} P<0,001$ vs MSG-DN. 


\subsection{Expressão de mRNA em tecido adiposo perigonadal}

\subsection{1 mRNA Tnfa}

Na Figura 17 estão ilustrados os resultados de expressão do mRNA Tnfa. Animais MSG-DH apresentaram expressão significantemente aumentada desde 4 semanas, quando comparados aos animais dos grupos C-DN $(P<0,001)$. Já nos períodos mais tardios $(12$ e 16 semanas), este aumento também ocorreu nos animais MSG-DN, quando comparados aos CDN ( $P<0,01$ e $P<0,001$ conforme o grupo e o período).

A)

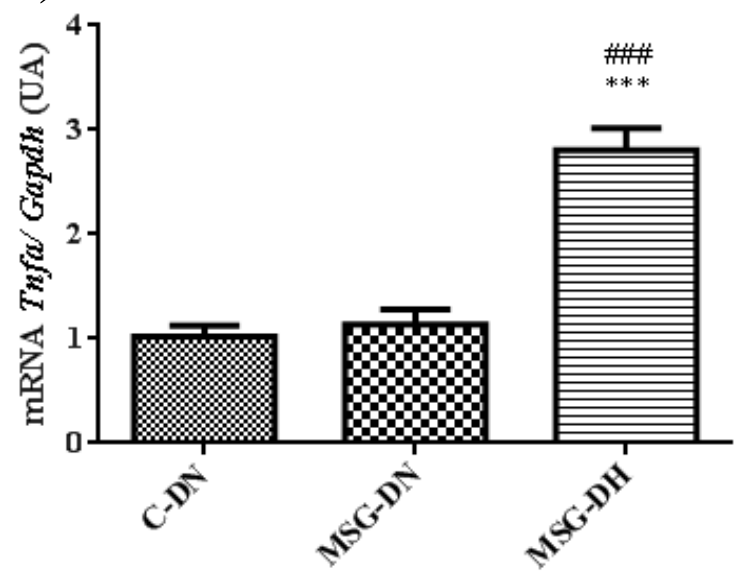

C)

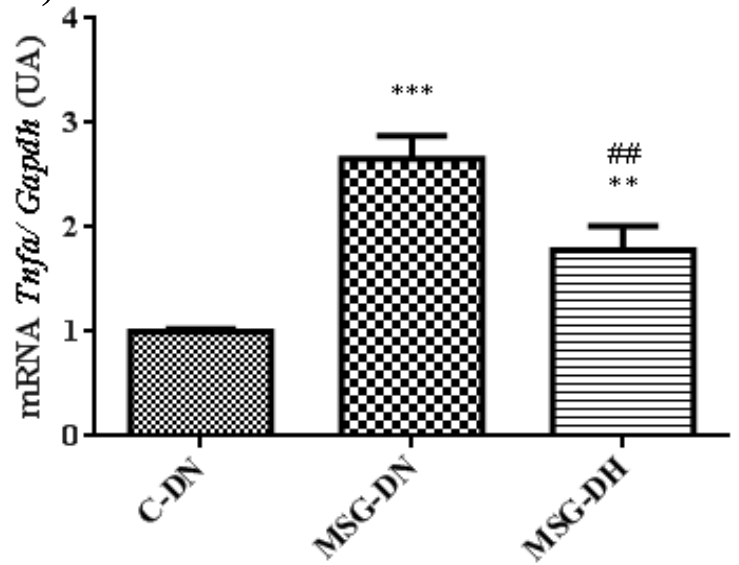

B)

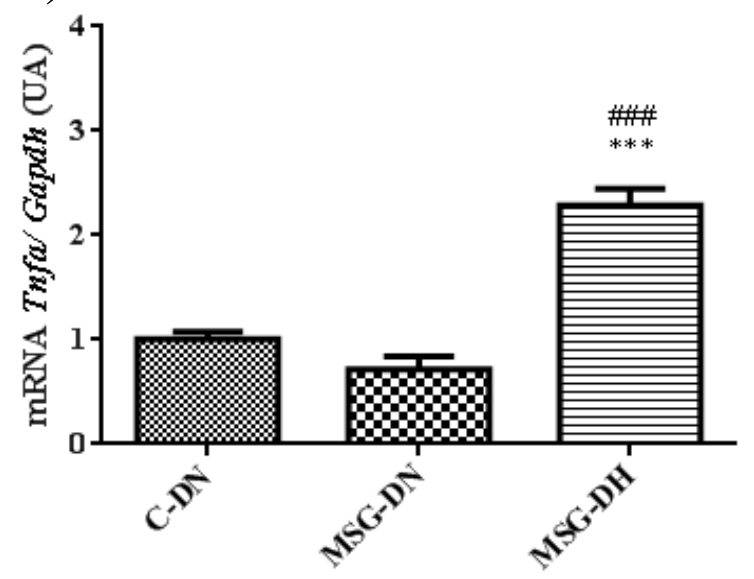

D)

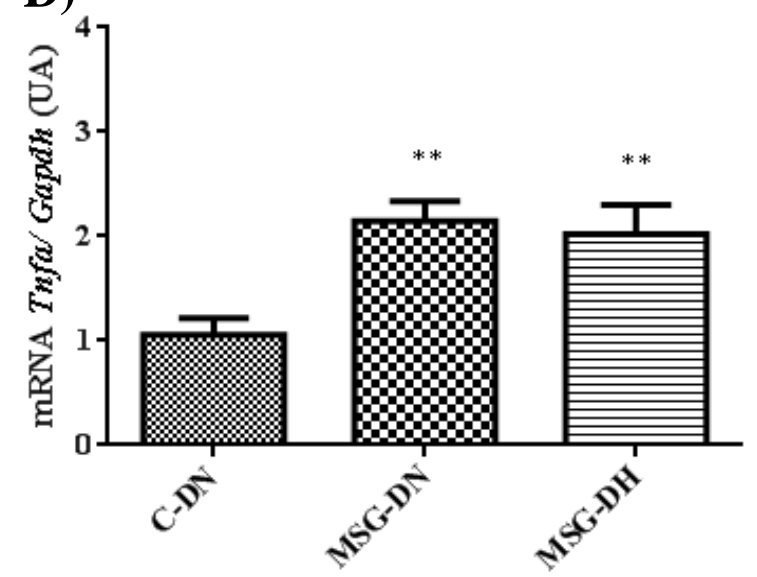

Figura 17 - mRNA Tnfa em tecido adiposo perigonadal de animais controles (C-DN) e obesos alimentados com dieta normolipídica (MSG-DN) ou hiperlipídica (MSG-DH), durante os períodos de 4 (A), 8 (B), 12 (C) e 16 (D) semanas de tratamento. Valores são médias \pm EPM, ANOVA de uma via seguida de Student-Newman-Keuls; $\mathrm{n}=3$ a 7 animais. ${ }^{* *} P<0,01$ e ${ }^{* * *} P<0,001$ vs C-DN; ${ }^{\# \#} P<0,01 \quad$ e

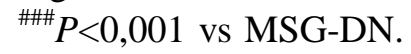




\subsection{2 mRNA Rela}

A figura abaixo ilustra a expressão do mRNA Rela ao longo do estudo. Nota-se que, em 4 e 8 semanas $(P<0,05$ e $P<0,01$, respectivamente), a expressão deste gene está significantemente aumentada no grupo MSG-DH, quando comparado ao grupo C-DN e ao grupo MSG-DN. No entanto, em 12 e 16 semanas, esta expressão apresentou-se reduzida tanto em MSG-DN quanto em MSH-DH, quando comparados ao grupo C-DN $(P<0,001$ e $P<0,05$, respectivamente).

A)

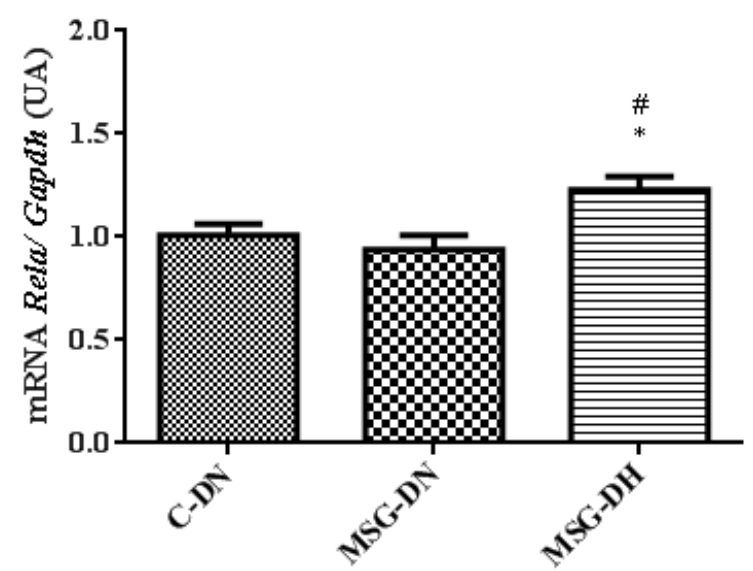

C)

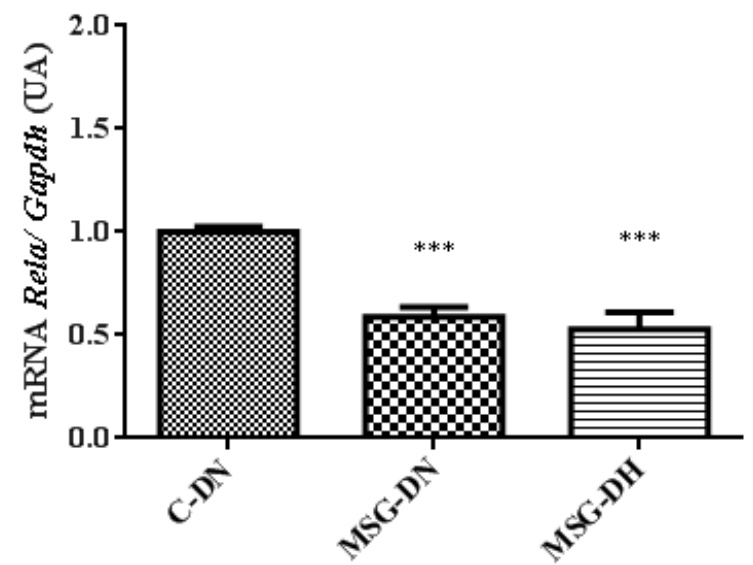

B)

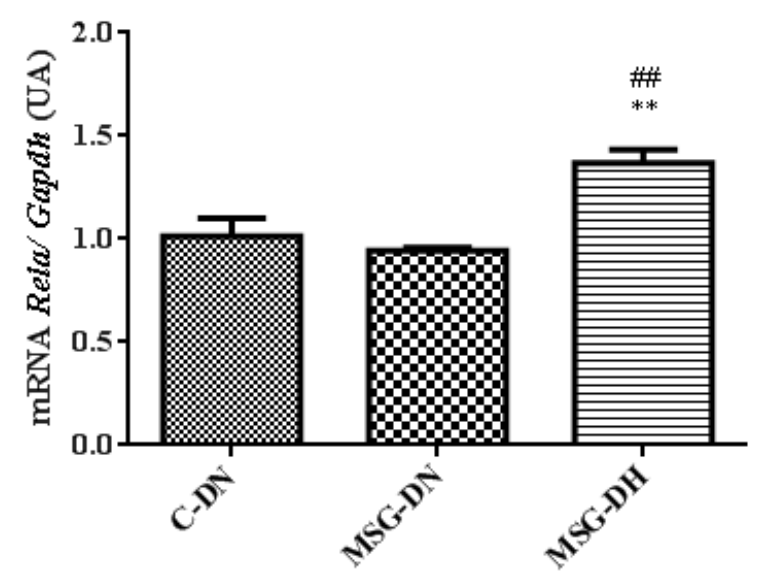

D)

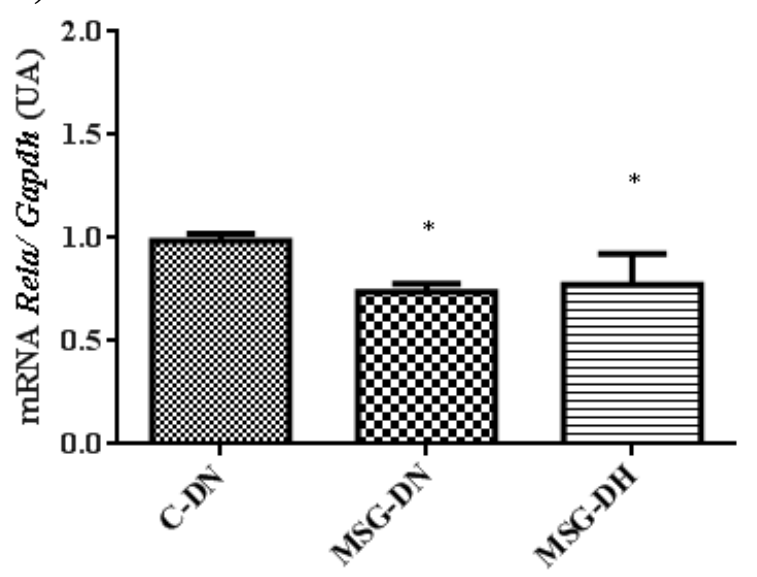

Figura 18 - mRNA Rela em tecido adiposo perigonadal de animais controles (C-DN) e obesos alimentados com dieta normolipídica (MSG-DN) ou hiperlipídica (MSG-DH), durante os períodos de 4 (A), 8 (B), 12 (C) e 16 (D) semanas de tratamento. Valores são médias \pm EPM, ANOVA de uma via seguida de Student-Newman-Keuls; $\mathrm{n}=4$ a 9 animais. ${ }^{*} P<0,05,{ }^{* * *} P<0,01$ e ${ }^{* * * *} P<0,001$ vs C-DN; ${ }^{\#} P<0,05$ e ${ }^{\# \#} P<0,01$ vs MSG-DN. 


\subsection{3 mRNA Slc2a4}

A Figura 19 apresenta os valores de expressão do mRNA Slc2a4 ao longo do estudo. Em 4 semanas, animais MSG-DH já apresentaram redução na expressão deste gene, quando comparados aos MSG-DN $(P<0,01)$. Além disso, a partir da oitava semana de tratamento, tanto o grupo MSG-DN quanto o MSG-DH apresentaram redução significante deste mRNA, quando comparados aos animais do grupo C-DN $(P<0,001)$.
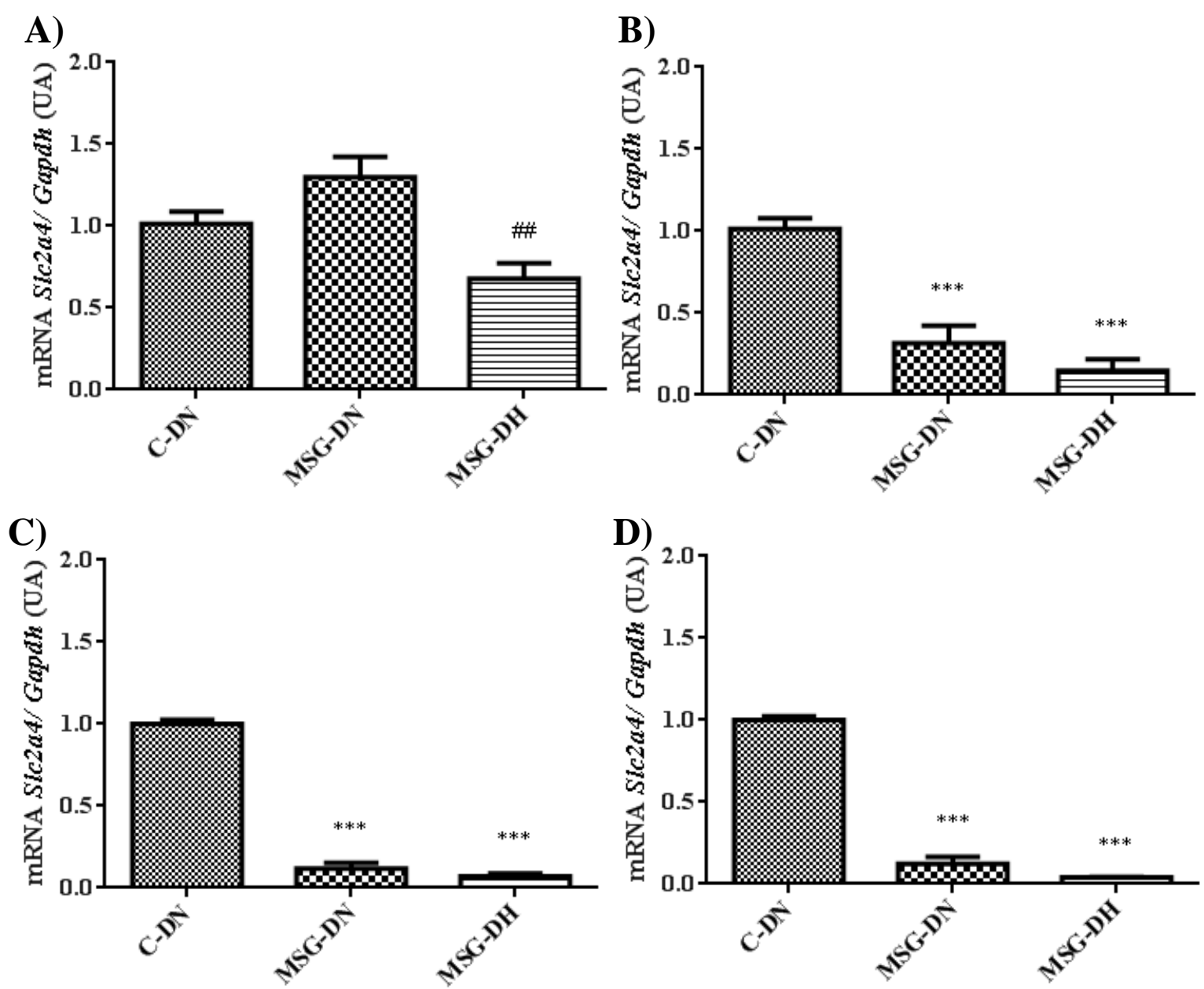

Figura 19 - mRNA Slc2a4 em tecido adiposo perigonadal de animais controles (C-DN) e obesos alimentados com dieta normolipídica (MSG-DN) ou hiperlipídica (MSG-DH), durante os períodos de 4 (A), 8 (B), 12 (C) e 16 (D) semanas de tratamento. Valores são médias \pm EPM, ANOVA de uma via seguida de Student-Newman-Keuls; $\mathrm{n}=3$ a 8 animais. ${ }^{* * *} P<0,001$ vs C-DN; ${ }^{\# \#} P<0,01$ vs MSG-DN. 


\section{DISCUSSÃO}

A administração de altas doses de MSG, no período neonatal, causa lesão ao sistema nervoso central, incluindo núcleo arqueado e parte do núcleo ventro-medial, o que desencadeia diversas alterações que contribuem para o desenvolvimento da obesidade (KIZER; NEMEROFF; YOUNGBLOOD, 1978; NAGATA et al., 2006). Os principais fatores resultantes da ação do MSG, responsáveis pelo desenvolvimento da obesidade em animais, são: a) deficiência no hormônio de crescimento (GH)- o que caracteriza o menor crescimento desses animais e maior acúmulo de gordura (KOVACS et al., 2000; MAITER et al., 1991; NEMEROFF et al., 1977); b) redução na atividade termogênica em tecido adiposo marrom (YOSHIOKA; YOSHIDA; KONDO, 1991) e c) hipercorticosteronemia (HIMMS-HAGEN, 1989; MAGARIÑOS et al., 1988). Esses fatores em conjunto otimizam o desenvolvimento da obesidade, mesmo não havendo aumento na ingestão calórica.

Conforme esperado, os animais MSG apresentaram menor peso corporal inicial (logo após desmame), o que se modificou com o passar do tempo (APÊNDICE A). Ao final de cada período de tratamento o peso dos animais MSG foi cada vez maior, e isso foi exacerbado pela adição da dieta hiperlipídica. Considerando a ingestão alimentar em gramas de animais MSG, alguns autores os classificam como obesos hipofágicos (MORRIS et al., 1998; OLNEY, 1969). Porém, se avaliarmos a ingestão alimentar dos animais MSG-DN (ainda em gramas), relativamente ao peso corporal, nenhuma alteração ocorreu em comparação aos animais C-DN, o que permite classificar esta obesidade como normofágica (APÊNDICE B), passando a hipofágica após 16 semanas. Isso explica porque este modelo experimental tem sido classificado tanto hipofágico como normofágico. Ainda, os animais MSG alimentados com DH, apresentaram redução na ingestão alimentar (em gramas) devido à alta densidade calórica da dieta; porém, a partir de 8 semanas, o consumo diário em calorias passou a ser maior nesses animais (MSG-DH), conforme já descrito (BELL et al., 1997; HERBERG et al., 1974).

A obesidade nem sempre se evidencia por aumento absoluto no peso corporal, e, por isso, medidas de adiposidade devem ser utilizadas como critérios de identificação. Rogers e Webb (1980) correlacionaram vários parâmetros (índice de Lee, densidade, conteúdo de água corporal e peso relativo do tecido adiposo gonadal) com a porcentagem da massa gordurosa corporal e verificaram que, em uma população de camundongos normais e obesos (machos e fêmeas), todos os quatro parâmetros citados acima se correlacionaram significantemente com a massa gordurosa. No presente estudo, a obesidade dos animais MSG foi detectada desde 4 
semanas pós-desmame, tanto pelo índice de Lee como pelo peso da gordura epididimal. A obesidade foi se exacerbando com o passar do tempo, e a ingestão de dieta hiperlipídica acelerou esta evolução. É comum fazerem análise de peso da gordura relativo ao peso corporal, quando não se observa alteração no peso absoluto, o que não foi o caso no presente estudo.

O teste de tolerância à insulina mostrou, a partir de 8 semanas, uma progressiva perda na capacidade dos animais clarearem a glicose sanguínea em resposta a insulina, independentemente da dieta. Após 16 semanas essa importante resistência à insulina acompanhou-se de hiperinsulinemia, o que tem sido frequentemente descrito em camundongos MSG de longa evolução (MACHADO; SHIMIZU; SAITO, 1993; PAPA; SERAPHIM; MACHADO, 1997). O agravamento da resistência à insulina leva à perda de controle glicêmico (MACHADO; SHIMIZU; SAITO, 1993; PAPA; SERAPHIM; MACHADO, 1997), permitindo, inclusive, o diagnóstico de DM2, uma vez que as glicemias podem chegar a valores claramente acima de $250 \mathrm{mg} / \mathrm{dL}$. No presente estudo, a dieta hiperlipídica exacerbou o descontrole glicêmico dos animais MSG. Entretanto, não ficou claro qual o fator, dentre os avaliados, contribuiu para esse efeito da dieta ao final do tratamento, embora em etapas anteriores, tanto a obesidade como a resistência insulínica foram maiores nos animais MSG alimentados com DH.

Diferentemente, na avaliação mais precoce (4 semanas de dieta, 7 semanas de vida), os animais MSG-DN mostraram maior sensibilidade à insulina (maior kITT), sem alteração na insuilinemia ou na glicemia. Nessa etapa, a obesidade estava em franca evolução, para o que esse quadro metabólico pode desempenhar um importante papel. Aumento de sensibilidade insulínica em períodos iniciais do desenvolvimento da obesidade MSG em camundongos já foi descrito na literatura (PAPA et al., 2002). Por outro lado, a ingestão de dieta hiperlipídica por 4 semanas exacerbou o desenvolvimento da obesidade, e, talvez por isso, impediu o aumento da sensibilidade à insulina observado nos animais MSG-DN. Na literatura há evidências de que o aumento de adipócitos jovens, característico de períodos iniciais da obesidade, pode estar relacionado à melhor sensibilidade insulínica (QUEIROZ et al., 2009), explicando os resultados observados em animais MSG-DN de 4 semanas. De fato, a sensibilidade à insulina da célula adiposa diminui conforme esta aumenta de tamanho (CRAIG; GARTHWAITE; HOLLOSZY, 1987; SALANS; DOUGHERTY, 1971; SALANS; KNITTLE; HIRSCH, 1968), sendo a hipertrofia do adipócito uma característica da evolução da obesidade (CINTI et al., 2005; MACHADO; SAITO, 1995; SALANS; KNITTLE; 
HIRSCH, 1968). Essa resposta pode até estar relacionada com alteração na expressão de GLUT4 no tecido adiposo, conforme será discutido adiante.

Quando avaliamos o conteúdo de GLUT4, observamos um paralelismo com a sensibilidade à insulina medida no ITT. De maneira relevante, observou-se em MSG-DN que o GLUT4 aumentou após 4 semanas, quando a sensibilidade insulínica estava aumentada, o que deve ter desempenhado papel importante no desenvolvimento inicial da obesidade, proporcionando maior captação de glicose para os adipócitos jovens. Posteriormente, quando a resistência insulínica se instala, observou-se redução de GLUT4. No caso da dieta hiperlipídica, que exacerbou o desenvolvimento da obesidade, a redução do GLUT4 foi observada desde a quarta semana.

Avaliamos o conteúdo de GLUT4 por grama de tecido adiposo perigonadal (APÊNDICE C) e notamos que em todos os períodos de tratamento, os animais obesos apresentaram redução neste parâmetro. Porém, com o desenvolvimento (aumento) da massa adiposa, a redução do GLUT4/g tecido tende a ser compensada, destacando que a massa adiposa no seu todo, representada pelo GLUT4/tecido inteiro, que participa do clearance da glicose circulante em resposta à insulina. Interessantemente, nos animais MSG-DN de 4 semanas, o conteúdo de GLUT4 por tecido inteiro (APÊNDICE D) mostrou-se aumentado quando comparados aos animais C-DN ( $P=0.0442$, teste "t" de Student, dado não mostrado na figura). Isso reforça a observação de que no início do desenvolvimento da obesidade, um aumento do GLUT4 no tecido adiposo participa de maior clearance de glicose plasmática em resposta à insulina.

É importante destacar que o controle da homeostase glicêmica não depende apenas da utilização de glicose pelo tecido adiposo, mas também da participação do músculo esquelético e do fígado (DEFRONZO et al., 1981). Entretanto, embora alguns autores reportem que o tecido adiposo seja responsável por menos de $10 \%$ da captação de glicose total (JAMES; BURLEIGH; KRAEGEN, 1985), já foi comprovado que, na obesidade, pelo aumento significante da massa adiposa, o papel do tecido adiposo passa a ser muito relevante, representando até 40\% da captação total de glicose nos indivíduos (MARIN et al., 1987).

No presente estudo, a obesidade acompanhou-se de alterações no perfil lipídico plasmático. Não foram observadas alterações na trigliceridemia, o que corrobora dados da literatura em animais alimentados com dieta hiperlipídica por até 10 (WHITE et al., 2013), 12 (BUETTNER; SCHOOLMERICJ; BOLLHEIMER, 2007) e 14 semanas (SCHREYER; WILSON; LEBOEUF, 1998). Por ouro lado, observamos aumento significante nos níveis 
plasmáticos de colesterol total em 8, 12 e 16 semanas dos animais MSG-DH. Essa observação parece não se relacionar com o grau de resistência à insulina, que em 12 e 16 semanas é semelhante entre animais MSG-DN e MSG-DH; por outro lado, o grau de obesidade é maior nos animais MSG-DH (comparados aos MSG-DN), e aqui pode estar um fator indutor da hipercolesterolemia. De fato, o quadro de obesidade tem sido associado a dislipidemias; porém, tanto camundongos alimentados com dieta hiperlipídica durante 16 semanas (FRAULOB et al., 2010), como camundongos MSG com 23 semanas de idade (FURUYA et al., 2010), mostraram aumento na trigliceridemia, mas não na colesterolemia. Provavelmente, essa regulação seja feita de acordo com o tempo e o grau de evolução da obesidade, além do modelo, sendo difícil estabelecer as comparações.

Quanto ao perfil inflamatório ao longo do desenvolvimento da obesidade, importante resultado foi obtido. As análises de expressão gênica foram realizadas após confirmação da estabilidade da expressão do gene Gapdh (APÊENDCE E), utilizado então como controle endógeno. A expressão do TNFA deve aumentar com a obesidade (HOTAMISLIGIL; SHARGILL; SPIEGELMAN, 1993; HOTAMISLIGIL et al., 1995), e nossa hipótese é que esse fato desempenhe papel chave na repressão do gene SLC2A4 durante a evolução da obesidade. Nesse sentido, os resultados mostram uma correlação positiva entre a massa adiposa e a expressão do mRNA Tnfa no tecido adiposo, em qualquer dos quatro períodos estudados (APÊNDICE F). A expressão do mRNA Tnfa aumentou tanto em MSG-DN como em MSG-DH de 12 e 16 semanas quando a expressão de Slc2a4/GLUT4 estava fortemente reduzida. Adicionalmente, o mRNA Tnfa foi visto aumentado, precocemente, em tecido de animais MSG-DH de 4 e 8 semanas, situações em que a expressão de Slc2a4/GLUT4 também já estava reduzida. Interessantemente, na fase inicial do desenvolvimento da obesidade (4 semanas) nos animais MSG-DN, quando o Slc2a4/GLUT4 estavam até aumentados, nenhuma alteração no Tnfa foi observada.

Assim a elevada atividade pró-inflamatória do tecido adiposo na obesidade, com maior indução de Tnfa, parece ter desempenhado importante papel repressor na expressão do GLUT4. O TNFA é potente ativador da via canônica do NFKB, que leva a repressão do gene SLC2A4 conforme recentemente demonstrado pelo nosso grupo (FURUYA et al., 2013) e, por isso, avaliamos a expressão do mRNA Rela, que codifica uma das mais importantes isoformas de NFKB (p65). Diferente do que esperávamos a expressão desse gene até diminuiu em ambos os obesos de 12 e 16 semanas. Entretanto, para desencadear a inibição do gene Slc2a4 o importante é a migração nuclear do dímero, e sua ligação ao promotor do Slc2a4 (FURUYA et al., 2013), eventos esses não obrigatoriamente dependentes de aumento da expressão do 
Rela. Além disso, há evidências de que camundongos obesos knockouts para Rela, e alimentados com dieta hiperlipídica, não mostraram inibição da atividade inflamatória e mantiveram o perfil pró-apoptótico dos adipócitos, sugerindo que, em situações crônicas, este fator transcricional não seja fundamental para estimular inflamação decorrente da obesidade (GAO et al., 2015).

Em síntese, a análise dos resultados permite propor que durante a fase inicial da obesidade, a expressão do GLUT4 aumenta, contribuindo para aumento da sensibilidade à insulina e maior desenvolvimento da massa adiposa. Posteriormente, com a progressão da obesidade, aumenta a produção de TNFA o que leva à redução do GLUT4, instalando-se uma resistência insulínica que evolui para o DM2. 


\section{CONCLUSÃO}

O objetivo do presente estudo foi analisar a evolução da regulação de expressão do Slc2a4/GLUT4, em tecido adiposo perigonadal de camundongos CD1, durante a progressão do desenvolvimento da obesidade induzida por MSG, e exacerbada com dietahiperlipídica.

Os resultados obtidos em camundongos tratados com MSG permitem concluir que o desenvolvimento da obesidade iniciou-se com aumento do GLUT4 e da sensibilidade à insulina. Posteriormente, a atividade inflamatória reduziu o GLUT4, e induziu resistência insulínica, levando ao surgimento de DM2. O consumo de dieta hiperlipídica acelerou/exacerbou essa evolução. 


\section{REFERÊNCIAS ${ }^{1}$}

ABEL, E. D.; PERONI, O.; KIM, J. K.; KIM, Y. B.; BOSS, O.; HADRO, E.; MINNEMANN, T.; SHULMAN, G. I.; KAHN, B. B. Adipose-selective targeting of the GLUT4 gene impairs insulin action in muscle and liver. Nature, v. 409, n. 6821, p. 729-733, 2001.

AHIMA, R. S.; FLIER, J. S. Adipose tissue as an endocrine organ. Trends Endocrinology Metabolism Journal, v. 11, p. 327-332, 2000.

AL-HASANI H.; JOOST H. G. Nutrition-/diet-induced changes in gene expression in white adipose tissue. Clinical Endocrinology \& Metabolism, v. 19, n. 4, p. 589-605, 2005.

BAPTISTA L. S.; SILVA K. R., BOROJEVIC R. Obesity and weight loss could alter the properties of adipose stem cells? World Journal of Stem Cells, v. 7, n. 1, p. 165-173, 2015.

BELL, R. R.; SPENCER, M. J.; SHERRIFF, J. L. Voluntary exercise and monounsaturated canola oil reduce fat gain in mice fed diets high in fat. The Journal of Nutrition, v. 127, n. 10, p. 2006-2010, 1997.

BERGER, J.; BISWAS, C.; VICARIO, P. P.; STROUT, H. V.; SAPERSTEIN, R.; PILCH, P. F. Decreased expression of the insulin- responsive glucose transporter in diabetes and fasting. Nature, v. 340, n. 6228, p. 70-72, 1989.

BESANCON, E.; GUO, S.; LOK, J.; TYMIANSKI, M.; LO, E. H. Beyond NMDA and AMPA glutamate receptors: emerging mechanisms for ionic imbalance and cell death in stroke. Trends in Pharmacological Sciences, v. 2, n. 5, p. 268-275, 2008.

BIDDINGER, S. B.; KAHN, C. R. From mice to men: Insights into the insulin resistance syndromes. Annual Review of Physiology, v. 68, p. 123-158, 2006.

BJÖRNHOLM, M.; ZIERATH, J. R. Insulin transduction in human skeletal muscle: indentifying the defects in type II diabetes. Biochemical Society Transactions, v. 33, n. 2, p. 354-357, 2005.

BRADY, M. J.; PESSIN, J. E.; SALTIEL, A. R. Spatial compartimentalization in the regulation of glucose metabolism by insulin. Trends Endocrinology Metabolism Journal, v. 10, n. 10, p. 408-413, 1999.

BRESLIN, W. L.; STROHACKER, K.; CARPENTER, K. C.; ESPOSITO, L.; Mc FARLIN, B.K. Weight gain in response to high-fat feeding in CD-1 male mice. Laboratory Animals, v. 44, p. 231-237, 2010.

BRYANT, N. J.; GOVERS, R.; JAMES, D. E. Regulated transport of the glucose transporter GLUT4. Nature Reviews Molecular Cells Biology, v. 3, n. 4, p. 267-277, 2002.

\footnotetext{
${ }^{1}$ De acordo com: ASSOCIAÇÃO BRASILEIRA DE NORMAS TÉCNICAS. NBR 6023: informação e documentação: referências: elaboração. Rio de Janeiro, 2002.
} 
BUERTTNER, R.; SCHOOLMERICH, J.; BOLLHEIMER, L. C. High-fat diets: modeling the metabolic disorders of human obesity in rodents. Obesity, v. 15, p. 798-808, 2007.

CAI, D.; YUAN, M.; FRANTZ, D. F.; MELENDEZ, P. A.; HANSEN, L.; LEE J.; SHOELSON, S. E. Local and systemic insulin resistance resulting from hepatic activation of IKK-beta and NF-kappaB. Nature Medicine, v. 11, n. 2, p. 183-190, 2005.

CARVALHEIRA, J. B. C.; ZECCHIN, H. G.; SAAD, M. J. A. Via de sinalização da insulina. Arquivos Brasileiros de Endocrinologia e Metabologia, v. 46, n. 4, p. 419-423, 2002.

CESCHI, M.; GUTZWILLER, F.; MOCH, H.; EICHHOLZER, M.; PROBST-HENSCH, N. M. Epidemiology and pathophysiology of obesity as cause of cancer. Swiss Medical Weekly, v. 137, p. 50-56, 2007.

CHAN, R. S. M.; WOO, J. Prevention of overweight and obesity: How effective is the current public health approach. International Journal of Environmental Research and Public Health, v. 7, p. 765-783, 2010.

CHANG, L.; CHIANG, S.; SALTIEL, A. R. Insulin signaling and the regulation of glucose transport. Molecular Medicine, v. 10, n. 7-12, p. 65-71, 2004.

CHIELLINI, C.; BERTACCA, A.; NOVELLI, S. E.; GORGUN, C. Z., CICCARONE, A.; GIORDANO, A.; XU, H.; SOUKAS, A.; COSTA, M.; GANDINI, D.; DIMITRI, R.; BOTTONE, P.; CECCHETTI, P.; PARDINI, E.; PEREGO, L.; NAVALESI, R.; FOLLI, F.; BENZI, L.; CINTI, S.; FRIEDMAN, J. M.; HOTAMISLIGIL, G. S.; MAFFEI, M. Obesity modulates the expression of haptoglobin in the white adipose tissue via TNF alpha. Journal of Cellular Physiology, v. 190, n. 2, p. 251-258, 2002.

CINTI, S.; MITCHELL, G.; BARBATELLI, G.; MURANO, I.; CERESI, E.; FALOIA, E.; WANG, S.; FORTIER, M.; GREENBERG, A. S.; OBIN, M. S. Adipocyte death defines macrophage localization and function in adipose tissue of obese mice and humans. The Journal of Lipid Research, v. 46, n. 11, p. 2347-2355, 2005.

COPPACK, S. W. Pro-inflammatory citokines and adipose tissue. Proceedings of the Nutrition Society, v. 60, p. 349-356, 2001.

CÔRREA-GIANNELA, M.L.; MACHADO, U.F. SLC2A4 gene: a promising target for pharmacogenomics of insulin resistance. Pharmacogenomics, v. 14, n. 8, p. 847-850, 2013.

COYLE, J. T.; BIRD, S. J.; EVANS, R. H.; GULLEY, R. L.; NADLER, J. V.; NICKLAS, W. J.; OLNEY, J. W. Excitatory aminoacid neurotoxin: selectivity, sprecificity and mechanisms of action. Neuroscience Research Program Bulletin, v. 19, n. 4, p. 331-427, 1981.

CÔRREA-GIANNELA, M.L.; MACHADO, U.F. SLC2A4 gene: a promising target for pharmacogenomics of insulin resistance. Pharmacogenomics, v. 14, n. 8, p. 847-850, 2013.

CRAIG B. W.; GARTHWAITE S. M.; HOLLOSZY J. O. Adipocyte insulin resistance: effects of aging, obesity, exercise, and food restriction. Journal of Applied Physiology, v. 62, n. 1, p. 95-100, 1987. 
CURUVINEL, W. M.; JÚNIOR, D. D.; ARAÚJO, J. A. P.; CATELAN, T. T. T.; SOUZA, A. W. S.; SILVA, N. P.; ANDRADE, L. E. C. Sistema imunitário- Fundamentos da imunidade inata com ênfase nos mecanismos moleculares e celulares da resposta inflamatória. Revista Brasileira de Reumatologia, v. 50, n. 4, p. 434-461, 2010.

CUSHMAN, S.; WARDZALA, L. J. Potencial mechanism of insulin action on glucose transport in the isolated rat adipose cell. The Journal of Biological Chemestry, v. 255, n. 10, p. 4758-4762, 1980.

DEFRONZO, R. A.; JACOT, E.; JEQUIER, E.; MAEDER, E.; WAHREN, J.; FELBER, J. P. The effect of insulin on the disposal of intravenous glucose. Results from indirect calorimetry and hepatic and femoral venous catheterization. Diabetes, v. 30, n. 12, p. 1000-1007, 1981.

FONSECA-ALANIZ, M. H.; TAKADA, M.; ALONSO-VALE, M. I.; LIMA, F. B. The adipose tissue as a regulatory Center of the metabolism. Arquivos Brasileiros de Endocrinologia e Metabologia, v. 50, p. 216-229, 2006.

FRALOUB, J. C.; OGG-DIAMANTINO, R.; FERNANDES-SANTOS, C.; AGUILA, M. B.; MANDARIM-DE-LACERDA, C. A. A mouse model of metabolic syndrome: insulin resistance, fatty liver and non-alcoholic fatty pancreas disease (NAFPD) in c57bl/6 mice fed a high fat diet. Journal of Clinical Biochemistry and Nutrition, v. 46, n. 3, p. 1-12, 2010.

FUKUMOTO, H.; KAYANO, T.; BUSE, J. B.; EDWARDS, Y.; PILCH, P. F.; BELL, G. I.; SEINO, S. Cloning and characterization of the major insulin-responsive glucose transporter expressed in human skeletal muscle and other insulin-responsive tissues. The Journal of Biological Chemestry, v. 264, n. 14, p. 7776-7779, 1989.

FURUYA, D. T.; POLETTO, A. C.; FAVARO, R. R.; MARTINS, J. O.; ZORN, T. M.; MACHADO, U. F. Anti-inflammatory effect of atorvastatin ameliorates insulin resistance in monosodium glutamate-treated obese mice. Metabolism Clinical and Experimental, v. 59, p. 395-399, 2010.

FURUYA, D. T.; NERI, E. A.; POLETTO, A.C.; ANHÊ, G. F.; FREITAS, H. S.; CAMPELLO, R. S.; REBOUÇAS, N. A.; MACHADO, U. F. Identification of nuclear factor$\mathrm{kB}$ sites in the Slc2a4 gene promoter. Molecular and Cellular Endocrinology, v. 370, p. 8795, 2013.

GAO, M.; MA, Y.; LIU, D. High-fat diet-induced adiposity, adipose inflammation, hepatic steatosis and hyperinsulinemia in out bred CD-1 mice. Plos One, n. 10, v. 3, 2015.

GAO, Z.; ZHANG, J.; HENAGAN, T. M.; LEE, J. H.; YE, X.; WANG, H.; YE, J. P65 inactivation in adipocytes and macrophages attenuates adipose inflammatory response in lean but not in obese mice. American Journal of Physiology, Endocrinology and Metabolism, v. 308, p. 496-505, 2015.

GREGOR, M. F.; HOTAMISLIGIL, G. S. Inflammatory mechanisms in obesity. Annual Review of Immunology, v. 29, p. 415-445, 2011. 
HABER, E. P.; CURI, R.; CARVAlHO, C. R. O.; CARPINELli, A. R. Secreção da insulina: Efeito autócrino da insulina e modulação por ácidos graxos. Arquivos Brasileiros de Endocrinologia e Metabologia, v. 45, n. 3, p. 219-226, 2001.

HIMMS-HAGEN, J. Brown adipose tissue thermogenesis and obesity. Progress in Lipid Research, v. 28, n. 2, p. 67-115, 1989.

HERBERG, L.; DÖPPEN, W.; MAJOR, E.; GRIES, F. A. Dietary-induced hypertrophic hyperplastic obesity in mice. Journal of Lipidic Research, v. 6, n. 15, p. 580-585, 1974.

HOCHBERG, I.; HOCHBERG, Z. Expanding the definition of hypolamic obesity. Obesity Reviews, v. 11, p. 709-721, 2010.

HOTAMISLIGIL, G. S.; SHARGILL, N. S.; SPIEGELMAN, B. M. Adipose expression of tumor necrosis factor-alpha: direct role in obesity-linked insulin resistence. Science, v. 259, n. 1, p. 87-91, 1993.

HOTAMISLIGIL, G. S.; ARNER, P.; CARO, J. F.; ATKINSON, R. L.; SPIEGELMAN, B. M. Increased adipose tissue expression of tumor necrosis factor-alpha in human obesity and insulin resistance. Journal of Clinical Investigation, v. 95, n. 5, p. 2409-2415, 1995.

JAMES, D. E., BURLEIGH K. M., KRAEGEN E. W. Time dependence of insulin action in muscle and adipose tissue in the rat in vivo. An increasing response in adipose tissue with time. Diabetes, v. 34, n. 10, p. 1049-1054, 1985.

JÉQUIER, E.; TAPPY, L. Obesity. Molecular Aspects Medicine, v. 18, p. 249-305, 1997.

JOOST, H. G.; THORENS, B. The extended GLUT-family of sugar/polyol transport facilitators: nomenclature, sequence characteristics, and potential function of its novel members (Review). Molecular Membrane Biology, v. 18, p. 247-256, 2001.

JOOST, H. G.; BELL, G. I.; BEST, J. D.; BIRNBAUM, M. J.; CHARRON, M. J.; CHEN, Y. T.; DOEGE, H.; JAMES, D. E; LODISH, H. F.; MOLEY, K. H.; MOLEY, J. F.; MUECKLER, M.; ROGERS, S.; SCHURMANN, A.; SEINO, S.; THORENS, B. Nomenclature of the GLUT/ SLC2A family of sugar/ polyol transport facilitators. American Journal of Physiology, Endocrinology and Metabolism, v. 282, p. E974- E976, 2002.

KAHN, C. R. The molecular mechanism of insulin action. Annual Review of Medicine, v. 36, p. 429-451, 1985.

KANZAKI, M. Insulin receptor signals regulating GLUT4 translocation and actin dynamics. Endocrine Journal, v. 53, n. 3, p. 267-293, 2006.

KASUGA, M.; KARLSSON, F. A.; KAHN, C. R. Insulin stimulates the phosphorylation of the 95,000-dalton subunit of its own receptor. Science, v. 215, n. 4529, p. 185-187, 1982.

KISER, J. S.; NEMEROFF, C. B.; YOUNGBLOOD, W. W. Neurotoxic aminoacids and structurally analogs. Pharmacological Reviews, v. 29, n. 4, p. 301-318, 1978. 
KOISTINEN, H. A.; ZIERATH, J. R. Regulation of glucose transport in human skeletal muscle. Annals of Medicine, v. 34, p. 410-418, 2002.

KOIVISTO, V. A.; PELKONEN, R.; CANTELL, K. Effect of interferon on glucose tolerance and insulin sensitivy. Diabetes, v. 38, n. 5, p. 641-647, 1989.

KOVACS, M.; KINEMAN, R. D.; SCHALLY, A. V.; FLERKO, B.; FROHMAN, L. A. Increase in mRNA concentrations of pituitary receptors for growth hormone-releasing hormone and growth hormone secretagogues after neonatal monosodium glutamate treatment. Journal of Neuroendocrinology, v. 12, p. 335-341, 2000.

KRETZ-REMY, C.; MEHLEN, P.; MIRAULT, M. E.; ARRIGO, A. P. Inhibition of I kappa B-alpha phosphorylation and degradation and subsequent NF- kappa B activation by glutathione peroxidase overexpression. The Journal of Cell Biology, v. 133, n. 5, p. 10831093, 1996.

KRONENBERG, H. M.; MELMED, S.; POLONSKY, K. S.; LARSEN, P. R. Williams tratado de endocrinologia. 11. ed. Rio de Janeiro: Elsevier, 2010. 1929 p.

LI, L. RAGE on the Toll Road? Cellular and Molecular Immunology, v. 3, n. 5, p. 351358, 2006.

LI, Q.; VERMA, I. NF-kappa B regulation in the immune system. Nature Reviews Immunology, v. 10, n. 2, p. 725-734, 2002.

LIMA, F. B.; CURI, R. Moléculas ativas produzidas por órgãos não endócrinos. In: AIRES, M. M. Fisiologia. 3. ed. Rio de Janeiro: Guanabara Koogan, 2012. p. 1139-1156.

MACHADO, U. F.; SHIMIZU, I.; SAITO, M. Reduced content and preserved translocation of glucose transporter (GLUT4) in white adipose tissue of obese mice. Physiology and Behavior, v. 55, n. 4, p. 621-625, 1994.

MACHADO, U. F.; SHIMIZU, I.; SAITO, M. Decreased glucose transporter (GLUT4) content in insulin-sensitive tissues of obese Aurothioglucose- and Monosodium glutamatetreated mice. Hormone and Metabolic Research, v. 25, p. 462-465, 1993.

MACHADO, U. F., SAITO, M. The effect of adipose cell size on the measurement of GLUT 4 in white adipose tissue of obese mice. Brazilian Journal of Medical Biological Research, v. 28, n. 3, p. 369-76, 1995.

MACHADO, U. F.; SHAAN, B. D.; SERAFIM, P. M. Transportadores de glicose na síndrome metabólica. Arquivos Brasileiros de Endocrinologia e Metabologia, v. 50, n. 2, p. 177-189, 2006.

MACHADO, U. F. Transportadores de glucose. Arquivos Brasileiros de Endocrinologia e Metabologia, v. 42, n. 6, p. 413-421, 1998.

MACHO, L.; FICKOVÁ, M.; JEZOVÁ; ZÓRAD, S. Late effects of postnatal administration of monosodium glutamate on insulin action in adult rats. Physiological Research, v. 49, p. S79-S85, 2000. 
MAGARIÑOS, A. M.; ESTIVARIZ, F.; MORADO, M. I.; DE NICOLA, A. F. Regulation of the central nervous system-pituitary-adrenal axis in rats after neonatal treatment with monosodium glutamate. Neuroendocrinology, v. 48, n. 2, p. 105-111, 1988.

MAITER, D.; UNDERWOOD, L. E.; MARTIN, J. B.; KOENIG, J. I. Neonatal treatment with monosodium glutamate: effects of prolonged growth hormone $(\mathrm{GH})$-releasing hormone deficiency on pulsatile GH secretion and growth in female rats. Endocrinology, v. 128, n. 2, p. 1100-1106, 1991.

MARIN, P.; REBUFFÉ-SCRIVE, M.; SMITH, U.; BJORNTORP, P. Glucose uptake in human adipose tissue. Metabolism, n. 12, v. 36, p. 1154-1160, 1987.

MARTINEZ-SANTIBAÑEZ, G.; CHO, K. W.; LUMENG, C. N. Imaging white adipose tissue with confocal microscopy. Methods in Enzimlogy, n. 537, p. 17-30, 2014.

MONTGOMERY, M. K.; HALLAHAN, N. L.; BROWN, S. H.; LIU, M.; MITCHELL, T. W.; COONEY, G. J.; TURNER, N. Mouse strain-dependent variation in obesity and glucose homeostasis in response to high-fat feeding. Diabetologia, n. 56, p. 1129-1139, 2013.

MORRIS, M. J.; TORTELLI, C. F.; FILIPPIS, A.; PROIETTO, J. Reduced BAT function as a mechanism for obesity in the hypophagic, neuropeptide $\mathrm{Y}$ deficient monossodium glutamate-treated rat. Regulatory Peptides, v. 75-76, n. 25, p. 441-447, 1998.

MÖSSENBÖCK, K.; VEGIOPOULOS, A.; ROSE, A. J.; SIJMONSMA, T. P.; HERZIG, S.; SCHAFMEIER, T. Browning of white adipose tissue uncouples glucose uptake from insulin signaling. Plos One, v. 9, n. 10, 2014.

NAGATA, M.; SUZUKI, W.; IIZUKA, S.; TABUCHI, M.; MARUYAMA, H.; TAKEDA, S.; ABURADA, M.; MIYAMOTO, K. Type 2 diabetes mellitus in obese mouse model induced by monosodium glutamate. Experimental Animals, v. 55, p. 109-115, 2006.

NELSON, K. A.; WALSH, D.; SHEEHAN, F. A. The cancer anorexia- cachexia syndrome. Journal of Clinical Oncology, v. 12, n. 1, p. 213-225, 1994.

NEMEROFF, C. B.; GRANT, L. D.; BISSETTE, G.; ERVIN, G. N.; HARRELL, L. E.; PRANGE, A. J. Growth, endocrinological and behavioral deficits after monosodium Lglutamate in the neonatal rat: possible involvement of arcuate dopamine neuron damage. Psychoneuroendocrinology, n. 2, v. 2, p. 179-196, 1977.

OLNEY, J. W. Brain lesions, obesity, and other disturbances in mice treated with monosodium glutamate. Science, v. 880, n. 164, p. 719-721, 1969.

OLSON, A. L. Regulation of GLUT4 and insulin-dependent glucose flux. ISRN Molecular Biology, 2012.

PAIGEN, B. Genetics of responsiveness to high-fat and high-cholesterol diets in the mouse. The American Journal of Clinical Nutrition, n. 62, p. 458S-462S, 1995.

PARK, A.; KIM, W. K.; BAE, K. H. Distinction of white, beige and brown adipocytes derived from mesenchymal stem cells. World Journal of Stem Cells, v. 6, n. 1, 2014. 
PAPA, P. C.; VARGAS, A. M.; DA SILVA, J. L.; NUNES, M. T.; MACHADO, U. F. GLUT4 protein is differently modulated during development of obesity in monosodium glutamate- treated mice. Life Sciences, v. 71, n. 16, p. 1917-1928, 2002.

PAPA, P. C.; SERAPHIM, P. M.; MACHADO, U. F. Loss of weight restores GLUT 4 content in insulin-sensitive tissues of monosodium glutamate-treated obese mice. International Journal of Obesity and Related Metabolic Disorders, v. 21, n. 11, p. 10651070, 1997.

PERKINS, N. D. Integrating cell-signalling pathways with NF-kappa B and IKK function. Nature Review Molecular Cell Biology, v. 1, n. 8, p. 49-62, 2007.

PICKUP, J. C.; MATTOCK, M. B.; CHUSNEY, G. D.; BUTT, D. NIDDM as a disease of the innate immune system: association of acute-phase reactants and interleukin-6 with metabolic syndrome X. Diabetologia, v. 40, p. 1286-1292, 1997.

QUEIROZ, J. C. F.; ALONSO-VALE, M. I. C.; CURI, R.; LIMA, F. B. Control of adipogenesis by fatty acids. Arquivos Brasileiros de Endocrinologia e Metabologia, v. 53, n. 5, p. 582-594, 2009.

REA, S.; JAMES, D. E. Moving GLUT4: The biogenesis and trafficking of GLUT4 storage vesicles. Diabetes, v. 46, p. 1667-1677, 1997.

ROGERS, P.; WEBB, G. P. Estimation of body fat in normal and obese mice. British Journal of Nutrition, v. 43, n. 1, p. 83-86, 1980.

ROSENWALD, M.; WOLFRUM, C. The origin and definition of brite versus white and classical brown adipocytes. Adipocyte, v. 3, n. 1, 2014.

SALANS, L.; KNITTLE, J.; HIRSCH, J. The role of adipose cell size and adipose tissue insulin sensitivity in the carbohydrate intolerance of human obesity. Journal of Clinical Investigation, v. 47, n. 1, p. 153-165, 1968.

SALANS, L.; DOUGHERTY, J. W. The effect of insulin upon glucose metabolism by adipose cells of different size. Influence of cell lipid and protein content, age, and nutritional state. Journal of Clinical Investigation, v. 50, n. 7, p. 1399-1410, 1971.

SALTIEL, A. R.; KANH, C. R. Insulin signaling and the regulation of glucose and lipid metabolism. Nature, v. 414, p. 799-805, 2001.

SCHEEPERS, A.; JOOST, H.; SCHURMANN, A. The glucose transporter families SGLT and GLUT: Molecular basis of normal and aberrant function. Journal of Parenteral and Enteral Nutrition, v. 28, n. 5, p. 364-371, 2004.

SCHREYER, S. A.; WILSON, D. L.; LEBOEUF, R. C. C57BL/6 mice fed high fat diets as models for diabetes-accelerated atherosclerosis. Atherosclerosis, v. 136, p. 17-24, 1998.

SØRENSEN, L. P.; PARKNER, T.; SØNDERGAARD, E.; BIBBY, B. M.; MØLLER, H. J.; NIELSEN, S. Visceral obesity is associated with increased soluble CD163 concentration in men with type 2 diabetes mellitus. Endocrine Connections, v. 4, p. 27-37, 2015. 
TAI, N., WONG, F. S., WEN, L. The role of gut microbiota in the development of type 1, type 2 diabetes mellitus and obesity. Reviews in Endocrine and Metabolic Disorders, 2015.

THORENS, B.; CHARRON, M. J.; LODISH, H. F. Molecular physiology of glucose transporters. Diabetes Care, v. 13, n. 3, p. 209-218, 1990.

TOKER, A.; MARMIROLI, S. Signaling specificity in the Akt pathway in biology and disease. Advances in Biological Regulation, v. 55, p. 28-38, 2014.

TOZZO, E.; GNUDI, L.; KAHN, B. B. Amelioration of insulin resistance in streptozotocin diabetic mice by transgenic overexpression of GLUT4 driven by adipose-specific promoter. Endocrinology, v. 138, n. 4, p. 1604-1611, 1997.

TRAN, T. T.; KAHN, C. R. Transplantation of adipose tissue and adipose-derived stem cells as a tool to study metabolic physiology and for treatment of disease. Nature Reviews Endocrinology, n. 6, v. 4, p. 195-213, 2010.

WHITE, P. A. S.; CERCATO, L. M.; ARAÚJO, J. M. D.; SOUZA, L. A.; SOARES, A. F.; BARBOSA, A. P. O.; NETO, J. M. R.; MARÇAL, A. C.; MACHADO, U. F.; CAMARGO, E. A.; SANTOS, M. R. V., BRITO, L. C. Model of high-fat diet-induced obesity associated to insulin resistance and glucose intolerance. Arquivos Brasileiros de Endocrinologia e Metabologia, v. 57, n. 5, p. 339-345, 2013.

WORLD HEALTH ORGANIZATION. Global Health Observatory (GHO) data. Risk factors: Overweight and obesity. Disponível em <http://www.who.int/gho/ncd/risk_factors/overweight/en/>. Acesso em: 25 jun. 2015.

WONG, M. L.; MEDRANO, J. F. Real-time PCR for mRNA quantitation. The International Journal of Life Science Methods, v. 39, n. 1, 2005.

WOOD, I. S.; TRAYHURN, P. Glucose transporters (GLUT and SGLT): expanded families of sugar transport protein. British Journal of Nutrition, v. 89, n. 1, p. 3-9, 2003.

WRIGHT, E. M.; LOO, D. D.; HIRAYAMA, B. A.; TURK, E. Surprising versatility of $\mathrm{Na}^{+}-$ Glucose cotransporters: SLC5. Physiology, v. 19, p. 370-376, 2004.

YAMAUCHI, T.; KAMON, J.; WAKI, H.; TERAUCHI, Y.; KUBOTA, N.; HARA, K.; MORI, Y.; IDE, T.; MURAKAMI, K.; TSUBOYAMA-KASAOKA, N.; EZAKI, O.; AKANUMA, Y.; GAVRILOVA, O.; VINSON, C.; REITMAN, M. L.; KAGECHIKA, H.; SHUDO, K.; YODA, M.; NAKANO, Y.; TOBE, K.; NAGAI, R.; KIMURA, S.; TOMITA, M.; FROGUEL, P.; KADOWAKI, T. The fat-derived hormone adiponectin reverses insulin resistance associated with both lipoatrophy and obesity. Nature, v. 7, n. 8, p. 941-946, 2011.

YIN, H.; PASUT, A.; SOLEIMANI, V. D.; BENTZINGER, C. F.; ANTOUN, G.; THORN, S.; SEALE, P.; FERNANDO, P.; VAN IJCKEN, W.; GROSVELD, F.; DEKEMP, R. A.; BOUSHEL, R.; HARPER, M. E.; RUDNICKI, M. A. MicroRNA-133 controls brown adipose determination in skeletal muscle satellite cells by targeting prdm16. Cell Metabolism, v. 17, p. 210-224, 2013. 
YOSHIOKA, K.; YOSHIDA, T.; KONDO, M. Reduced Brown adipose tissue thermogenesis and metabolic rate in pre-obese mice treated with monosodium-Lglutamate. The Japan Endocrine Society, v. 38, n. 1, p. 75-79, 1991.

YUDKIN, J. S.; STEHOUWER, C. D.; EMEIS, J. J.; COPPACK, S. W. C-reative protein in healthy subjects: associations with obesity, insulin resistance, and endothelial dysfunction: a potential role for cytokines originating from adipose tissue? Arteriosclerosis, Thrombosis and Vascular Biology, v. 19, n. 4, p. 972- 978, 1999.

ZHANG, Y.; PROENCA, R.; MAFFEI, M.; BARONE, M,; LEOPOLD, L.; FRIEDMAN, J. M.. Positional cloning of the mouse obese gene and its human homologue. Nature, v. 372, n. 6505, p. 425-432, 1994. 


\section{APÊNDICE A - Peso corporal final}

A figura abaixo mostra a massa corporal dos animais ao final dos períodos de 4, 8, 12 e 16 semanas de tratamento. Na quarta semana de tratamento, os animais MSG-DN ainda apresentavam peso corporal menor que os C-DN $(P<0,05)$, entretanto, a dieta hiperlipídica já induziu aumento significante na massa corporal tanto em comparação a C-DN como a MSGDN $(P<0,001)$. Com 8 semanas de tratamento, o peso de MSG-DN se equiparou ao de C-DN, e a dieta hiperlipídica exacerbou o aumento já detectado com 4 semanas $(P<0,001$ vs MSGDN e C-DN). Após 12 semanas, MSG-DN superou o peso de C-DN $(P<0,001)$, e mais uma vez a dieta hiperlipídica exacerbou a evolução da massa corporal $(P<0,001$ vs MSG-DN e CDN). Este perfil permaneceu o mesmo após 16 semanas de dietas.
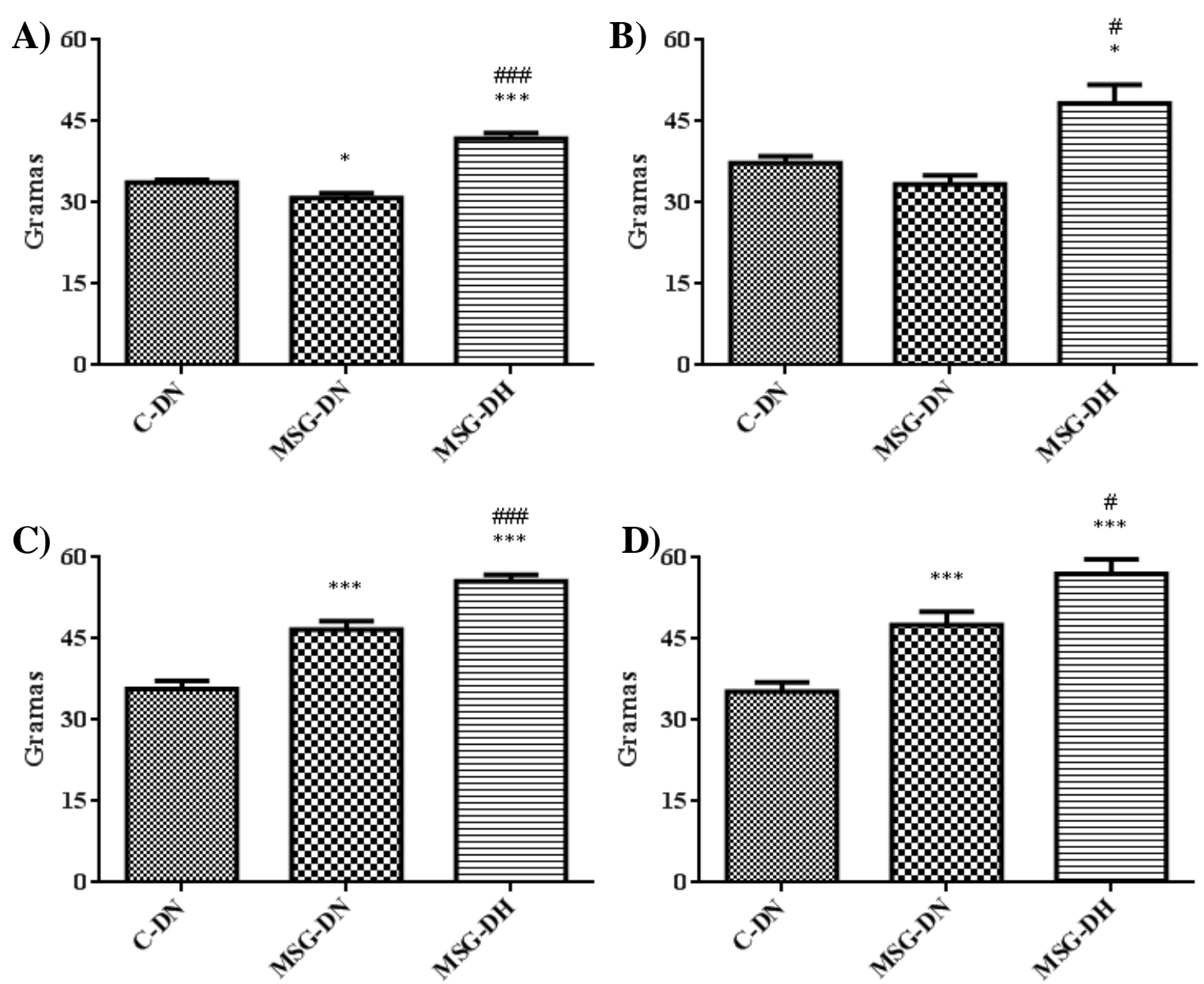

Figura A - A figura representa a massa corporal no final do consumo das dietas nos grupos controle alimentado com dieta normolipídica (C-DN) e obeso alimentado com dieta normolipídica (MSG-DN) ou hiperlipídica (MSG-DH), após 4 (A), 8 (B), 12 (C) e 16 (D) semanas de tratamento. Valores são médias \pm EPM, comparados por ANOVA one-way seguido de teste Student-Newman-Keuls; $\mathrm{n}=5$ a 15 animais. ${ }^{*} P<0,05,{ }^{* *} P<0,01$ e ${ }^{* * *} P<0,001$ vs C-DN; ${ }^{\#} P<0,05 \mathrm{e}^{\# \# \#} P<0,001$ vs MSG-DN. 
APÊNDICE B - Consumo de dieta relativo ao peso corporal

Quanto ao consumo de dieta em relação ao peso corporal demonstrado abaixo, podese observar que, em 4, 8 e 12 semanas de tratamento, animais MSG-DH apresentaram redução significante deste parâmetro quando comparados aos animais C-DN e MSG-DN $(P<0,001)$ e, em 16 semanas, animais MSG-DN apresentaram significante redução quando comparado aos animais C-DN $(P<0,01)$, assim como animais MSG-DH, quando comparados aos animais CDN $(P<0,001)$ e MSG-DN $(P<0,01)$.
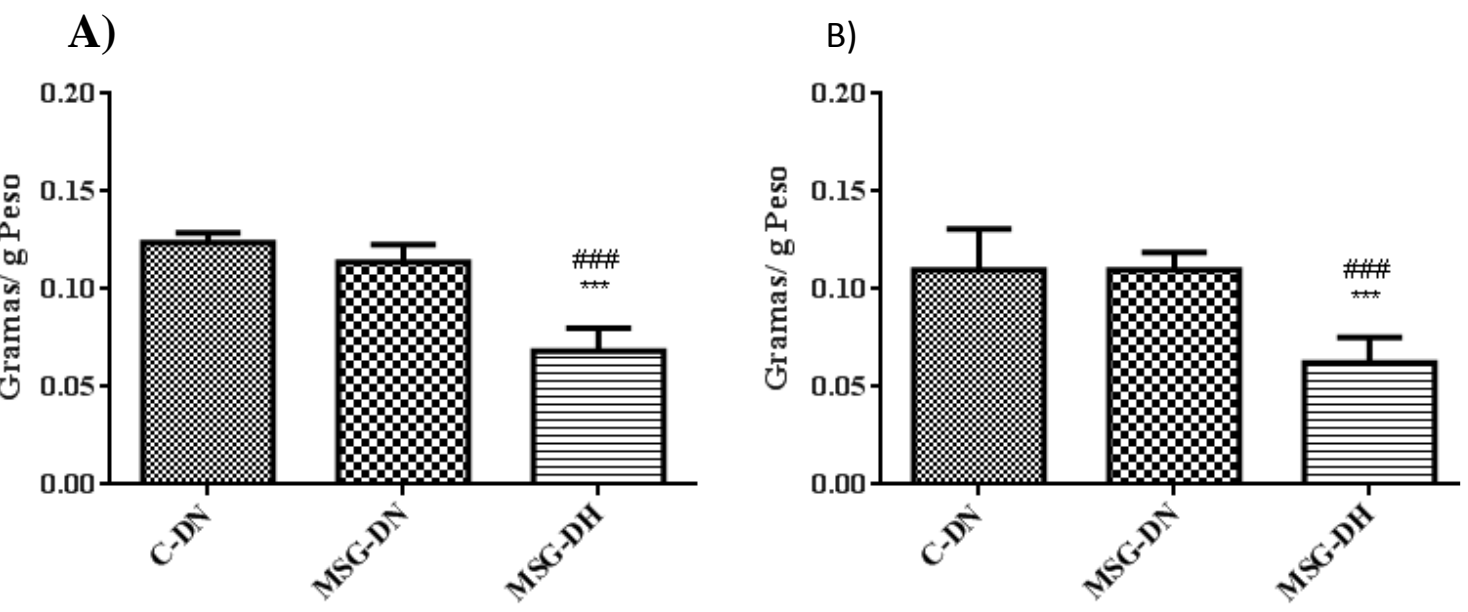

C)

D)
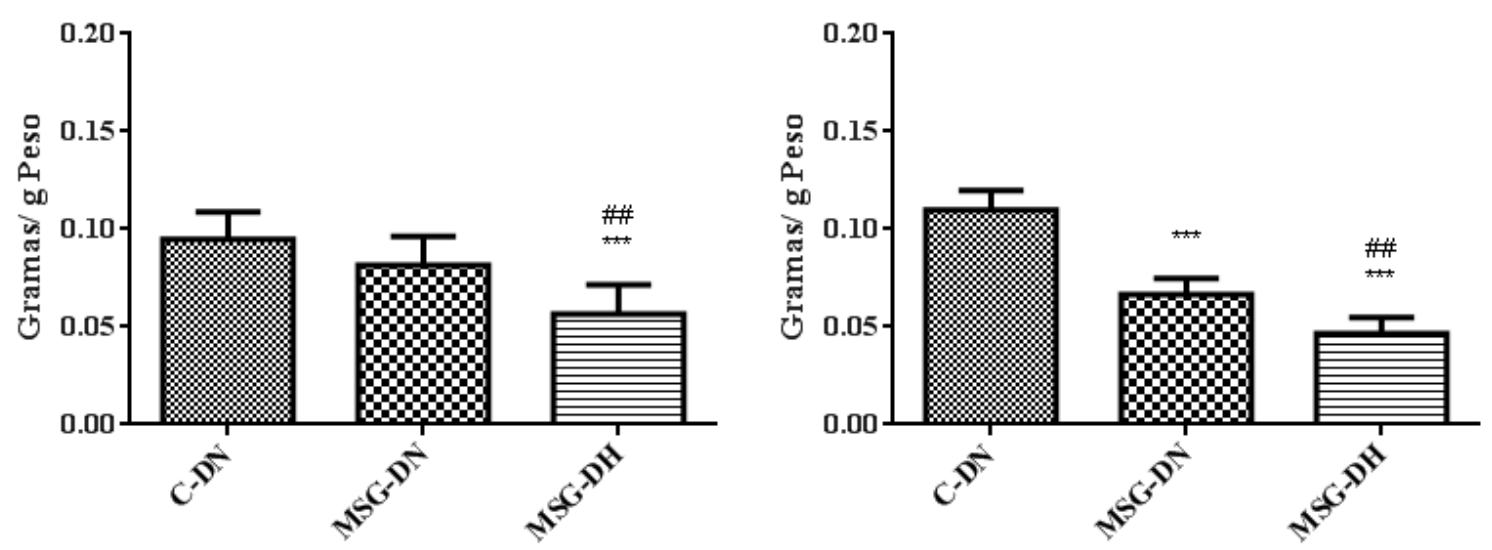

Figura B - A figura representa o consumo de dieta relativo ao peso corporal em 4 (A), 8 (B), 12 (C) e 16 (D) semanas de tratamento, de animais do grupo controle alimentados com dieta normolipídica (CDN) e do grupo obeso alimentados com dieta normolipídica (MSG-DN) ou hiperlipídica (MSG-DH). Valores são médias \pm EPM, comparados por ANOVA one-way, seguido do teste Student-NewmanKeuls; $\mathrm{n}=5$ a 9 animais. ${ }^{* * *} P<0,001$ vs C-DN; ${ }^{\# \#} P<0,01$ e ${ }^{\# \# \#} P<0,001$ vs MSG-DN. 
APÊNDICE C - Conteúdo de GLUT4 por grama de tecido adiposo perigonadal

A figura abaixo mostra o conteúdo de GLUT4/ g de tecido adiposo perigonadal. Nota- se que, em todos os períodos de tratamento, os animais obesos (MSG) alimentados com DN ou DH, apresentaram redução significante deste parâmetro quando comparados aos animais do grupo C-DN $(P<0,001)$ e, ainda, em 4 semanas de tratamento, o grupo MSG-DH também apresentou redução quando comparado ao grupo MSG-DN $(P<0,01)$.
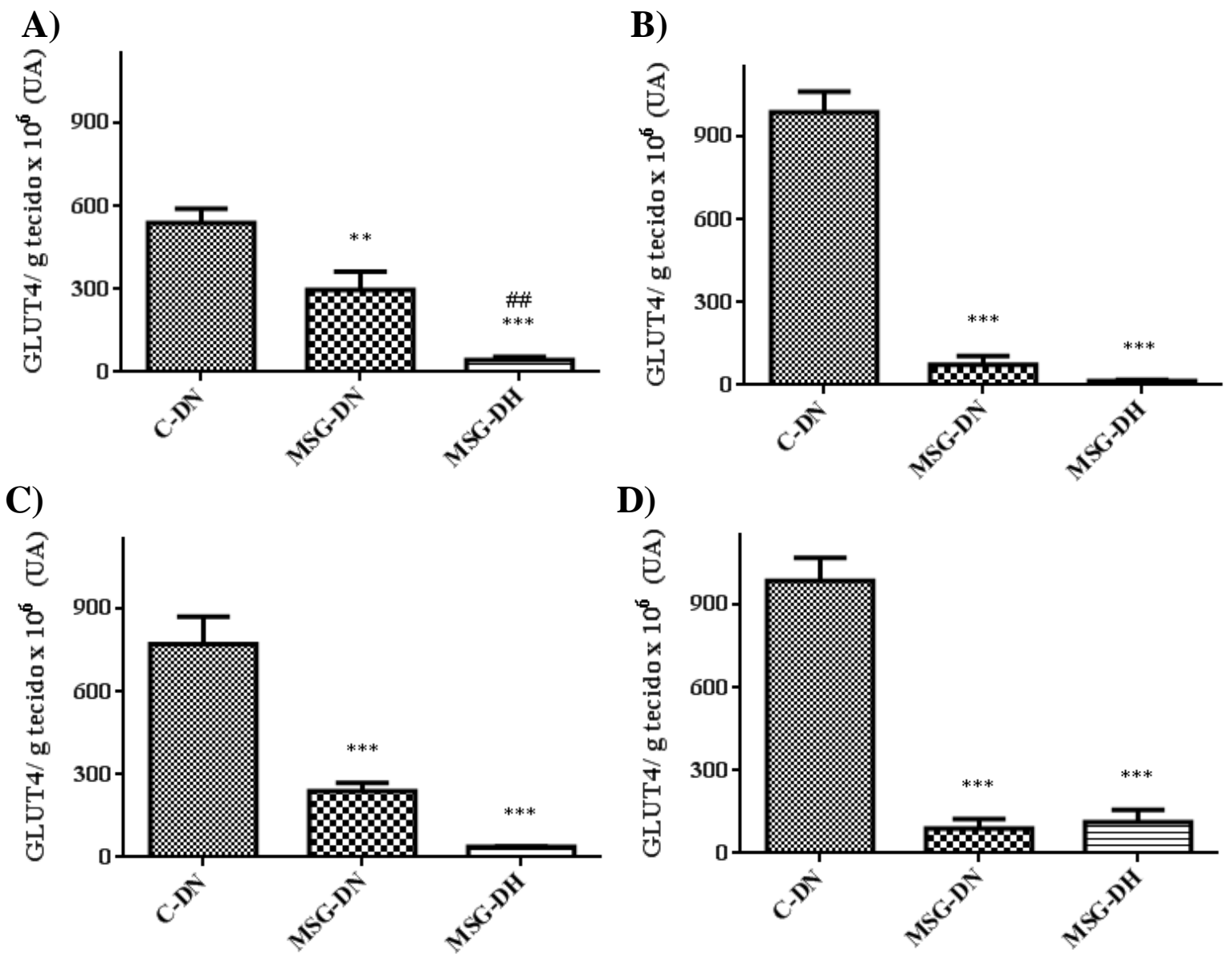

Figura C - A figura representa o conteúdo de GLUT4/ g de tecido adiposo perigonadal em 4 (A), 8 (B), 12 (C) e 16 (D) semanas de tratamento, em animais do grupo controle alimentados com dieta normolipídica (C-DN) ou obeso, alimentados com dieta normolipídica (MSG-DN) ou hiperlipídica (MSG-DH). Valores são médias \pm EPM, comparados por ANOVA one-way seguido de teste StudentNewman-Keuls; $\mathrm{n}=3$ a 5 animais. ${ }^{* * *} P<0,01$ vs C-DN; ${ }^{* * * *} P<0,001$ vs $\mathrm{C}-\mathrm{DN} ;{ }^{\# \#} P<0,01$ vs MSG-DN. 
APÊEDICE D- Conteúdo de GLUT4 por tecido adiposo perigonadal total

A figura abaixo demonstra o conteúdo de GLUT4/ tecido adiposo perigonadal total. A partir da oitava semana de tratamento, os animais MSG-DH apresentaram redução do conteúdo desta proteína, quando avaliado pelo total de tecido adiposo perigonadal em relação ao grupo C-DN $(P<0,001)$ e, ainda, em 12 semanas, esta redução também foi significante quando comparada aos animais MSG-DN $(P<0,01)$. Animais MSG-DN também apresentaram redução deste parâmetro avaliado quando comprado com animais C-DN $(P<0,05$ em 12 semanas e $P<0,001$ em 8 e 16 semanas).
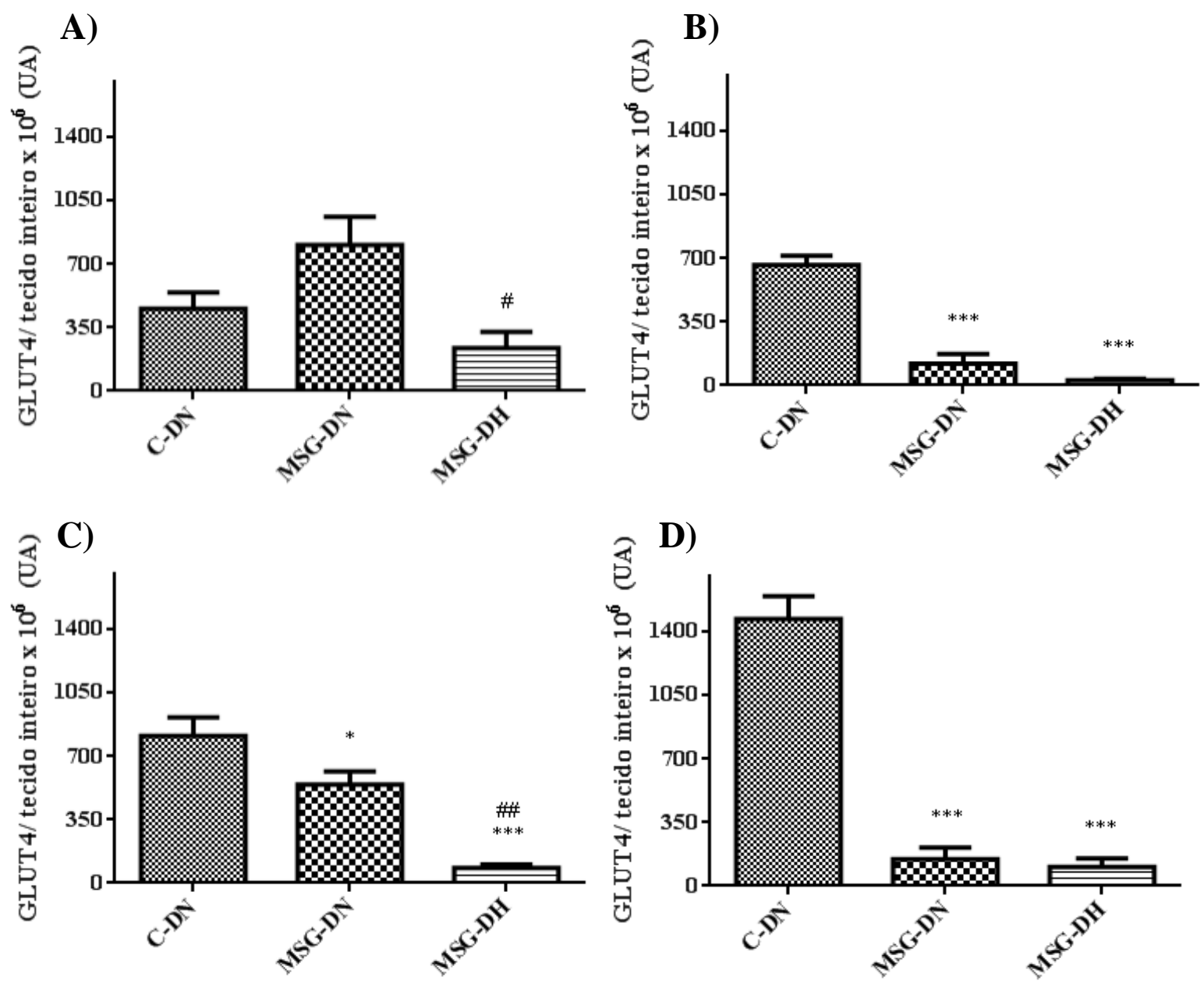

Figura D - A figura representa o conteúdo de GLUT4/ tecido adiposo perigonadal total em 4 (A), 8 (B), 12 (C) e 16 (D) semanas de tratamento, em animais do grupo controle alimentados com dieta normolipídica (C-DN) ou obeso, alimentados com dieta normolipídica (MSG-DN) ou hiperlipídica (MSG-DH). Valores são médias \pm EPM, comparados por ANOVA one-way seguido de teste StudentNewman-Keuls; $\mathrm{n}=3$ a 5 animais. ${ }^{*} P<0,05$ vs C-DN; ${ }^{* * * *} P<0,001$ vs $\mathrm{C}-\mathrm{DN} ;{ }^{\#} P<0,05$; ${ }^{\# \#} P<0,01$ vs MSG-DN. 


\section{APÊNDICE E - Expressão de mRNA Gapdh}

A figura abaixo ilustra a expressão do gene para Gapdh em tecido adiposo perigonadal de animais controle e obesos, durante os períodos de tratamento do estudo. Não foram observadas diferenças significantes neste parâmetro em qualquer período de tratamento.
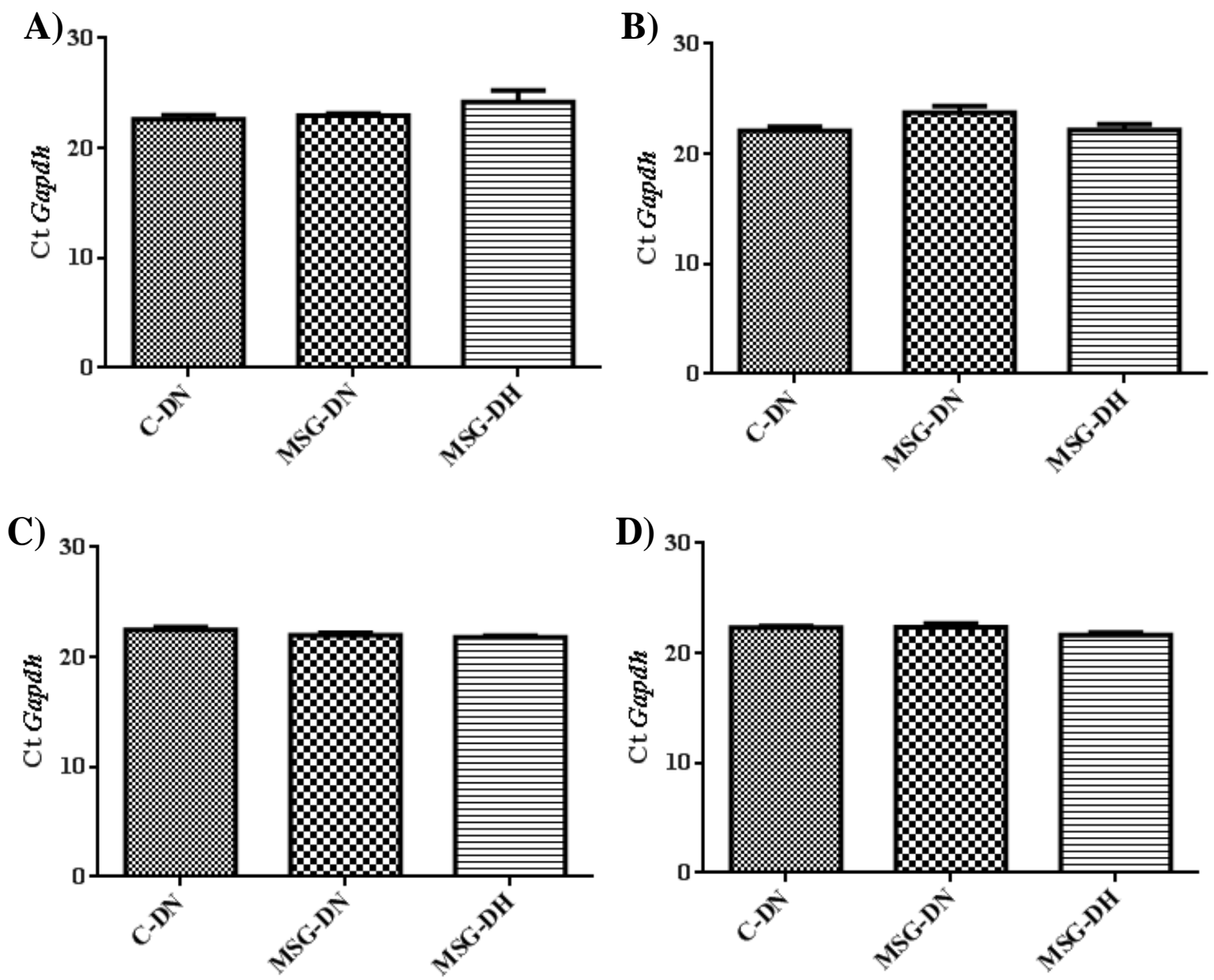

Figura E - A figura representa a expressão de mRNA para o gene Gapdh nos períodos de 4 (A), 8 (B), 12 (C) e 16 (D) semanas de tratamento em tecido adiposo perigonadal dos animais de grupo controle alimentados com dieta normolipídica (C-DN) ou obeso, alimentados com dieta normolipídica (MSGDN) ou hiperlipídica (MSG-DH). Valores são médias \pm EPM, comparados por ANOVA one-way seguido de teste Student-Newman-Keuls; $\mathrm{n}=5$ a 13 animais. 
APÊNDICE F- Correlação entre tecido adiposo perigonadal e mRNA Tnfa

A correlação entre o peso do tecido adiposo perigonadal total e a expressão de mRNA para Tnfa é mostrada na figura abaixo. Nota-se que em todos os períodos de tratamento houve correlação positiva entre estes parâmetros, conforme ilustrado abaixo.

A)

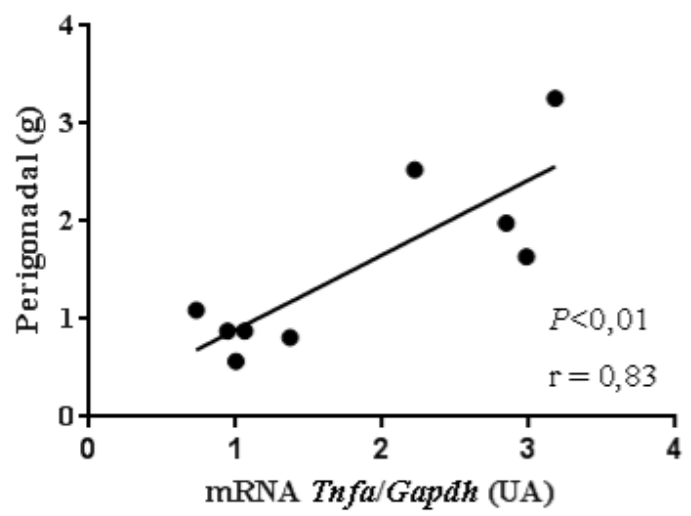

C)

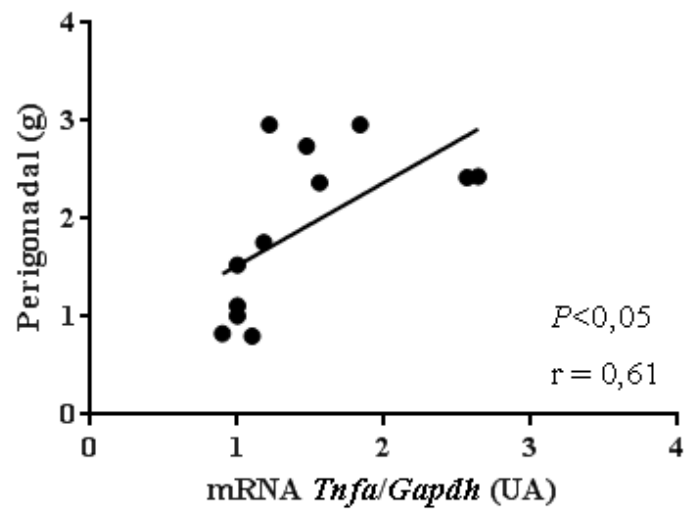

B)

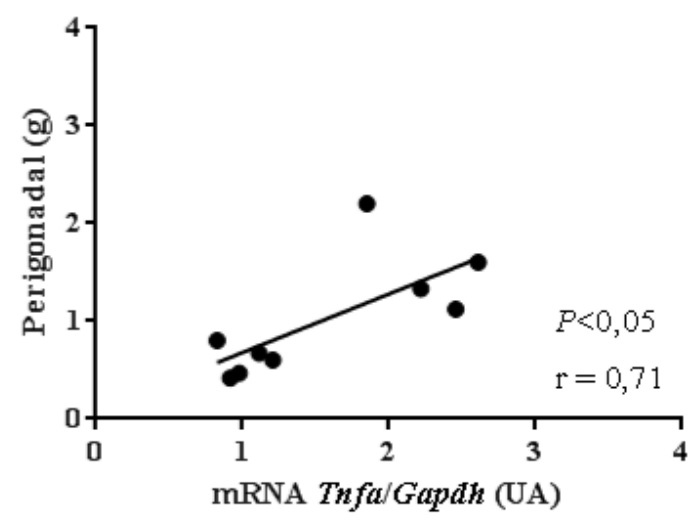

D)

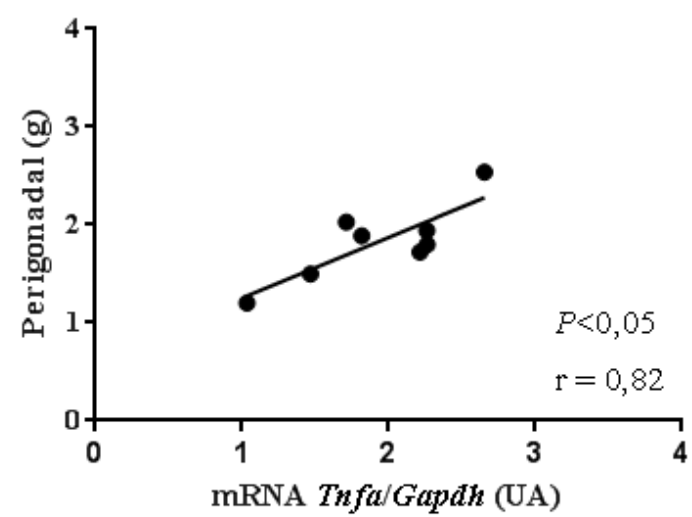

Figura F - A figura representa a correlação entre o tecido adiposo perigonadal total e a expressão de mRNA para Tnfa entre animais do grupo controle alimentados com dieta normolipídica (C-DN) e animais do grupo obeso, alimentados com dieta hiperlipídica (MSG-DH) durante 4 (A), 8 (B), 12 (C) e 16 (D) semanas de tratamento. Foi realizada análise por correlação de Pearson. n= 8 a 12 pares. 